\title{
A S'IUDY OF PRECIPITATION IN COPPER+13 ATOMIC PERCENT BERYLLIUM BY NUCLEAR MAGNETIC RESONANCE AND FIELD ION MICROSCOPY
}

\author{
Andrew ChIen-Chong Yen \\ Department of Metallurgical Engineering \\ and Materials Research Laboratory \\ University of Illinols, Urbana, Illinois
}

June 1974

This technical information document is based on a thesis submitted in partial fulfillment of the requirements for the degree of Doctor of Philosophy in Metallurgical Engineering in the Graduate College of the University of Illinols, 1974. This research was supported in part by the U. S. Atomic Energy Commission under Contract AT(11-1)-1198. 


\section{DISCLAIMER}

This report was prepared as an account of work sponsored by an agency of the United States Government. Neither the United States Government nor any agency Thereof, nor any of their employees, makes any warranty, express or implied, or assumes any legal liability or responsibility for the accuracy, completeness, or usefulness of any information, apparatus, product, or process disclosed, or represents that its use would not infringe privately owned rights. Reference herein to any specific commercial product, process, or service by trade name, trademark, manufacturer, or otherwise does not necessarily constitute or imply its endorsement, recommendation, or favoring by the United States Government or any agency thereof. The views and opinions of authors expressed herein do not necessarily state or reflect those of the United States Government or any agency thereof. 


\section{DISCLAIMER}

Portions of this document may be illegible in electronic image products. Images are produced from the best available original document. 
A STUDY OF PRECIPITATION IN COPPER+13 ATOMIC PERCENT BERYLLIUM BY NUCLEAR MAGNETIC RESONANCE AND FIELD ION MICROSCOPY

Andrew Chien-chong Yen, Ph.D. Department of Metallurgy and Mining Engineering University of Illinois at Urbana-Champalgn, 1974

A study of precipitation in a copper-beryllium alloy has been carried out by means of nuclear magnetic resonance and fleld ion microscopy. For. the $\alpha$ solid solution the wipe-out-number describing the copper resonance amplitude is found to be 18 for the central transition. Aging data are obtained for Cu+13 at.\% Be at two different temperatures, $280^{\circ}$ and $350^{\circ} \mathrm{C}$. Our observed aging curves are shown to be consistent with published values of the activation energy for diffusion of $\mathrm{Be}$ in $\mathrm{Cu}$. An apparent equilibrium composition of the $\alpha$-matrix at various temperatures has been evaluated from the NMR absorption intensity in the completely precipitated state. A deviation from the beryllium solvus boundary is observed and found to be a temperature (aging) dependent quantity.

A fleld ion microscope was constructed; various conditions of image gas composition and pressure were tried for imaging pure copper and $\mathrm{Cu}+13$ at.\% Be. Both pure copper and the alloy were successfully imaged. The precipitate in Cu+13 at. $\%$ Be formed at $280^{\circ} \mathrm{C}$ is observed and its size is found to be in the order of $2 \times 10^{4} \AA^{3}$. A thin layer of copper atoms around each precipltate particle is excluded from the observed NMR absorption intensity because of local lattice and electronic effects. Small precipitate particles, such as those observed with the field ion microscope, embedded in the $\alpha$-matrix cause a shift in the equilibrium beryllium concentration in the $\alpha$-phase. This 1s expressed by the Thomson-Freundich equation. Results from this experiment together with the Thomson-Freundlich equation are used to estimate the interface energy. The value obtained, $577 \mathrm{ergs} / \mathrm{cm}^{2}$, falls reasonably well within the range of known surface energies. 
The Knight shift of CuBe is measured for the first time; its value $\mathrm{K}_{\mathrm{CuBe}}=0.13 \%$ is found to be very close to that of $\mathrm{CuZn}, \mathrm{K}_{\mathrm{CuZn}}=0.15 \%$ measured by G. W. West; both compounds have the same crystal structure. 


\section{ACKNOWLEDGMENTS}

I would like to express my deep gratitude to Professor T. J. Rowland for his guidance and continuing encouragement during the entire course of this work. Thanks are due. Professor C. A. Wert, Head of the Department: of Metallurgical Englneering, for his support. Also thanks are due Professor G. Ehrlich, Dr. H. C. Tong and Dr. W. Graham for their Invaluable suggestions and discussions concerning FIM.

I am Indebted to Professor R. W. Bohl and Professor P. A. Beck for their helpful discussions concerning alloy making and for the use of their furnaces.

I would like to thank Dr. C. A. Evans and the MRL analysis group for. performing chemlcal analyses; to Mr. J. Woodhouse for his help in the work with: the scanning electron microscope; also to Mr. D. Follstaedt for his help. in the high field NMR work:

Thanks are extended to Mr. F. O'Connor, Mr. W. Craig and their machinists of the Department of Metaliurgical Englneering and of the Materlals Research Laboratory, respectively; also to Mr. W. Lawrence and Mr. N. Vassos of the Coordinated Science Laboratory.

I appreciate the help and assistance of past and current members of Professor Rowland's research group, especially that of Mr. R. H. Gells for the designing of the calibrator unit.

Finally, I would like to thank my wife, Chou-yong, for her continuing encouragement and help during the entire course of this research work and her typing of the rough drafts.

The author gratefully acknowledges the Atomic Energy Commission that provided financial support under contract No. AT(11-1)-1198 and the Department of Metallurgy and Mining Engineering. 
TABLE OF CONTENTS

CHAPTER

Page

I. INTRODUCTION . . . . . . . . . . . . . . . . . . 1

II. BASIC THEORY OF NUCLEAR MAGNETIC RESONANCE (NMR) . . . . . . 5

A. General Formulation. . . . . . . . . . . . . 5

B. Nuclear Magnetic Resonance in Metals . . . . . . . . . 12

III. NMR EXPERIMENTAL TECHNIQUE AND PROCEDURES. . . . . . . . . . . 23

A. Experimental NMR Apparatus . . . . . . . . . . . 23

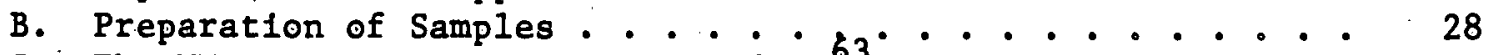

C. The NMR Intensity Measurement of $\mathrm{Cu}^{63^{\circ}} . . .2 . . .2 . . .32$

IV. NMR EXPERIMENTAL RESULT AND DISCUSSION . . . . . . . . • . . 36

V. FIELD ION MICROSCOPY (FIM) . . . . . . . . . . . . . 58

A. Polishing of the Specimen Tip................ 58

B. Principle of Imaging . . . . . . . . ........ 58

C. Fleld Ionization... . . . . . . . . . . . . . 62

D. Fleld Evaporation. . . . . . . . . . . . . . . 66

E. The Microscope ....................... . 71

F. The Image Intensifier. . . . . . . . . . . . . . . 72

G. The Fluorescent Screen ................... 79

VI. FIM EXPERIMENTAL TECHNIQUE AND PROCEDURES. . . . . . . . . . . . 81

VII. FIM EXPERIMENTAL RESULT AND BISCUSSION . . . . . . . . . . . 88

VIII. CONCLUSIONS. . . . . . . . . . . . . . . . . . 115

LIST OF REFERENCES. 。 . • . . . . . . . . . . . . . . . . . 117 
LIST OF TABLES

Table

Page

1. Results of Chemical Analysis of Cu-Be Samples . . . . . . 30

2. Results of Trace Quantitative Analysis of $\mathrm{Cu}-\mathrm{Be}$ Samples . ... 30

3. Data of NMR Measurements on Solution Heat Treated Alloys. . . 37

4. Aging Data of $\mathrm{Cu}+13$ at.\% Be at $280^{\circ} \mathrm{C}$. . . . . . . . 40

5. AgIng Data of $\mathrm{Cu}+13$ at.\% Be at $350^{\circ} \mathrm{C} \ldots \ldots$......... 43

6. $u(t)$, the Weight Fraction Transformed of $\alpha$-Phase, as a Function of Aging Time, $t$, at Aging Temperature $T=2800^{\circ} \mathrm{C}$. . . 46

7. $u(t)$, the Weight Fraction Transformed of $\alpha$-Phase, as a Function of Aging Time, $t$, at Aging Temperature $T=350^{\circ} \mathrm{C}$. . . . 46

8. Beryllium Concentration in Equilibrium $\alpha$-Phase.

(A) Derived from NMR Intensity Measurements Not Including

Particle Size Effects。 (B) From Published Phase Diagram ... 


\section{LIST OF FIGURES}

Figure

Page

1. Energy Levels of $\mathrm{CU}^{63}$ in a Magnetic Field. . ... . . . . 6

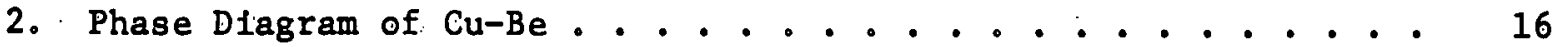

3. Block Diagram of NMR Experimental Apparatus. . . . . . . . . 24

4. Circult Dlagram of Calibrator Unit . . . . . . . . . . 26

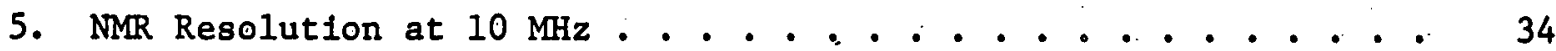

6. $\ln \left(I_{\mathrm{Cu}}(C)\right)$ v8. $\ln (1-C)$ Plot. . . . . . . . . . . . . 38

7. AgIng Curve of $\mathrm{Cu}+13$ at.\% Be at $280^{\circ} \mathrm{C} . \ldots . . . . . . .41$

8. Aging Curve of $\mathrm{Cu}+13$ at.\% Be at $350^{\circ} \mathrm{C}$. . . . . . . . 44

9. $u(t)$ vs. $t$ at $280^{\circ} \mathrm{C}$. . . . . . . . . . . . . . 47

10. $u(t)$ vs. $t$ at $350^{\circ} \mathrm{C}$...................... 49

11. $\mathrm{Cu}^{63}$ NMR Spectrum of $\mathrm{CU}+13$ at:\% Be, Two Phase System. Precipitation Completed at $2800^{\circ}$. Data Taken at $66 \mathrm{MHz}$

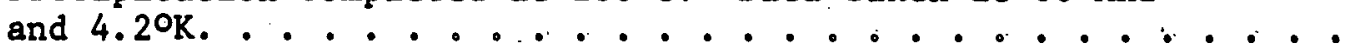

12. Cu+13 at. \% Be Sample T1ps Observed in a Scanning Electron Microscope $(30,000 \mathrm{X})$. . . . . . . . . . . .

13. (a) Potential-Energy Diagram for the ls Electron of an H Atom in a Field of $2 \mathrm{~V} / \mathrm{A}$. (b). Same Atom at a Distance of 5.5 \& from a Tungsten Surface . . . . . . . . . . .

14. (a) Schematic Dlagram of the Form of the Potential Energy Curves when Field Evaporation Is Preceded by Ionization. (b) Schematic Diagram of the Form of the Potentlal Energy Curves when Ionization Occurs at the Moment of Field Evaporation. . . . . . . . . . . 68

15. Field-Ion Microscope. (Front View). . . . . . . . . . 73

16. Field-Ion Microscope Including Image Gas Handling System. (SIde Vlew) . . . . . . . . . . . . . . . . . .

17. Relative Positions of Channel Plate and Fluorescent: Screen with Respect to Sample Tip. . . . . . . . . . . .

18. A Helium Ion Image of Tungsten at Liquid Nitrogen Temperature and $8 \mathrm{kV}$ Tip Voltage, in $4.5 \times 10^{-5}$ Torr. Helium Gas . . . . . . . . . . . . . . . . . . . . . 
19. Temperature Calibration of a Speer Resistor

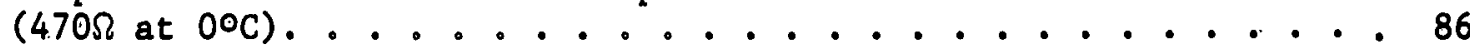

20. A Helium Ion Image of Fully Precipitated $\left(280{ }^{\circ} \mathrm{C}\right) \mathrm{Cu}+13$ at.\% Be at Liquid Helium Temperature and $18.8 \mathrm{kV}$ Tip Voltage, in 2.1X10-3 Torr of Hellum Gas. . . . . . . . . .

21. Pure Copper Tip Imaged in $3.8 \times 10^{-4}$ Torr Neon Gas and at $22^{\circ} \mathrm{K}$, the Tip Voltage Is $17.6 \mathrm{kV}$. . . . . . . . . . . 91

22. A Cu+13 at.\% Be T1p with 50\% Precipitation Completed. Imaged in 6X10-5 Torr Helium Gas at Liquid Helium Temperature, the Tip Voltage Is $8.5 \mathrm{kV}$. . . . . . . . . . 93

23. A. Cu+13 at.\% Be Tip with $50 \%$ Precipitation Completed. Imaged in $2.5 \times 10^{-5}$ Torr Helium Mixed with $1.5 \times 10^{-5}$ Torr Neon, at $220 \mathrm{~K}$, the Tip Voltage Is $5.7 \mathrm{kV}$. . . . . . . . 95

24. (A) A Completely Precipitated Cu+13 at.\% Be Tip, After Field Evaporation in $1 \times 10^{-5}$ Torr. Helium Mixed with $1 \times 10^{-5}$ Torr Neon at 220 K. Imaged in the Same Conditions. Its Tip Voltage Is $14 \mathrm{kV}$. (B) Selected Area Enlarged. Arrows Point at a Precipltate Particle . . . . . . . . . . . .

25. (A) A Completely Preclpitated Cu+13 at.\% Be Tip After Field Evaporation in $1 \times 10^{-5}$ Torr Helium Gas at Liquid Helium Temperature. Imaged in $1.5 \times 10^{-5}$ Torr Helium Mixed with 1.25x10-5 Torr Neon Gas and at $220 \mathrm{~K}$, the Tip Voltage Is $11.5 \mathrm{kV}$. (B) Selected Area Enlarged. Arrows Point at a Precipitate Particle. . . . . . . . . . . . . . . 100

26. (A) A Completely Precipitated Cu+13 at.\% Be Tip After Field Evaporation In 1X10-5 Torr Helium Gas at Liquid

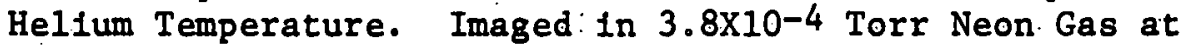
$220 \mathrm{~K}$, the $\mathrm{T} 1 \mathrm{p}$ Voltage Is $23.8 \mathrm{kV}$. (B) Selected Area Enlarged. Arrows Point at Precipitate Particle. . . . . . . . 102

27. (A) Same Tip as in Fig. 26 and Under Same Conditions, but Tip Voltage Is $27 \mathrm{kV}$. (B) Selected Area Enlarged. Arrows Point at Precipitate Particles. . . . . . . . . . . . . . 104

28. (A) Same Tip as in F1g. 26 and Under Same Conditions, but T1p Voltage is $28 \mathrm{kV}$. (B) Selected Area Enlarged. Arrows Point at Preclpitate Particles. . . . . . . . . . 106

29. Sequential Change of the Preclpitate (c) of Fig. 28 Resulting from Successive Fleld Evaporations . . . . . . . . 108

30. Indexed Crystal Planes in the Same Sample Tip as in F1g. 26. . . . . . . . . . . . . . . . . . . . . 110 
CHAPTER I

INTRODUCTION

Precipitation from supersaturated solid solution affects many physical properties of alloys. Although measurement of some of these properties such as electrical conductivity, lattice parameter, and magnetic properties have been utilized to investigate the precipitation process, the interpretation is usually difficult. An alloy system as classical as beryllium-copper remains worthy of study because of its high strength and its wide use for practical. purposes. Its transition from ductile solid solution to spring material due to precipitation makes it useful in manufacturing springs, surgical instruments, contact bridges, dies, and many other special products. Besides the Improvement in the mechanical properties of this alloy, the electrical conductivity is improved by heat treatment. It is 17 per cent I.A.C.S. (International Annealed Copper Standard) when it is in the solid solution condition, but by heat treatment increases to 32 to 38 per cent I.A.C.S., a value sufficlently attractive for many. applications. The commercially produced beryllium-copper contains 2.0 to 2.25 weight per cent beryllium. The binary alloys containing up to about, I per cent beryllium are not agehardenable; it aiso has been found that those alloys containing over 2.5 weight per cent berylifum are so hard and brittle as to be impractical to produce. There are still differing views on the aging process of this alloy system. Also the mutual effect between the final stable precipitate and the final equilibrium matrix is not yet well understood.

For nearly thirty years, many investigators have been interested in these alloys; electron microscope, ${ }^{(1)-(8)} \mathrm{X}$-ray $^{(9)-(12)}$ and other ${ }^{(13)}$ techniques were used in their investigation. The striations on the magnified 
micrographs and relrods on the diffraction patterns seem to be consistently observed. The transformation sequence of this alloy is thought: to be:

$$
\text { Supersaturated } \alpha \rightarrow G . P . \text { Zones } \rightarrow \gamma^{\prime \prime} \rightarrow \gamma^{\prime} \rightarrow \gamma
$$

Coherent plates on $\{100\}_{\alpha}$ are the products of the first two transformation stages where $\gamma^{\prime \prime}$ is an ordered structure. The $\gamma^{\prime}$-phase is a b.c.t. structure with $a=b=2.53 . \AA, c=3.58 \AA$, while the $\gamma$-phase is an ordered $b . c . c$. equilibrium precipitate (CsCi) with $a=2.70$ \&. Most work done on this alloy system has concerned its early stages of precipitation because the G.P. zones and intermediate precipitates are thought to cause its great hardness upon aging.

In this work new techniques have been employed in studying this alloy, namely Nuclear Magnetic Resonance (NMR) and Fleld Ion Microscopy (FIM). Both of them are powerful tools used to study metal systems down to the atomic scale; NMR is often used to explore the relative atomic arrangement of solvent and solute atoms, while FIM can provide direct observation of microstructures with a magnification around $10^{6}$. K. B. Danesh ${ }^{(14)}$ has done a preliminary study of age hardening $\mathrm{Cu}-\mathrm{Be}$ alloys. The technique has also been used to study precipitation in A1-Cu by M. W. Perra. ${ }^{(15)}$ Application of FIM to the study of non-refractory metals was shown to be possible around 1969; at that time the image intensifier (channel plate) became commercially available. Some field-ion microscope observations on copper and copper alloys have been made recently ${ }^{(16)-(19)}$ by other. workers.

In this work the NMR measurements are made at two different frequencles: $10 \mathrm{MHz}$ and $66 \mathrm{MHz}$. The copper nuclear signals from the precipitate and remaining matrix are well resolved at the higher frequency. 
From this fact we can prove 1) that the low frequency intensity measurements are the contribution of only one of the two phases, 1.e., the $\alpha$-phase without: any Interference from the precipitated phase, 2.) the position of the resonance of copper in the precipitate with respect to that in the remaining matrix Indicates that the smaller copper nuclear signal arises from the precipitate. The measurement of the copper nuclear signal from the $\alpha$-phase is employed to examine the entire aging process. By converting a resonance intensity into welght fraction transformed (as a function of aging time $t$ ) the activation energy of diffusion of beryllium in copper is estimated at a temperature around $300^{\circ} \mathrm{C}$.

At the completion of the aging process the beryllium-copper alloy (1.3 at.\% Be) does not give the full copper resonance intensity expected from a calculation based on empirical theory for solid solutions by Bloembergen and Rowland. ${ }^{(20)}$ and the phase diagram.(21) The solvus of beryllium in copper determined from NMR data lies on the beryllium rich side of the published curve. The deviation increases as the aging temperature is. decreased. In order to correlate this temperature dependent deviation to the precipitate size, a field ion microscope was constructed and applied to these alloys. From the observed precipitate particle size it was possible to explain the discrepancy on the basis of a volume effect and the influence of particle size on equilibrium concentration.

When the size of the second phase particle is as small as those observed in the fleld Ion microscope in this investigation, one has to take the following effect into consideration. The solubility of the second phase, CuBe, in $\alpha-8011 d$ solution is exponentially dependent on the particle radius $r$, at a given temperature: ${ }^{(22)}$ This relation is known as Thomson-Freundlich 
equation. The surface energy, of the interface between the precipitate and solid solution is evaluated from the above equation by use of the solubility determined in this work.

The relative Knight shift of the $\mathrm{Cu}^{63}$ resonance in $\mathrm{CuBe}$ ( $\alpha$-phase) with respect to that of pure copper is also measured the result is very close to that of CuZn measured by G.A. West. (23) 
CHAPTER II

BASIC THEORY OF NUCLEAR MAGNETIC RESONANCE (NMR)

A. General Formulation

A nucleus can be considered as a system of many particles coupled together so that in any given state, it possesses a total angular momentum İh and a total magnetic moment $\vec{\mu}$. These two quantities are related by the "gyromagnetic ratio" $\gamma$.

$$
\vec{\mu}=\gamma \vec{f}
$$

When this magnetic moment is acted on by an externally applied magnetic field $\vec{H}$ the interaction energy is simply $-\vec{\mu} \cdot \vec{H}$, the corresponding Ham1ltonlan 18:

$$
F=-\vec{\mu} \cdot \vec{H}
$$

If we choose the direction of that applied field to be z-axis, then:

$$
\not=-\gamma H_{z} H_{0}
$$

where $H_{0}$. Is the magnitude of the applied magnetic fleld.

Take $\mathrm{Cu}^{63}$ as an example; it has $\mathrm{I}=3 / 2$ and its eigenstates are equally spaced in energy as shown in Fig. 1

The allowed energies are (from Equation (3))

$$
E=-\gamma^{k} H_{0} m . \quad m=I, I-1,-\cdots--I+1,-I
$$

In order to induce transitions between these.levels we need to apply an alternating magnetic fleld perpendicular to the static field; its 
Figure 1

Energy Levels of $\mathrm{Cu}^{63}$ in a Magnetic Field 


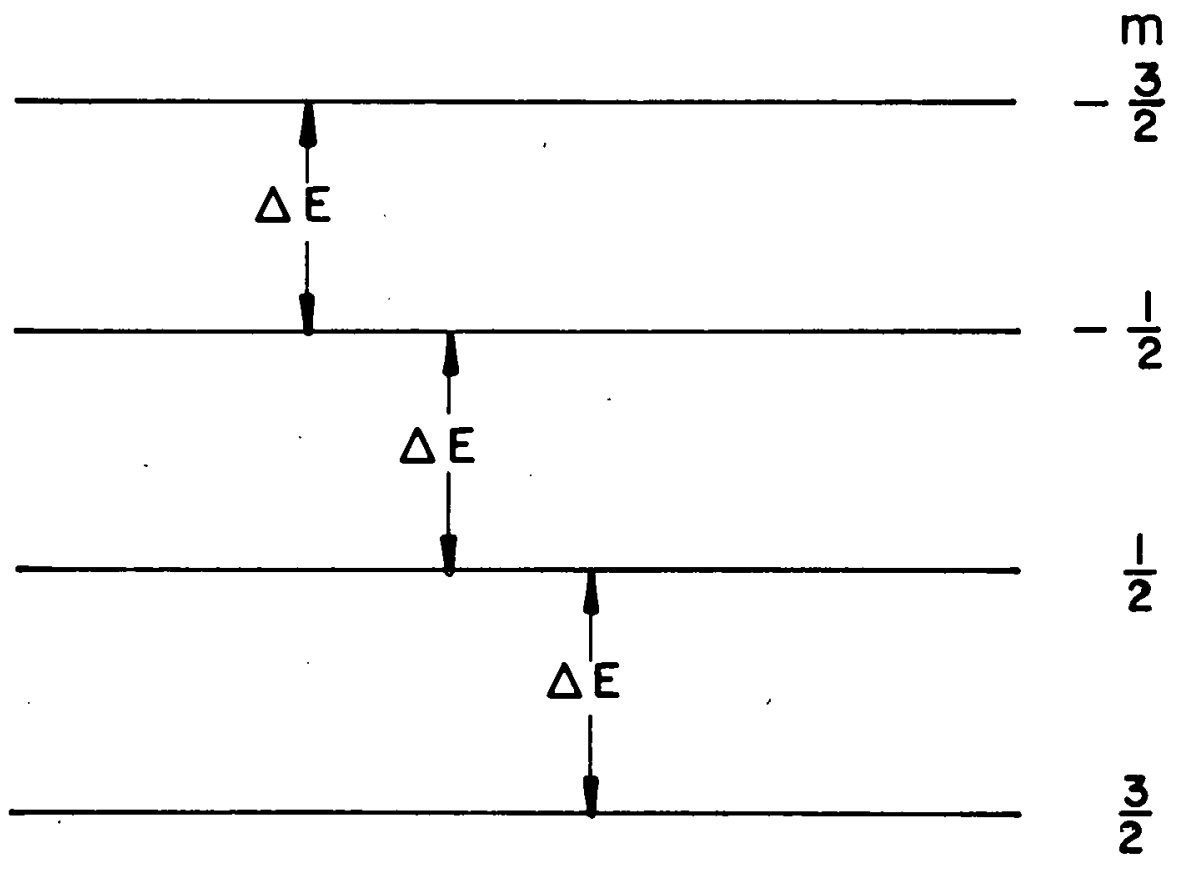


frequency satisfies

$$
h \nu=\Delta E
$$

where $\Delta E$ is the energy difference between the initial and final states. The alternating magnetic field is $\mathrm{H}_{x}=2 \mathrm{H}_{1}$ coswt; then the perturbing term in the Hamiltonian is:

$$
f_{\text {pert }}=-\oiint_{x} H_{x} I_{x}
$$

The operator $I_{x}$ has matrix elements between states $m$ and $m$ ', $\left(m^{\prime}\left|I_{x}\right| m\right)$, which vanish unless $m^{\prime}=m \pm 1$; therefore the allowed transitions are between adfacent energy. levels so that

$$
\hbar \omega=\Delta E=\gamma \hbar \mathrm{H}_{0}
$$

or,

$$
\omega=\gamma \mathrm{H}_{0}
$$

For a given element of known $\gamma$ one can always use equation (8) to calculate the frequency needed to observe the resonance.

The classical way of estimating the gyromagnetic ratio $\gamma$ can be 11lustrated by a simple example:

A particle of mass $m$ and charge $e$ is moving in a circle of radius $r$ with period $T$, its angular momentum is then

$$
J=\operatorname{mvr}=\frac{2 \pi r^{2}}{T}
$$

where

$$
J=\hbar I
$$

and its classical magnetic dipole moment is 


$$
\mu=1 A,
$$

where 1 is the current produced by the circularly moving charge e, and $A$ is the area of the circle. Thus $1=e / c T, A=\pi r^{2}$.

$$
\text { Now } \quad \mu=\frac{e}{c} \frac{\pi r^{2}}{T}
$$

from equations (9), (10) and (11) we have

$$
\gamma=\frac{\mu}{\mathrm{Fh}}=\frac{\mathrm{e}}{2 \mathrm{mc}}
$$

If we substitute the mass of the proton for $\dot{m}$ and the accepted values for $e$ and $c$ we find

$$
\gamma_{n}=\frac{e}{2 M_{p} C}=4.79 \approx 10^{3} \mathrm{sec}^{-1} \text { gauss }^{-1}
$$

The actual magnetic moment is measured by its maximum observable component and is often expressed

$$
\mu_{\max }=g I \mu_{n}
$$

where $g$ is the nuclear $g$-factor and $\mu_{n}=e /\left(2 M_{p} c\right)=5.05 \times 10^{-24}$ (erg/gauss) is the nuclear magneton. Thus, for the proton, the experimental result is

$$
\gamma_{p}=\frac{\mu_{\max }}{I_{n}}=\frac{g I \mu_{n}}{I_{n}}=\frac{g e}{2 M_{p} c}=g \gamma_{n}
$$

The value of $\gamma_{p}$ for a proton was measured at the National Bureau of Standards in Washington by Thomas et al。(24), (25), (26). They made an accurate absolute measurement of a magnetic field $H_{0}$ in which the proton resonance frequency $\omega_{p}$ was determined by equation ( 8 ). They found

$$
\gamma_{p}=2.675 \times 100^{4} \mathrm{sec}^{-1} \text { gauss }^{-1}
$$


In turn the $g$ value for the proton was found to be 5.58 .

We know the potential energles of the differently orlented nuclear moments are characterized by the quantum number $m$ as stated in equation (4). Using this, we can calculate the static nuclear susceptibility $\chi_{\odot^{\circ}}$ Let $N(m)$ be the number of nuclear moments per unit volume in state $\mathrm{m}$, then the relative populations at equilibrium are determined by the Boltzmann factor

$$
\frac{N(m)}{N\left(m^{\prime}\right)}=\exp \left[\frac{E\left(m^{\prime}\right)-E(m)}{k T}\right]
$$

The total moment per unit volume along the direction of the field is

$$
\mathrm{M}_{\mathrm{H}}=\sum_{\mathrm{m}} \mathrm{N}(\mathrm{m}) \gamma_{\mathrm{hm}}
$$

Using this result one can obtain the ${ }^{(27)}$ Brillouln expression for the static magnetization.

$$
\mathrm{M}_{\mathrm{H}}=\mathrm{N}_{0} \mathrm{H}\left\{\left(\frac{2 I+1}{2}\right) \operatorname{ctnh}\left[\frac{(2 I+1) x}{2}\right]-\frac{1}{2} \operatorname{ctnh}\left(\frac{x}{2}\right)\right\}
$$

where $N_{\odot}$ is the total number of nuclel per unit volume and $x=\gamma k \mathrm{H} / \mathrm{kT}$.

Since $x$ is much less than unity, equation (20) has the approximate. form :

$$
\mathrm{M}_{\mathrm{H}}=\frac{\mathrm{N}_{\mathrm{O}}}{3 \mathrm{kT}} \mathrm{r}^{2} \hbar^{2} I(I+1) \mathrm{H}
$$

and the static nuclear susceptibility $X_{0}$ is

$$
x_{0}=\frac{N_{0}}{3 k T} \gamma^{2} \hbar^{2} I(I+1)
$$

Bloch ${ }^{(28)}$ Initially treated nuclear Induction using phenomenological equations. An oscillating field $\mathrm{H}_{x}=2 \mathrm{H}_{1}$ coswt can be decomposed into two 
oppositely rotating fields in the $x-y$ plane. If $H_{0}$ is again along $z$ and $\gamma$ is positive, the vector field. is

$$
\begin{aligned}
& H_{x}=H_{1} \cos \omega t \\
& H_{y}=-H_{1} \sin \omega t \\
& H_{z}=H_{0}
\end{aligned}
$$

From the time-derivatives of the macroscopic magnetization, the components of the complex susceptibility $\chi^{\prime} \chi^{\prime}-1 \chi^{\prime \prime}$ are found:

$$
\begin{aligned}
\chi^{i} & =\frac{1}{2} \chi_{0} \omega_{0} \mathrm{~T}_{2} \frac{\mathrm{T}_{2}\left(\omega_{0}-\omega\right)}{1+\mathrm{T}_{2}{ }^{2}\left(\omega_{0}-\omega\right)^{2}+\gamma^{2} \mathrm{H}_{1}{ }^{2} \mathrm{~T}_{1} \mathrm{~T}_{2}} \\
\vdots & \vdots \\
X^{\prime \prime} & =\frac{1}{2} \chi_{0} \chi_{0} \omega_{0} \mathrm{~T}_{2} \frac{1}{1+\mathrm{T}_{2}{ }^{2}\left(\omega_{0}-\omega\right)^{2}+\gamma^{2} \mathrm{H}_{1}{ }^{2} \mathrm{~T}_{1} \mathrm{~T}_{2}}
\end{aligned}
$$

These are Bloch susceptibilities and $T_{1}, T_{2}$ are spin-lattice and spin-spin relaxation time respectively, $X_{0}$ is the static nuclear susceptibllity derived above, and $\omega_{0}=\gamma_{n} H_{0} \cdot$

The sample placed in the alternating field absorbs energy from this field at a rate per unit volume given by

$$
\mathrm{w}=2 \mathrm{H}_{1}^{2} \omega x^{\prime \prime}
$$

Therefore the energy absorption is resonant in nature as clearly shown by the form of equation (25). 
B. Nuclear Magnetic Resonance in Metals

In a metal most of the electron spins are paired; only a small

fraction with their kinetic energy near the Fermi energy can have unpaired magnetic moments. One source of the shift of the nuclear resonance in metals relative to non-conductors is attributed to the Pauli paramagnet ism of the conduction electrons. The phenomenon was first discovered by Knight. (29). The relative shift is $(30)$

$$
\frac{\Delta \mathrm{H}}{\mathrm{H}_{0}}=\frac{\beta \mathrm{A}}{\mathrm{h}} \frac{\left\langle\left|\psi_{\text {met }}(0)\right|^{2}\right\rangle}{\left|\psi_{\text {at }}(0)\right|^{2}} \mathrm{v}_{\mathrm{a}} \mathrm{N}\left(\mathrm{E}_{\mathrm{F}}\right)
$$

where $A$ is the hyperfine interaction constant, $B$ is the Bohr magneton, $\left\langle\left|\psi_{\text {met }}(0)\right|^{2}\right\rangle_{\text {av }}$ is the square of the electronic wave function in the metal evaluated at the position of the nucleus, normalized over the atomic volume $v_{a}$ and averaged over the Ferm1 surface. $\left|\psi_{a t}(0)\right|^{2}$ is the absolute square of the outer $s$ function at the nucleus in the non-conductor, and $N\left(E_{F}\right)$ is the density of states of the conduction electrons at the Fermi surface per unit volume and per unit energy interval.

The shift may have different values at different nuclei, depending on the positions of nearby impurities. The actual shift can be calculated only If the wave equation including the potential perturbed by the impurity is solved:

The impurity concentration dependence of the shift has been extensively studied In various solid solutions and inside of two-phase regions. In the two-phase regions resonances appropriate to each of the phases may be observed.

Metals having nuclei of spin greater than $\frac{1}{2}$ and a sufficiently large quadrupole moment will be sensitive to the presence of foreign (solute) atoms 
In the lattice, and the resonance may show strong quadrupole effects. Either the strain field due. to the size difference between solvent and solute atoms, or the different electronic structure of the solvent and solute atoms will produce an electric fleld gradient in the lattice. The gradients may be very large near a solute atom so that the resonance absorption of any solvent atom, $\mathrm{Cu}^{63}$ for example, close to a solute atom will be unobservable; but at the same time the solvent atoms at greater distance from the solute may have their energy levels unperturbed.

Let us introduce a scalar quantity

$$
\text { eq }=\sum_{j}\left(3 \cos ^{2} \phi_{j}-1\right) r_{j}^{-3}
$$

where $q$ is the electric field gradient, $\phi_{f}$ is the angle between the radius vector $\vec{r}_{j}$ toward a charge $e_{j}$ in the lattice and an axis of cylindrical symetry. Denote the angle between this symmetry axis and the magnetic field by $\theta$. The energy difference between the levels $m$ and $m-1$ of the nuclear spin In the combined fields is given by a first-order perturbation calculation:

$$
\Delta E_{m \rightarrow m-1}=h \nu_{0}+(2 m-1)\left(3 \cos ^{2} \theta-1\right) \frac{3 e^{2} q Q}{8 I(2 I-1)}
$$

where $Q$ is the nuclear electric quadrupole moment. From equation (29) we see that the energy difference between the levels $m=\frac{1}{2}$ and $m=-\frac{1}{2}$ is unperturbed in this approximation. A second-order perturbation calculation gives for the energy difference between these levels:

$$
\Delta E_{\frac{1}{2} \rightarrow-\frac{1}{2}}=h \nu_{0}+\frac{9}{64} \frac{2 I+3}{4 I^{2}(2 I-1)} \frac{e^{4} q^{2} \theta^{2}}{h \nu_{0}}\left(1-9 \cos ^{2} \theta\right)\left(1-\cos ^{2} \theta\right)
$$

If a nucleus is located at a site of cubic symmetry, we have: 


$$
\frac{\partial^{2} v}{\partial x^{2}}=\frac{\partial^{2} v}{\partial y^{2}}=\frac{\partial^{2} v}{\partial z^{2}}
$$

When we combine this with Laplace's equation

$$
\nabla^{2} v=0
$$

we see that there is no field gradient at such a nuclear site. (One can always find principal axes of the potential $\mathrm{V}$ such that

$$
\left.\frac{\partial^{2} v}{\partial x_{\alpha} \partial x_{\beta}}=0 \quad \text { if } \alpha \neq \beta, \alpha, \beta=1,2,3\right) \text {. }
$$

Therefore, there is no quadrupole effect at lattice sites with cubic point symetry on the atomic scale (e.g., pure copper), but this symmetry is destroyed when one introduces solute atoms into the lattice.

Using the results on the central line intensity of $\mathrm{Cu}^{63}$ in brass as a function of solute concentration Rowland predicted that the intensity for copper with zinc as solute might be expected to vary roughly as: (31)

$$
0.6(1-C)^{600}+0.4(1-C)^{18}
$$

where $C$ is the solute concentration.* The first term is the satellite intensity, the second term is the central intensity. Recently this has been corroborated by Tompa ${ }^{(32)}$ : This explains the fact that only a few hundredths of a percent of solute could cause a marked decrease in the resonance intensity at the center position of the nuclear resonance. The satellite intensity for which $n_{8}=490$ (Tompa's value) is much more sensitive to solute

*" $C$ " Is the atomic fraction of solute, unless it is otherwise specified. 
concentration than the central intensity for which $n=18$. It will later be shown that for the range of solute concentrations of interest in this work we. need to consider the splitting of the central transition only.

In the aging (precipitation) process, the Be atoms are continuously extracted from the Initial solution heat treated alloy matrix; the new precipitate and final matrix are forming. Due to the decrease of Be concentration in the final matrix $\left(C_{1} \tilde{\cong} 13\right.$ at.\% $\rightarrow C_{f} \tilde{=1.3}$ at.\% Be) the central transition intensity is changed drastically and provides a powerful technique with which to follow the course of the precipitation process. It must be noted here that nuclear magnetic resonance is a suitable technique for studyIng the copper-beryllium system because the copper nuclear signal of the precipitate phase can be easily resolved from that of the matrix. No interference occurs in the measurement of peak-to-peak intensity using the first derivative of the matrix $\mathrm{Cu}^{63}$ absorption curve. Furthermore, neither the Iine shape nor the Knight shift of the $\mathrm{Cu}^{63}$ nuclear resonance show a significant change between the initial and the final $\alpha$-phase. Thus the intensity is related to the amount of matrix, its Be concentration, and indirectly to the amount of precipitate. Later we will show that the state of dispersion of the precipitate may also be important.

A model is needed if one wants to see the physical meaning of the measurement during the intermediate stages of aging. Let (see Figure 2) $\mathrm{W}=$ weight of $\mathrm{Cu}+13$ at.\% Be alloy, $\mathrm{W}^{\mathrm{Cu}}=$ weight of $\mathrm{Cu}$ in $\mathrm{W}$ grams of $\mathrm{Cu}+13$ at.\% $\mathrm{Be}$ alloy, $\mathrm{I}(13$ at.\% $\mathrm{Be})=$ intensity of $\mathrm{Cu}$ nuclear signal from $\mathrm{W}$ grams of $\mathrm{Cu}+13$ at.\% Be alloy occupying a given volume V, and 
Figure 2

Phase Diagram of $\mathrm{Cu}-\mathrm{Be}$.

The Dashed Line Is the Beryllium Concentration in Equilibrium $\alpha$-Phase Derived from NMR Intensity Measurements. 


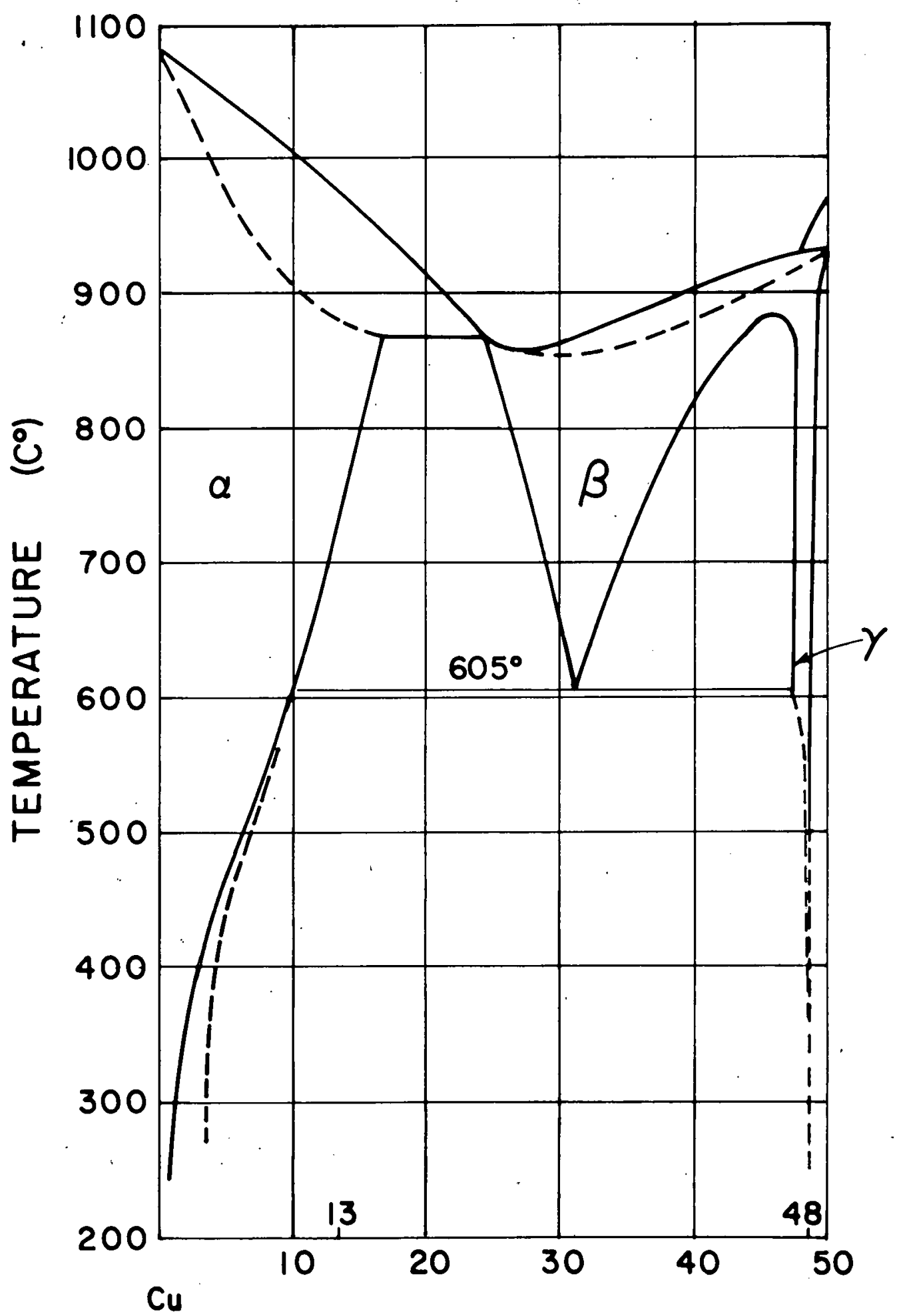

ATOMIC \% OF BERYLLIUM 
$\mathrm{I}_{\odot}=$ Intensity of $\mathrm{Cu}$ nuclear signal from $\mathrm{W}^{\mathrm{Cu}}$ grams of pure copper (central transition only; $1 . e . ., 40 \%$ of the total) occupying the same volume $V$. Then for the solution treated alloy

$$
I(C=0.13)=I_{0}(1-C)^{n_{n}}=I_{0}(1-0.13)^{18}
$$

where $\mathrm{C}=$ atomic fraction of $\mathrm{Be}$. Normalize equation (32) by dividing it by $W^{\mathrm{Cu}}$ grams, defining

$$
1(0.13)=\frac{I(0.13)}{W^{C u}}=\frac{I_{0}(1-C)^{n}}{W^{C u}}=\frac{I_{0}}{W^{C u}}(1-0.13)^{18}=i_{0}(1-0.13)^{18}
$$

Let us assume that at time $t$ during aging, the total copper intensity $I_{t}$ can be considered as due to both the copper nuclei in the final $\alpha$-phase matrix, and those in the remaining inftial solution heat treated matrix:

$$
I_{t}=1\left(C_{m}\right) W_{m}(t) f_{m}+1\left(C_{\alpha}\right) W_{\alpha}(t) f_{\alpha}
$$

where:

$W_{m}(t)=$ weight of initial matrix (13 at.\% Be) remaining at a given time $t$, $W_{\alpha}^{\prime}(t)=$ welght of transformed matr'lx $\left(\alpha\right.$-phase, $\left.c_{\alpha}=0.0125\right)$ present at a given time $t$, $f_{m}=\left(i-C_{m}^{w t} \cdot\right)=$ weight fraction $C u$ in inftial matrix, and $f_{\alpha}=\left(1-C_{\alpha}^{w t} \cdot\right)=$ weight fraction $C u$ in final $\alpha$-matrix.

$W_{m}$ can be expressed in terms of $W, W_{\alpha}$, and $W_{\gamma}$, the welght of the precipltated $\gamma$-phase (CuBe).

$$
W_{m}(t)=W-W_{\alpha}(t)-W_{\gamma}(t)=W-W_{\alpha}(t)-F W_{\alpha}(t)=W-(1+F) W_{\alpha}(t)
$$

where $F$ can be found from the phase diagram for a given aging temperature T. $\left(\mathrm{T}=280^{\circ} \mathrm{C}\right)$ 


$$
F \equiv\left(C_{m}^{w t} \cdot-C_{\alpha}^{w t} \cdot\right) /\left(C_{\gamma}^{w t} \cdot-C_{m}^{w t} \cdot\right)
$$

Using (35), Equation (34) becomes:

$$
\begin{aligned}
& I_{t .}=I\left(c_{m}\right)+\left[1\left(c_{\alpha}\right)\left(1-c_{\alpha}^{w t \cdot}\right)-i\left(c_{m}\right)\left(1-c_{m}^{w t} \cdot\right) \frac{c_{\gamma}^{w t} \cdot-c_{\alpha}^{w t}}{c_{\gamma}^{w t} \cdot-c_{m}^{w t}}\right] \cdot W_{\alpha}(t) \\
& I_{t}-I\left(c_{m}\right)=\left[\left(1-c_{\alpha}^{w t} \cdot\right)\left(\frac{1-C_{\alpha}}{1-C_{m}}\right)^{n}-\left(\frac{c_{\gamma}^{w t} \cdot-c_{\alpha}^{w t}}{C_{\gamma}^{w t} \cdot-c_{m}^{w t}}\right)\left(1-c_{m}^{w t} \cdot\right)\right] 1\left(c_{m}\right) W_{\alpha}(t)
\end{aligned}
$$

The left hand quant:1ties are measured from a "resonance intensity" aging curve; $\mathrm{n}$ and $\mathcal{I}\left(\mathrm{C}_{\mathrm{m}}\right)$ are obtained from the wipe-out-number curve for the Cu-Be dilute solid solution and from the solution heat treated alloy. All the other quantities, except $W_{\alpha}(t)$, are obtained from the phase diagram. Thus $W_{\alpha}(t)$ is found, and as $t$ approaches infinity, $w_{\alpha}(t \rightarrow \infty)$ is the amount of $\alpha$-phase corresponding to the equilibrium state of the system (see Fig. 7).

In its present form Equation (37) relates the measured intensities in an absolute way to the weight of $\alpha$-phase present at any time $t$. As will be shown later, our work leads to the conclusion that the precipitate morphology affects the measured Intensity, and thus Equation (37) is not to be relled upon to give the absolute quantity of $\alpha$-phase present in this alloy system. It assumes the intensity to be independent of precipitate morphology and to depend entirely upon equilibrium phase diagram considerations. As a:more directly useful quantity, we deflne the weight fraction of $\alpha$ transformed at time $t$.

$$
u(t)=\frac{W_{\alpha}(t)}{W_{\alpha}(\infty)}=\frac{I_{t}-I\left(C_{m}\right)}{I_{\infty}-I\left(C_{m}\right)}
$$

thus avoiding use of the constant terms in Equation (37). 
The basic relationship between $u, t$ and $T$ can be expressed by means of a rate equation, leading to the definition of an activation energy.

$$
\frac{Q\left(u_{1}\right)}{R}=-\left[\frac{\partial \ln (\partial u / \partial t)}{\partial(1 / T)}\right] u=u_{1}
$$

From the u vs. $t$ plots of the raw experimental data at each different temperature, one can determine the slope for a given value of $u_{=u_{1}}^{\prime}$, then plot In (slope) vs. 1/T. The activation energy $Q$ of the prectpitation process is just the slope of the latter plot times $R$, the universal gas constant. By comparing this determined $Q$ with that from diffusion data, we can see how important the role of diffusion in this precipitation process is.

When the copper-beryllium alloy is aged for a sufficiently long time, Equation (34) becomes much more simple, 1.e.,

$$
I_{\infty}=1(0.01) W_{\alpha}(\infty) f
$$

We designate this state to be the "completely precipitated state." For a given amount of alloy, say $\mathrm{W}$ grams, there are $\mathrm{N}^{\mathrm{Cu}}$ copper atoms contained in this sample, of which $\mathrm{N}_{\alpha}^{\mathrm{Cu}}$ copper atoms will be in final matrix phase ( $\alpha$-phase) when the complete precipitation has been reached; from the phase-diagram (at $\mathrm{T}=280^{\circ} \mathrm{C}$ ) we have

$$
N_{\alpha}^{C u}(T)=N_{t}\left[\left(C_{\gamma}-C_{m}\right) /\left(C_{\gamma}-C_{\alpha}\right)^{-}\right]\left(1-C_{\alpha}\right)
$$

where $\mathrm{N}_{t}$ is the total number of copper and beryllium atoms in the sample. But we kn॰w $\mathrm{N}^{\mathrm{Cu}}=\left(1-\mathrm{C}_{\mathrm{m}}\right) \mathrm{N}_{t}$, 80

$$
\mathrm{N}_{\mathrm{t}}=\mathrm{N}^{\mathrm{Cu}} /\left(1-\mathrm{C}_{\mathrm{m}}\right)
$$


therefore,

$$
\mathrm{N}_{\alpha}^{\mathrm{Cu}}(\mathrm{T})=\left(\frac{\mathrm{C}_{\gamma}-\mathrm{C}_{\mathrm{m}}}{\mathrm{C}_{\gamma}-\mathrm{C}_{\alpha}}\right)\left[\left(1-\mathrm{C}_{\alpha}\right) \frac{\mathrm{N}^{\mathrm{Cu}}}{1-\mathrm{C}_{\mathrm{m}}}\right]
$$

If we convert Equation (43) Into nuclear magnetic resonance intensity, and keep in mind that the NMR measurement is made on copper atoms in the solid solution phase ( $\alpha$-phase),

$$
I_{\infty}(T)=\left[\frac{c_{\gamma}-c_{m}}{c_{\gamma}-c_{\alpha}}\right] \cdot\left[\frac{i-c_{\alpha}}{1-c_{m}}\right] \cdot\left[I_{0}(1-C)^{18}\right]
$$

The quantity in the last bracket corresponds to the NMR intensity of $\mathrm{N}^{\mathrm{Cu}}$ copper atoms all in the a solid solution of $\mathrm{C}_{\alpha}$ at. fraction Be. Recall, here $I_{0}$ is the central component of the nuclear absorption of $\mathrm{N}^{\mathrm{Cu}}$ copper atoms in pure $\mathrm{Cu}$. In order to take care of this quantity properly, we ought to do the following; after the above measurement we solution heat treat the same sample at a temperature such that there is only one phase in the alloy (1.e., the intial matrix $\mathrm{Cu}+13$ at.\% $\mathrm{Be}$ ). Its copper nuclear absorption intensity follows the expression:

$$
I_{\text {sht }}=I_{\theta}\left(1-C_{m}\right)^{18}
$$

the $I_{0}$ In Equation (45) has exactly the same physical meaning as that of $I_{0}$ In Equation (44). Thus:

$$
I_{\infty}(T) / I_{\text {sht }}=\left[\left(C_{\gamma}-C_{m}\right) \cdot /\left(C_{\gamma}-C_{\alpha}\right)\right]\left[\left(1-C_{\alpha}\right)^{19} /\left(1-C_{m}\right)^{19}\right]
$$

Th1s equation assumes distinct, hypothetically separable phases, each behaving as if it were present in bulk only. That is, any possible size or surface effects due to precipitate morphology have been neglected. The left: hand side of Equation (46) is measured in the laboratory, the right-hand side 
may be calculated from the published phase diagram. Equality merely serves to check the correctness of our model up to this point. Inequality may Indicate that the copper atoms in the portion of final matrix surrounding the precipitates are not contributing to the NMR. intensity. The smaller the precipitates, or the larger the region of matrix strained, the larger the deviation that will be found between observation and Equation (46). This is because of the particle size dependence of the phase boundary. to $\gamma$-phase volume ratio. The strain field around stable precipitates has been observed in Al-4 wt.\%.Cu by $\mathrm{T}$. Imura et al. (34) who used the divergent beam $x$-ray technique and found that this strain fleld cannot be completely removed by aging treatment. 
CHAPTER III

NMR EXPERIMENTAL TECHNIQUE AND PROCEDURES

A. Experimental NMR Apparatus

The continuous wave nuclear magnetic resonance spectrometer used in this work was made by Varian Assoclates (model V-4210A); the block diagram of the complete apparatus is shown in Fig. 3.

An electromagnet and highly regulated power supply manufactured by Pacific Electric Motor Company were employed to produce the external magnetic fleld $H_{\odot}$; the pole face diameter is 5 inches tapered from 15 Inches and the air gap is 1.5 Inches. The fleld inhomogeneity across the sample volume is less than 0.0 .5 gauss. A motor driven potentiometer in the control circuit was used to sweep the fleld across the resonance. The modulation field was provlded by a Dynakit Mark III 60 watt aud 10 power amplifier driven by an audio oscillator (Hewlett-Packard Model $200 \mathrm{ABR}$ ). $\mathrm{H}_{0}$ was sinusoidally modulated at $26 \mathrm{~Hz}$ with a peak-to-peak amplitude of 2.5 gauss. The resonance signal is synchronously detected in the phase sensitive detecter (1ock-in amplifier) which maintains a bandwidth narrow enough $(<1 \mathrm{~Hz})$ for reasonably low noise. The probe used in this work, also made by Varian, contains the crossed coils, the balancing paddles and modulation coils, its working range is from $8 \mathrm{MHz}$ to $16 \mathrm{MHz}$.

The rf reference standard signal calibrator (see Fig. 4), designed by R. H. Geils in this laboratory, provides an adjustable constant leakage between the transmitter and recelver coll circults of the spectrometer, and thus supplies a constant unit scale for calibration of the peak-to-peak Intensity measurement. 
Figure 3

Block Diagram of NMR Experimental Apparatus. 


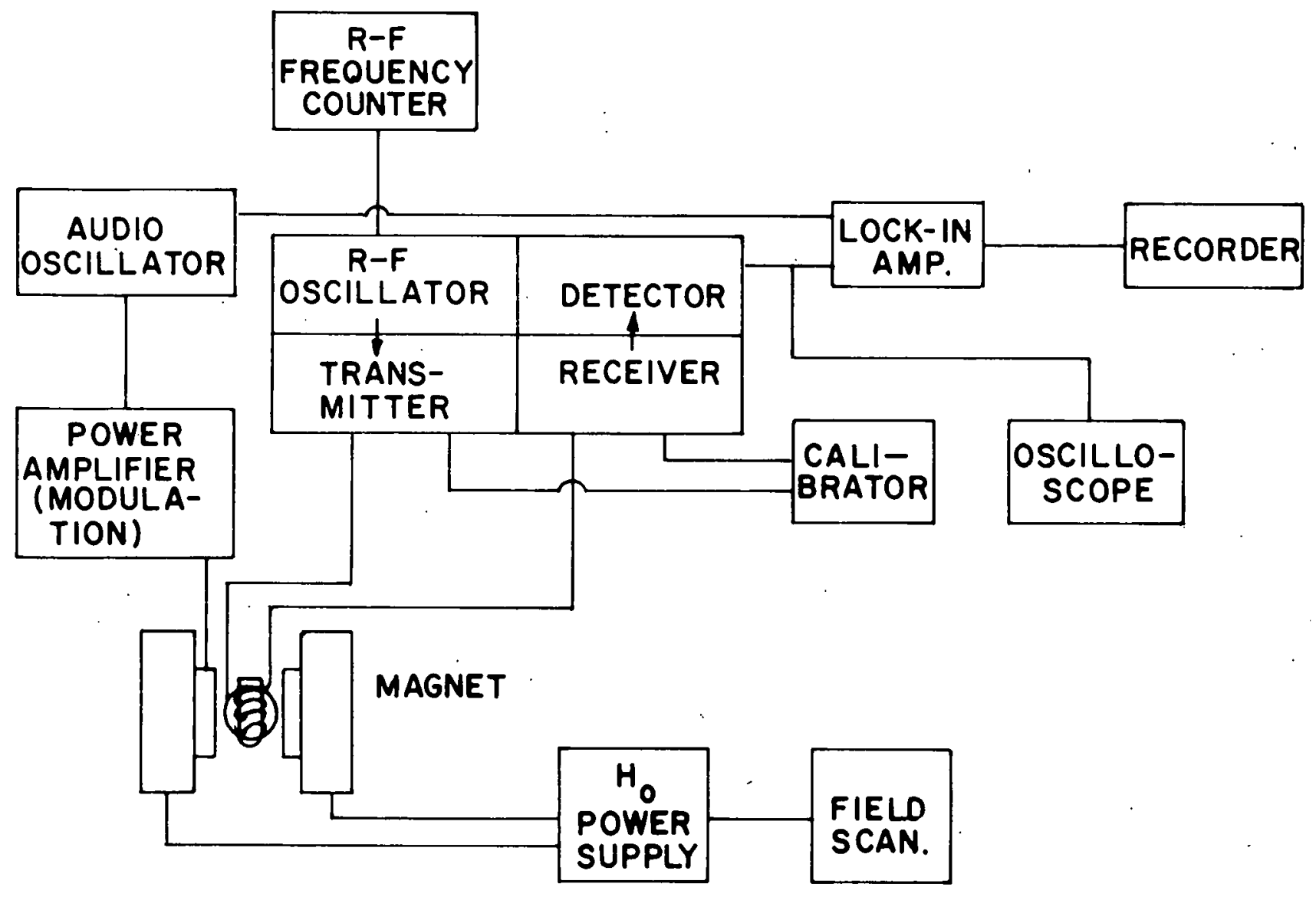



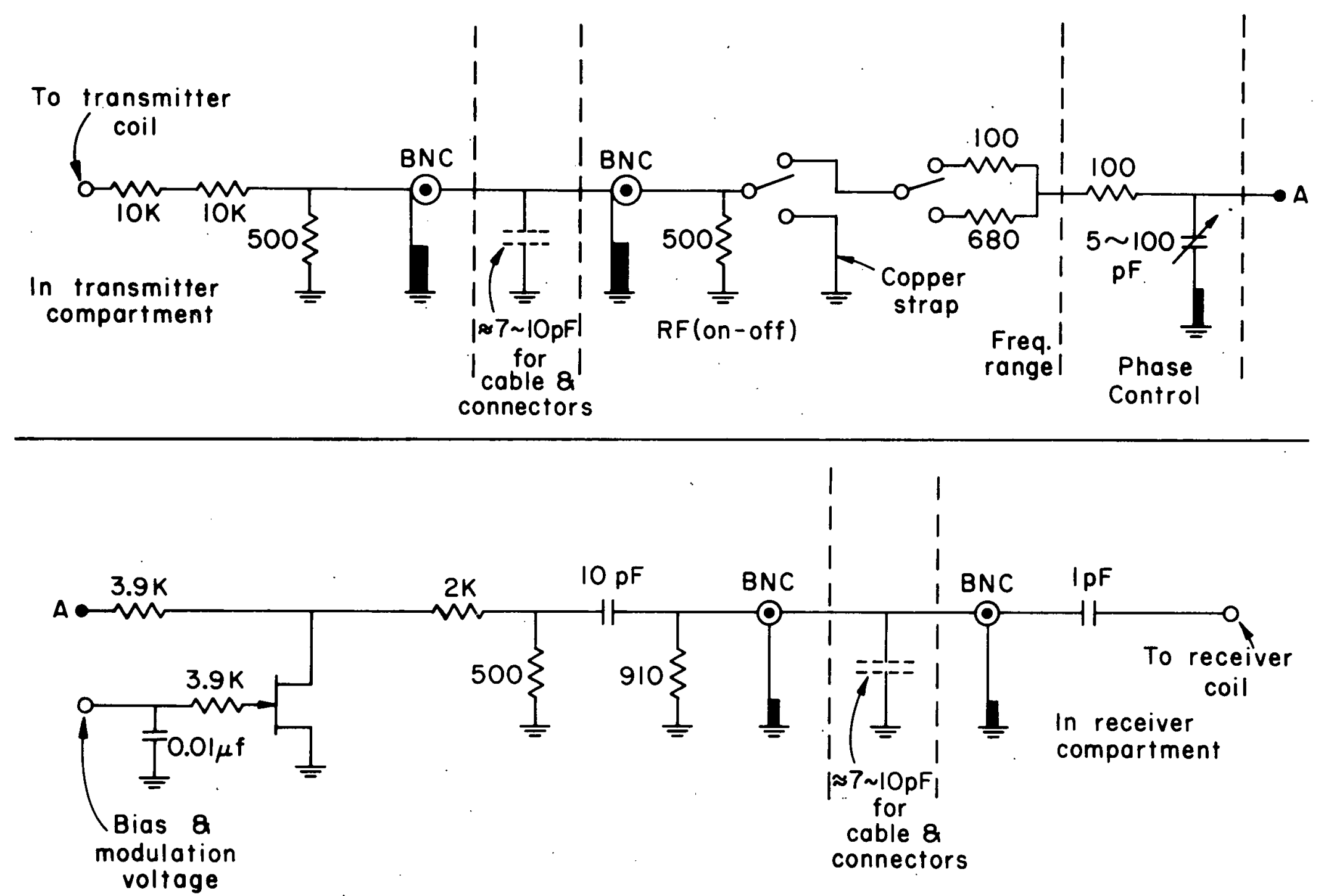
The field scanning unit slowly alters the field of the electromagnet

$\mathrm{H}_{\mathrm{o}}$ by controlling the magnet current. It supplies a voltage which is changed linearly with time by a synchronous motor, and is infected into the feedback loop of the constant current control.

The lock-in amplifier output is recorded by a Leeds \& Northrup Speedomax G pen recorder with a chart speed of 15 inches per hour. The scanning speed of the polarizing.field is 1.93 gauss per minute. The $\mathrm{H}_{1}$ is about 0.05 gauss and its frequency is $10 \mathrm{MHz}$. The radio frequency is measured by a General Radio Model 1191 counter.

\section{B. Preparation of Samples}

The material used in this research is a pure copper-beryllium binary alloy. Since beryilium is chemically a very active element the cholce of crucible materials is limited. It was decided to use pure high density beryllia (beryllium oxide) as the crucible material. A chill mold used for quenching was made of high purity high density graphite. Both of them had . been baked out before being used in the alloy making; also since both copper and beryllium are eastly oxidized, a vacuum furnace is required while making the alloy.

The pre-weighed $99.999 \%$ pure copper and $99.96 \%$ pure beryllium are. arranged inside a large beryllia crucible such that the beryllium (with lower specific gravity) is at the bottom and the copper is near the top of the crucible. The elements are melted inside the evacuated induction furnace chamber filled with argon gas to a pressure of one-quarter of an atmosphere. The temperature of the molten alloy mixture is measured by a calibrated. pyrometer to be about $1100^{\circ} \mathrm{C}$. The alloy is well stirred by the high frequency 
magnetic field inside the induction coil, and the mixture is held at this temperature for thirty minutes then it is furnace cooled with the induction furnace power off.

Due to the slow diffusion of beryllium in copper, the slow cooled alloy does not retain the homogeneous state, rather there is segregation of the solute. Therefore, it is necessary to remelt the slow cooled alloy in a beryllia crucible which is inside a tungsten resistance heater. Three minutes after the liquid alloy reaches $1100^{\circ} \mathrm{C}$, it is quickly poured into a graphite chill mold containing a slot. (3/8)" thick X (3/4)" wide X (1 1/2)" deep. All of the above remelting and chill casting process is done inside a vacuum bell-jar, the vacuum being about $6 \times 10^{-7}$ Torr. The 1ngot is then homogenized by annealing; during annealing the possible maximum diffusion path 1s 3/16". The annealing is done as follows: The ingot is wrapped inside a pure molybdenum foil and the whole thing is then sealed inside a quartz tube which is evacuated to $1 \times 10^{-6}$ Torr. The quartz tubing is heated up to $845^{\circ} \mathrm{C}$ for one week, then quenched to room temperature by breaking the tubing under water. After cleaning the outer surface, it is ready for chemical analysis. A master alloy of 26.8 at.\% Be is made first; then it is diluted to make five alloys of different beryllium contents. Every one of these six alloys is made according to the process described in the previous paragraphs.

The berylifum content of these alloys was determined by chemical analysis and the result is given in Table 1. A trace analysis was done for the master alloy and for sample No. 5 (1.e., Cu+13 at.\% Be). Results are shown in Table 2 . 
Table 1

Results of Chemical Analysis of Cu-Be Samples

\begin{tabular}{ccc}
\hline Sample No. & Wt.\% of Be & At.\% of Be \\
\hline 1 & 0.14 & 0.98 \\
2 & 0.26 & 1.80 \\
3 & 1.04 & 6.90 \\
4 & 1.56 & 10.05 \\
5 & 2.08 & 13.03 \\
\hline
\end{tabular}

Table 2

Results of Trace Quantitative Analysis of Cu-Be Samples

\begin{tabular}{|c|c|c|c|}
\hline \multicolumn{2}{|c|}{$\begin{array}{c}\text { Master Alloy } \\
\mathrm{Cu}+26.08 \text { at.\% Be }\end{array}$} & \multicolumn{2}{|c|}{$\begin{array}{r}\text { Sample No. } 5 \\
\text { Cu+13 at.\% Be } \\
\end{array}$} \\
\hline Impurity & $\begin{array}{l}\text { Content } \\
\text { (ppm) }\end{array}$ & Impurity & $\begin{array}{l}\text { Content } \\
\text { (ppm) }\end{array}$ \\
\hline $\mathrm{Na}$ & 0.5 & $\mathrm{Na}$ & 40 \\
\hline $\mathrm{A} 1$ & 0.4 & $\mathrm{Mg}$ & 12 \\
\hline 51 & 3.5 & $\mathrm{AI}$ & 1 \\
\hline $\mathbf{P}$ & 2 & $S 1$ & 6 \\
\hline $\mathrm{Cl}$ & 3.7 & $\mathrm{~K}$ & 1 \\
\hline $\mathrm{Ca}$ & 0.5 & $\mathrm{Ca}$. & 3 \\
\hline V & 0.2 & $\mathrm{Fe}$ & 1 \\
\hline $\mathrm{Cr}$ & 0.1 & $\mathrm{NI}$ & 0.2 \\
\hline $\mathrm{Fe}$ & 1.5 & $\mathrm{Ag}$ & 3 \\
\hline $\mathrm{Ni}$ & 0.2 & $\mathrm{~Pb}$ & 0.2 \\
\hline U & 0.3 & & \\
\hline
\end{tabular}


The nuclear magnetic resonance (NMR) sample is 200 mesh powdered beryllium-copper which has been filed from the ingot. To eliminate the strain introduced due to cold work (filing), it is necessary to anneal the powder at $845^{\circ} \mathrm{C}$ for few hours; then it is again quenched to room temperature. While annealing at such a high temperature the powder particles tend to sinter together and form a larger slze mass. In order to assure that the radio frequency field will penetrate as much of the sample volume as possible, the sample powder particle size has to be comparable to the skin depth of the sample material at the chosen radio frequency. Therefore, in the heat treatment: process the sample powder is mixed with beryllium oxide, a fine stable ceramic powder. The ceramic particles prevent the sintering of the sample particles and also reduce the possible reaction between the berylliumcopper and the quartz tubing.

Once the mixture of the ceramic and the sample powders is sealed inside the quartz tubing, it is used for the entire experiment without again opening the sample to the air. This way the geometrical configuration of the sample remains the same during the whole measurement. This: is important particularly in the peak-to-peak intensity measurement of the nuclear signal during the alloy aging process.

The sample used in field-1on-microscopy study is also made from the above ingot. Wires of square cross-section, 0.040 in. $X 0.040$ in., are spark cut from the ingot and then are swaged down to $0.019 \mathrm{in}$. In diameter. These wires are solution heat treated at $845^{\circ} \mathrm{C}$ by sealing them inside evacuated quartz tubing (at $1 \times 10^{-6}$ Torr). They are quenched to room temperature after being held at the high temperature for a couple of hours; then they are drawn again down to 0.013 In.. Going through the complete solution heat 
treatment cycle once more, those $0.013 \mathrm{in}$. diameter wires are aged at $280^{\circ} \mathrm{C}$ for 12 hours. In order to retain the two phases stable at $280^{\circ} \mathrm{C}$ these wires again are quenched to room temperature.

C. The NMR Intensity Measurement of $\mathrm{Cu}^{63}$

All the measurements are carried out at room temperature except that of the Knight shift. The filed NMR sample powders are selected by passing them through a 200 mesh gieve(difing openings) so that the smallest dimensions are less than the skin depth. Each sample weighs 2.256 grams and is mixed with beryllia powder to bring its volume up to 2 cubic centimeters; the powder mixture is then sealed Inside an evacuated quartz tube。

The concentration of beryllium ranges from 0.98 at.\% to 13 at.\%. At $845^{\circ} \mathrm{C}$ all five samples are in the solid solution state.

In order to use the empirical "all-or-nothing" model in our analysis (20) it is necessary first to determine the exponent $n$ (see Equation 32). The socalled wipe-out-number $n$ is found as follows: a) heat treat all the samples at $845^{\circ} \mathrm{C}$, so that they are In the random solid solution state, b) measure the magnetic resonance intensities of each, and c) plot $\ln \left(I_{1} / I_{C u}\right)$ vs. $\ln (1-C)$, where $I_{1}, I_{C u}$ are NMR copper intensities of alloy 1 and pure copper for the same weight of copper; $n$ is fust the slope of this curve.

The copper NMR intensities as function of aging time at a given aging temperature are observed at two different temperatures for the $13 \mathrm{at} . \% \mathrm{Be}$ sample. The sample is aged progressively: and is immediately quenched to room temperature at. the end of an intermediate aging treatment: thithe total aging time is taken to be the sum of all aging treatments prior to that NMR measurement. The aging curve for $280^{\circ} \mathrm{C}$ levels off at total time of about 1,000 
minutes; further aging does not cause any change in intensity up to 1,000 hours.

Two $\mathrm{Cu}^{63}$ resonance lines are observed during the aging process and both intensities increase with aging time. With an rf frequency of $10 \mathrm{MHz}$ these two lines are not completely-separated. Figure 5 1.11ustrates the NMR resolution at $10 \mathrm{MHz}$. It is necessary to prove that the precipitated phase is responsible for the smaller NMR resonance. To do this the same sample is observed at $65.87 \mathrm{MHz}$, the polarization field is about six times stronger. Due to the fact that the absolute Knight shift is linearly dependent on the static field, these two NMR lines will move farther apart if they represent the copper nuclei in each of the two phases; namely, the 1 at.\% Be solid solution ( $\alpha$-phase) and 48 at.\% Be CsCl ordered phase $(\gamma)$. It is clear from Equations (29) and (30) that the quadrupole shifts have different field de-. pendence: The first order quadrupole shift is independent of the static field while the second order quadrupole shift is inversely dependent on the static field. From the field dependence it is straightforward to verify the source of the smaller copper signal. In addition pure CuBe has been made and the $\mathrm{Cu}^{63}$ resonance from it found to coincide in knight shift with that of the smaller peak we observe.

A superconducting magnet was employed to produce the high field. : A complete description of this high field spectrometer is given in Dr. David Lo's thesis. (35)

I.t is found that even though the $\mathrm{Cu}^{63}$ signals from these two phases overlap somewhat at $10 \mathrm{MHz}$, the peak-to-peak intensity of the absorption derivative of the $\alpha$-phase is not affected by the presence of the nearby smaller signal from the ordered $\gamma$-phase. 


\section{Figure 5}

NMR Resolution at $10 \mathrm{MHz}$. Standard Calibrator Signals Are also Present 


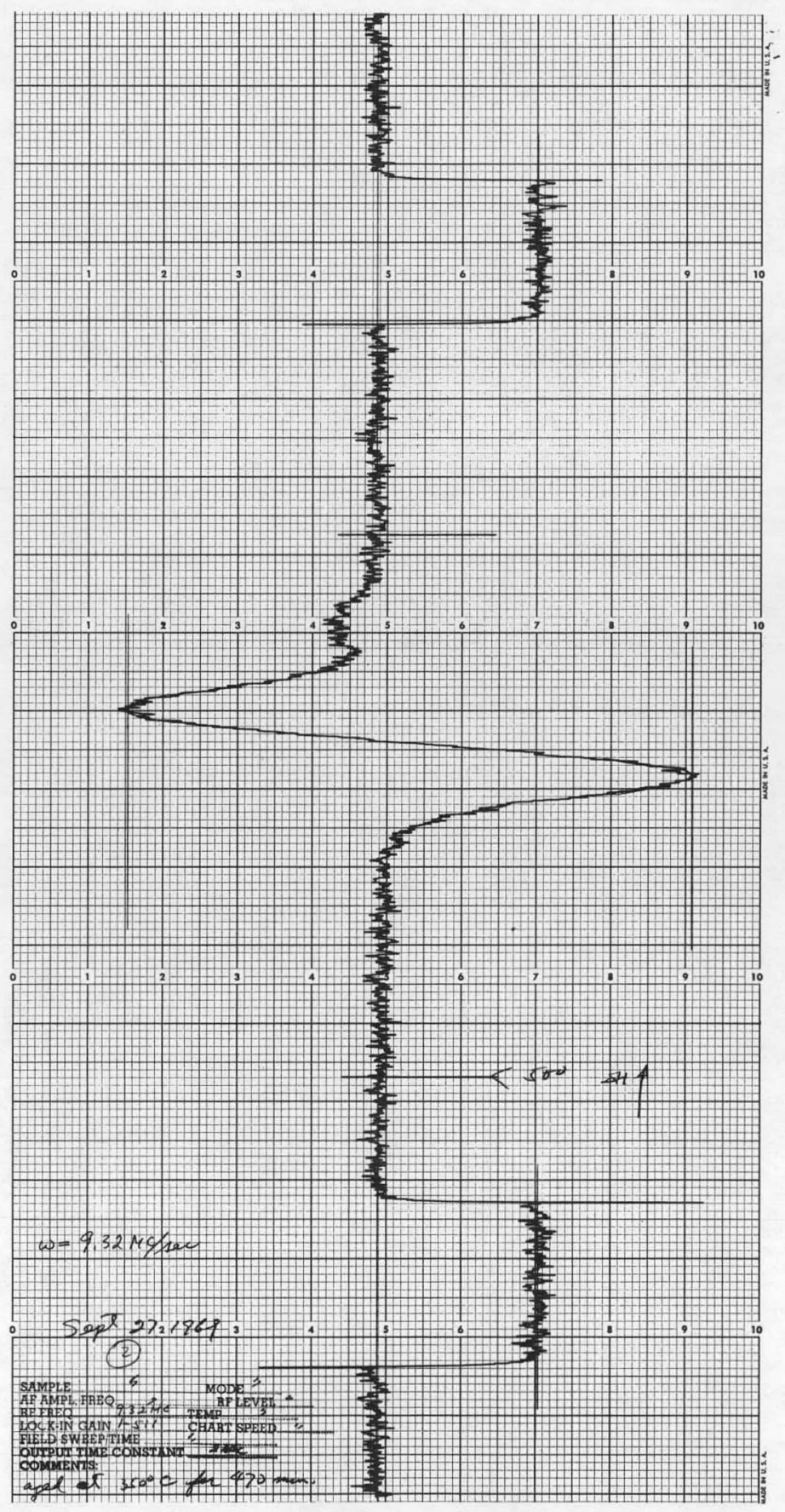


CHAPTER JV

MMR EXPERIMENTAL RESULT AND DISCUSSION

We first solution heat treat all five powder samples sealed in their capsules in an air furnace at $845 \pm 5^{\circ} \mathrm{C}$. After six hours the sample containing 0.98 at.\% Be is removed from the furnace and quickly quenched into water at room temperature, the other four samples being left inside the furnace. The freshly quenched alloy is then placed in the probe and the standard signal is adjusted such that its size is appropriate for all samples.

The measurement begins with recording the standard calibration signal at a lower field than that of $\mathrm{Cu}^{63}$, then starting the scanning motor and scanning the field across the $\mathrm{Cu}^{63}$ signal. Finally the standard signal is recorded again with the field higher than that of $\mathrm{Cu}^{63}$. Figure 5 is a typical recorded trace. The measured quantities; the average of standard signal amplitudes, $\bar{I}_{\text {std }}$, the peak-to-peak intensity of the absorption derivative, $I_{\mathrm{Cu}}^{\prime}$, and other related quantities, are listed in Table 3. The wipe-out-number $\mathrm{n}$ is determined from the slope of a plot of $\ln \left(I_{\mathrm{Cu}}(\mathrm{C})\right)$ vs. In (1-C) shown in Fig. 6.

It should be noted that the quantity $I_{\mathrm{Cu}}(\mathrm{C})$ of Table 3 and $\mathrm{Fig} \cdot 6$ is not the peak-to-peak amplitude measured from chart paper; rather it is standardized to a given weight of copper and takes $\overline{\mathrm{I}}_{\text {std }}$ as the unit of intensity. The wipe-out-number is found to be $18 \pm 1$ for the central transition. Having determined this number one can apply the model developed in Chapter II Section B to examine the aging process of this alloy system via NMR measurement. 
Table 3

Data of NMR Measurements on Solution Heat Treated Alloys

\begin{tabular}{|c|c|c|c|c|c|c|c|c|}
\hline $\begin{array}{l}\text { Atomic } \\
\text { Fraction } \\
\text { of } \mathrm{Be}\end{array}$ & $\left\{\begin{array}{c}\text { Atomic } \\
\text { Fraction } \\
\text { of } \mathrm{Cu}\end{array}\right.$ & $\begin{array}{l}\text { Weight } \\
\text { Fraction } \\
\text { of } \mathrm{Be}\end{array}$ & $\begin{array}{l}\text { Weight } \\
\text { Fraction } \\
\text { of } \mathrm{Cu}\end{array}$ & $\bar{I}_{\text {std }}$ & $I^{\prime} \mathrm{Cu}$ & $\begin{array}{r}{ }_{\mathrm{Cu}}= \\
\quad \mathrm{I}_{\mathrm{Cu}}^{\prime}\end{array}$ & $\ln (1-c)$ & $\ln \left(I_{\mathrm{Cu}}\right)$ \\
\hline$c$ & $(1-C)$ & $c^{\mathrm{Wt}}$. & $\left(1-C^{w t} \cdot\right)$ & $($ in.) & $\left.(\ln )_{0}\right)$ & $\bar{I}_{\operatorname{std}} x\left(1-C^{\text {wt. }}\right)$ & & \\
\hline 0 & 1.00 & 0 & 1.00 & & & $9.21 *$ & & $2.22 *$ \\
\hline .0098 & .9902 & .0014 & .9986 & 1.02 & 7.98 & 7.83 & -0.0099 & 2.059 \\
\hline .0180 & .9820 & .0026 & .9974 & 1.08 & 6.81 & 6.32 & -0.0182 & 1.844 \\
\hline .0690 & .9310 & .0104 & : 9896 & $2.25^{\circ}$ & 5.76 & 2.59 & -0.0715 & 0.953 \\
\hline$: 1005$ & .8995 & .0156 & .9844 & 3.93 & 5.13 & 1.33 & -0.1059 & 0.283 \\
\hline .1303 & .8697 & .0208 & .9792 & 4.05 & 2.87 & 0.72 & -0.1396 & -0.322 \\
\hline
\end{tabular}

* Value obtained by extrapolation (see Fig. 6).

The sample with 13 at.\% Be in $\mathrm{Cu}$ is solution treated at $845^{\circ} \mathrm{C}$ just before starting to observe its aging process; then it is aged at $280^{\circ} \mathrm{C}$ in 30 minute intervals. The aging data presented as the $\mathrm{Cu}$ intensity at time $t$, $I_{t}$, are given in Table 4 and 1 s plotted in Fig. 7. The results of similar treatment at $350^{\circ} \mathrm{C}$ abe given In Table 5 and Fig. 8. From these two aging curves, it is noticed that the completion of precipitation is indicated by the constant maximum NMR intensity. The latter is first attained in about 400 minutes for $280^{\circ} \mathrm{C}$ aging, and in approximately 200 minutes for $350^{\circ} \mathrm{C}$ aging. 
Figure 6

$\ln \left(I_{\mathrm{Cu}}(C)\right)$ vs. $\ln (1-C) P 1 \circ t$ 


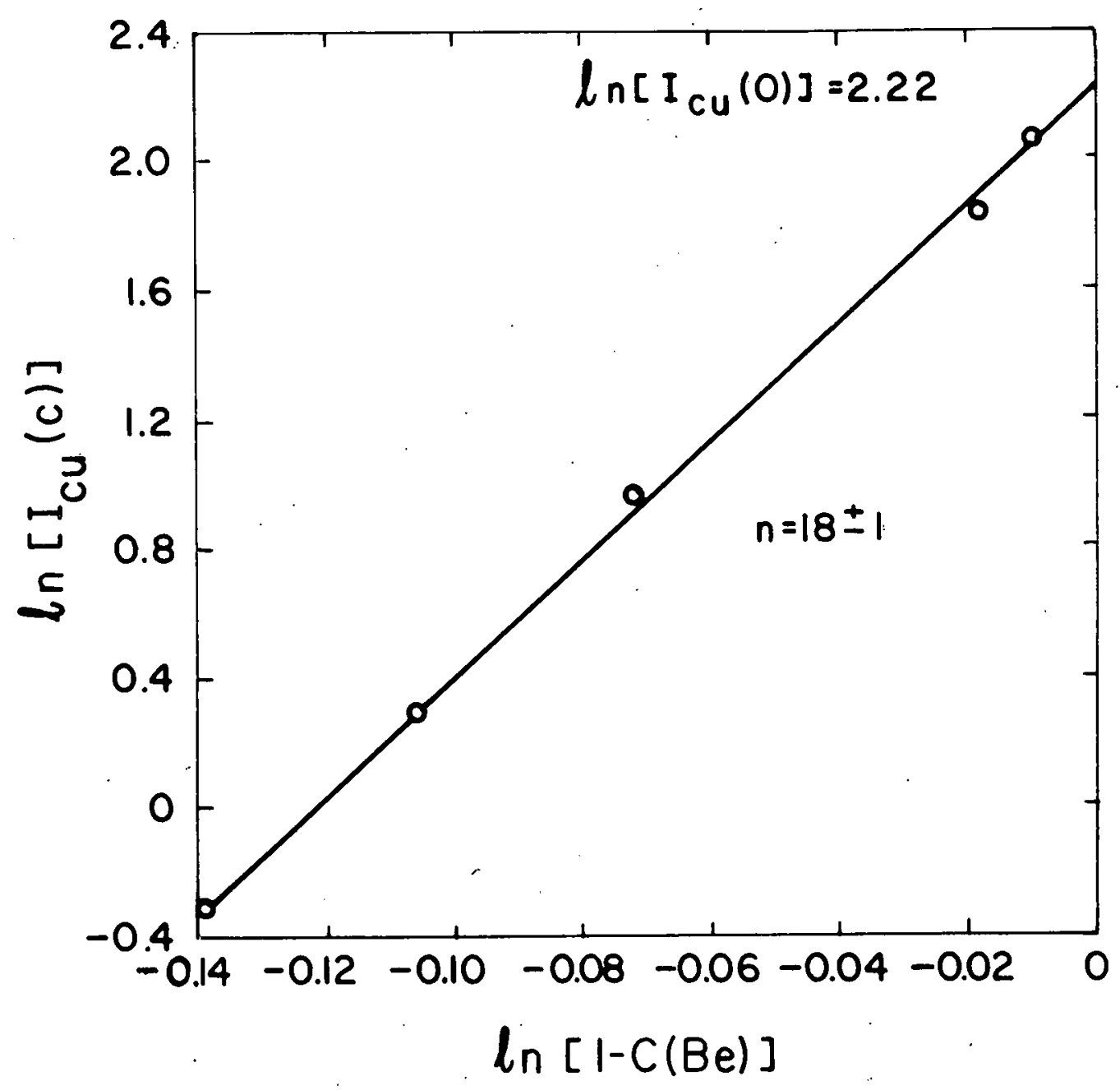


Table 4

Aging Data of Cu+13 at. $\%$ Be at $280^{\circ} \mathrm{C}$

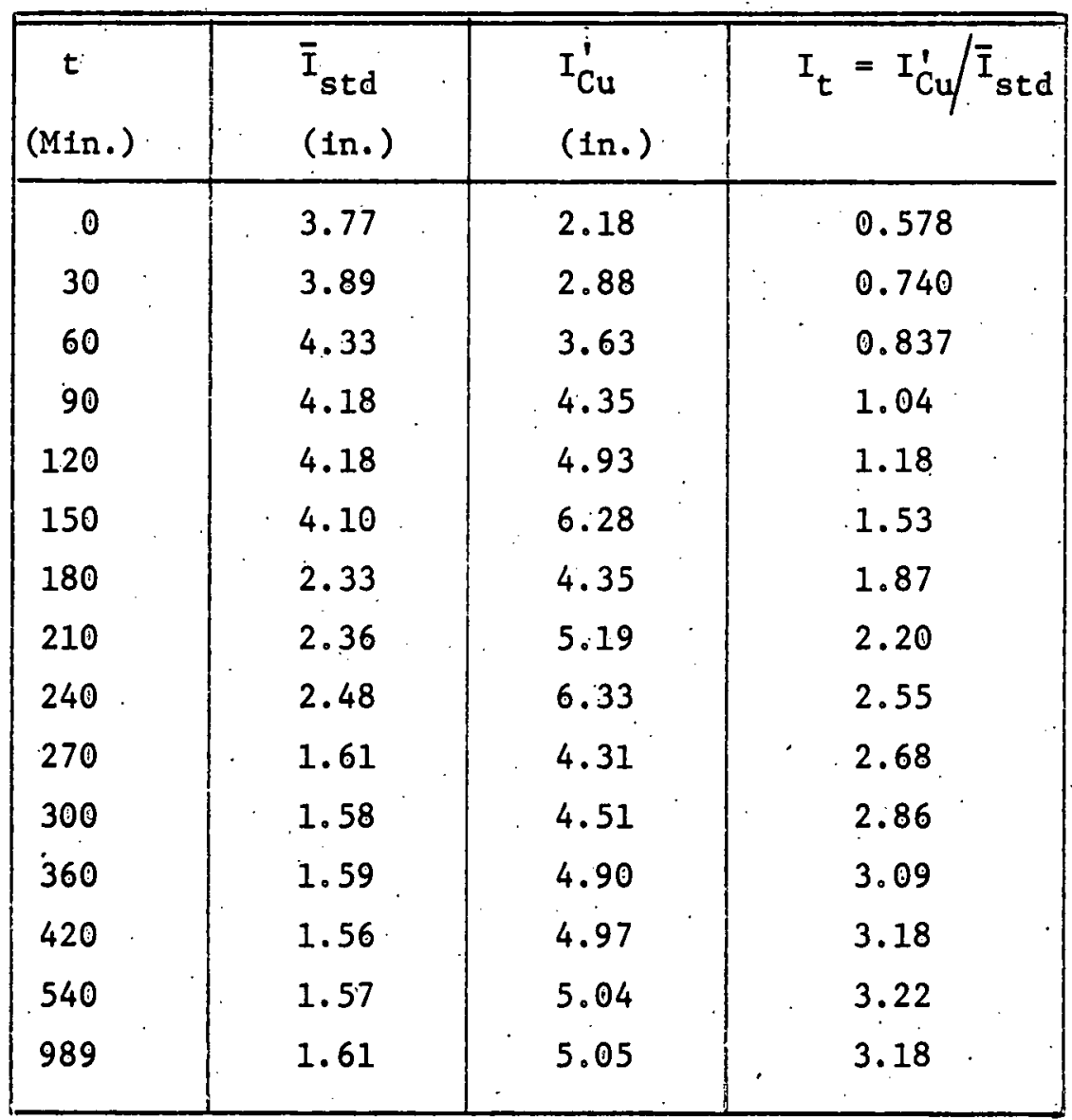


Figure 7

Aging Curve of $\mathrm{Cu}+13$ at. $\%$ Be at $280^{\circ} \mathrm{C}$ 


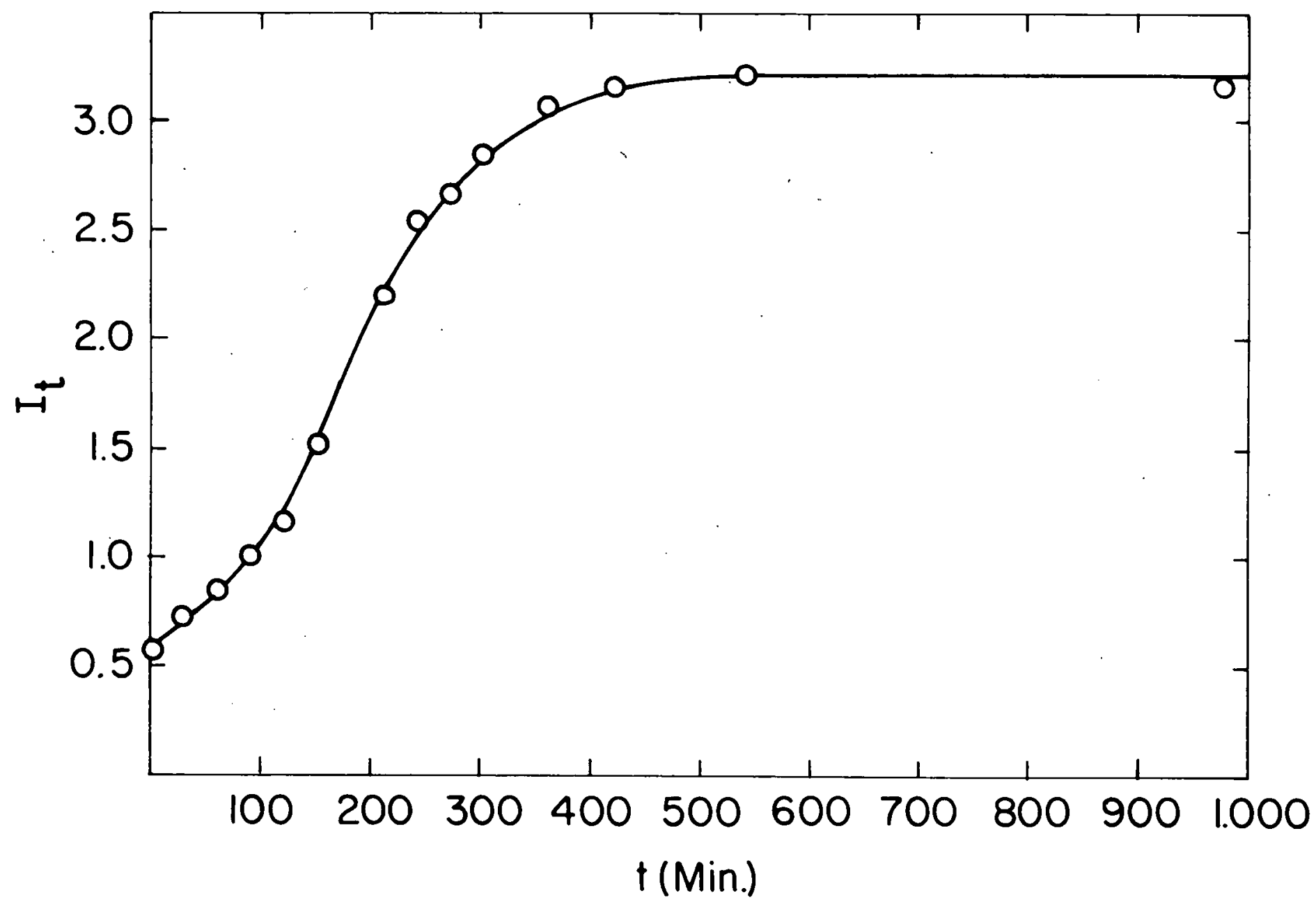


Table 5

Aging Data of Cu+13 at.\% Be at $350^{\circ} \mathrm{C}$

\begin{tabular}{|c|c|c|c|}
\hline $\begin{array}{c}1 \\
(\mathrm{MIn} .)\end{array}$ & $\begin{array}{c}\bar{I}_{\text {std }} \\
(\text { in.) }\end{array}$ & $\begin{array}{l}I_{\mathrm{Cu}}^{\prime} \\
\text { (in.) }\end{array}$ & $I_{t}=I_{\mathrm{Cu}}^{\prime} / \bar{I}_{\text {std }}$ \\
\hline 0 & 3.77 & 2.18 & 0.578 \\
5 & 4.38 & 3.45 & 0.79 \\
10 & 4.31 & 4.27 & 0.99 \\
20 & 4.29 & 6.12 & 1.43 \\
40 & 2.47 & 5.45 & 2.21 \\
90 & 2.45 & 6.62 & 2.70 \\
470 & 2.50 & 7.18 & 2.87 \\
1131 & 2.54 & 7.54 & 2.97 \\
\hline
\end{tabular}

During the course of aging, $I_{t}$ is directly related to $W_{\alpha}(t)$ as stated In Equation (37). At a given time t the weight fraction transformed of $\alpha$-phase $u(t)$ is determined using Equation (38). $u(t)$ as function of time has been calculated at two different temperatures, $280^{\circ}$ and $350^{\circ} \mathrm{C}$. These results are 11 sted in Tables 6 and 7 and plotted. In Figs. 9 and 10. From Equation (39.) we have

$$
\ln \left(\frac{\partial u}{\partial t}\right)_{\mu=u_{1}}=k(u)_{u=u_{1}}-\frac{Q(u)_{u=u_{1}}}{R T}
$$

where $k\left(u_{1}\right)$ is a constant.. 
Figure 8

Aging Curve of $\mathrm{Cu}+13$ at. $\%$ Be at $350^{\circ} \mathrm{C}$ 


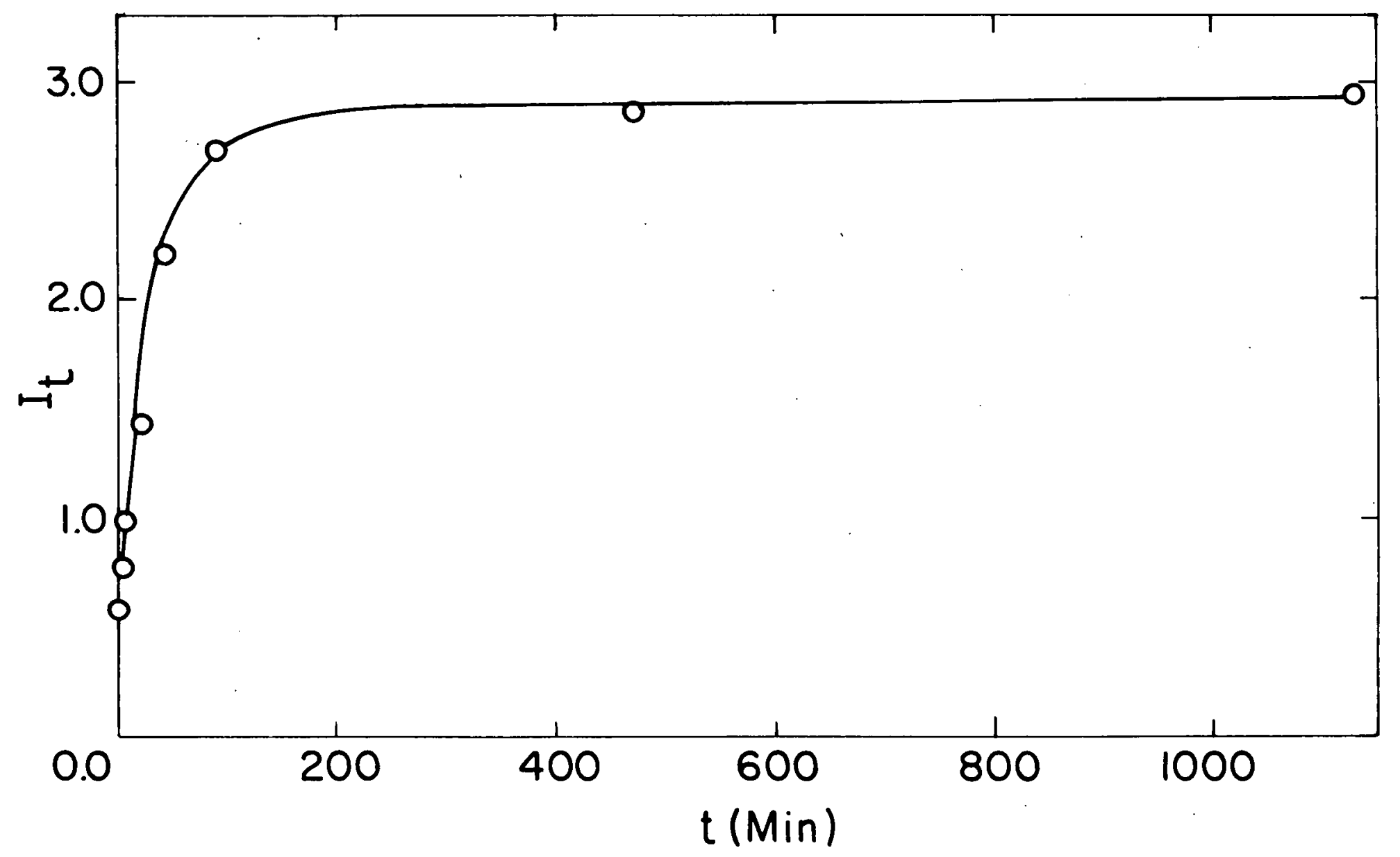


Table 6

$u(t)$, the Weight Fraction Transformed of $\alpha$-Phase, as a Function of Aging Time, $t$, at Aging Temperature $\mathrm{T}=2800^{\circ} \mathrm{C}$

\begin{tabular}{|c|c|c|}
\hline $\begin{array}{c}t \\
\left(M_{0} n_{0}\right)\end{array}$ & $I_{t}-I_{C u}(0.13)$ & $u=\frac{I_{t}-I(0.13)}{I_{\infty}-I(0.13)}$ \\
\hline 0 & 0 & 0 \\
30 & 0.19 & 0.062 \\
60 & 0.30 & 0.100 \\
90 & 0.53 & 0.178 \\
120 & 0.69 & 0.231 \\
150 & 1.09 & 0.366 \\
180 & 1.48 & 0.497 \\
210 & 1.87 & 0.623 \\
240 & 2.27 & 0.758 \\
270 & 2.42 & 0.808 \\
300 & 2.62 & 0.877 \\
360 & 2.88 & 0.965 \\
420 & 2.99 & 1 \\
540 & 3.04 & 1.02 \\
989 & 2.99 & 1 \\
\hline
\end{tabular}

Table 7

$u(t)$, the Weight Fraction Transformed of $\alpha$-Phase, as a Function of Aging Time, $t$, at Aging Temperature $\mathrm{T}=350^{\circ} \mathrm{C}$

\begin{tabular}{|c|c|}
\hline$t$ & $u \frac{I_{t}-I(0.13)}{I_{\infty}-I(0.13)}$ \\
$(M i n)$. & 0 \\
0 & 0.089 \\
5 & 0.172 \\
10 & 0.352 \\
20 & 0.682 \\
40 & 0.887 \\
90 & 0.958 \\
1131 & 1.0 \\
\hline
\end{tabular}




\section{Figure 9}

Weight Fraction of $\alpha$-Phase as Function of Time, at $280^{\circ} \mathrm{C}$ 


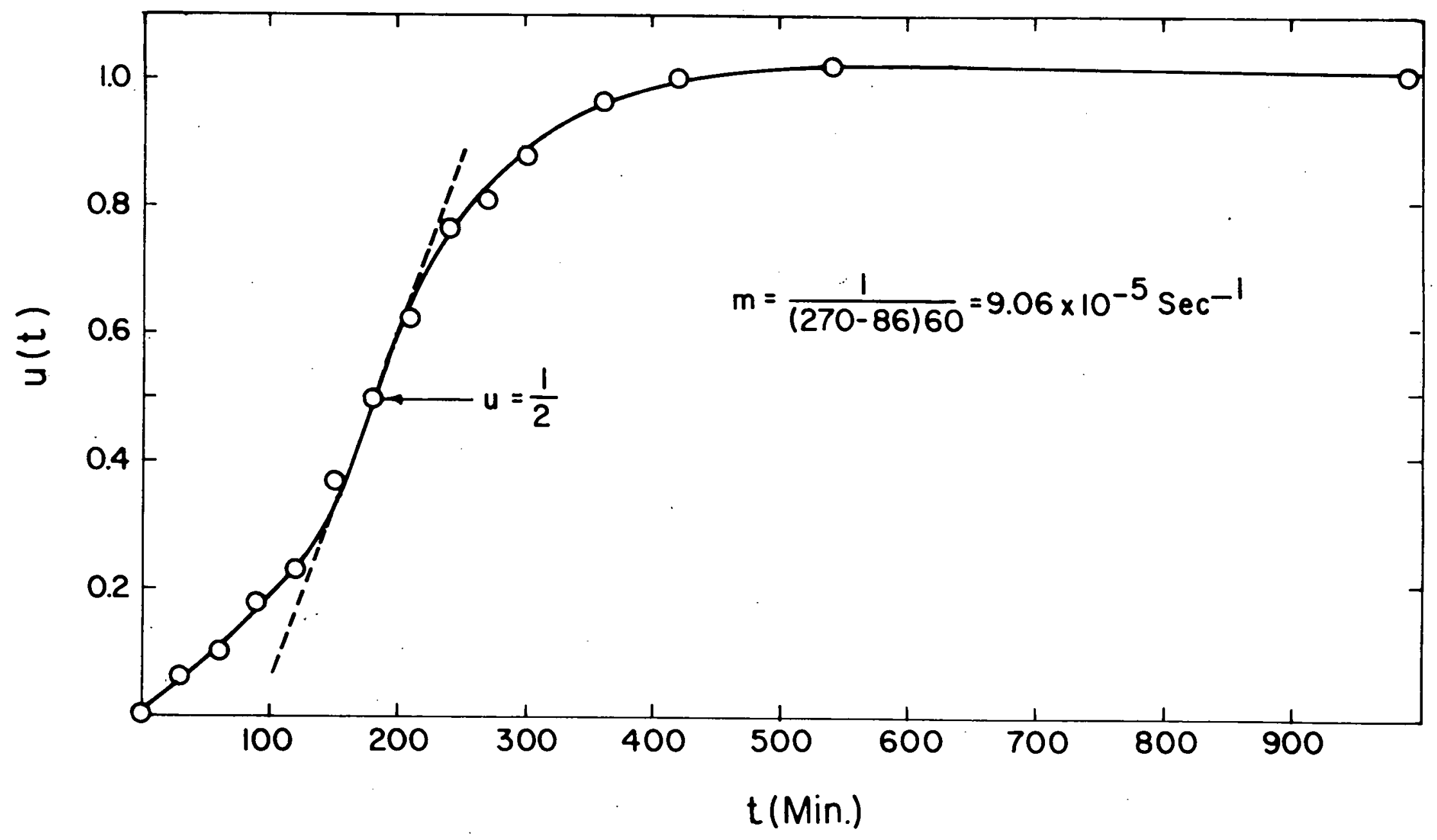


Figure 10

Weight Fraction of $\alpha$-Phase as Function of T.ime, at $350^{\circ} \mathrm{C}$ 


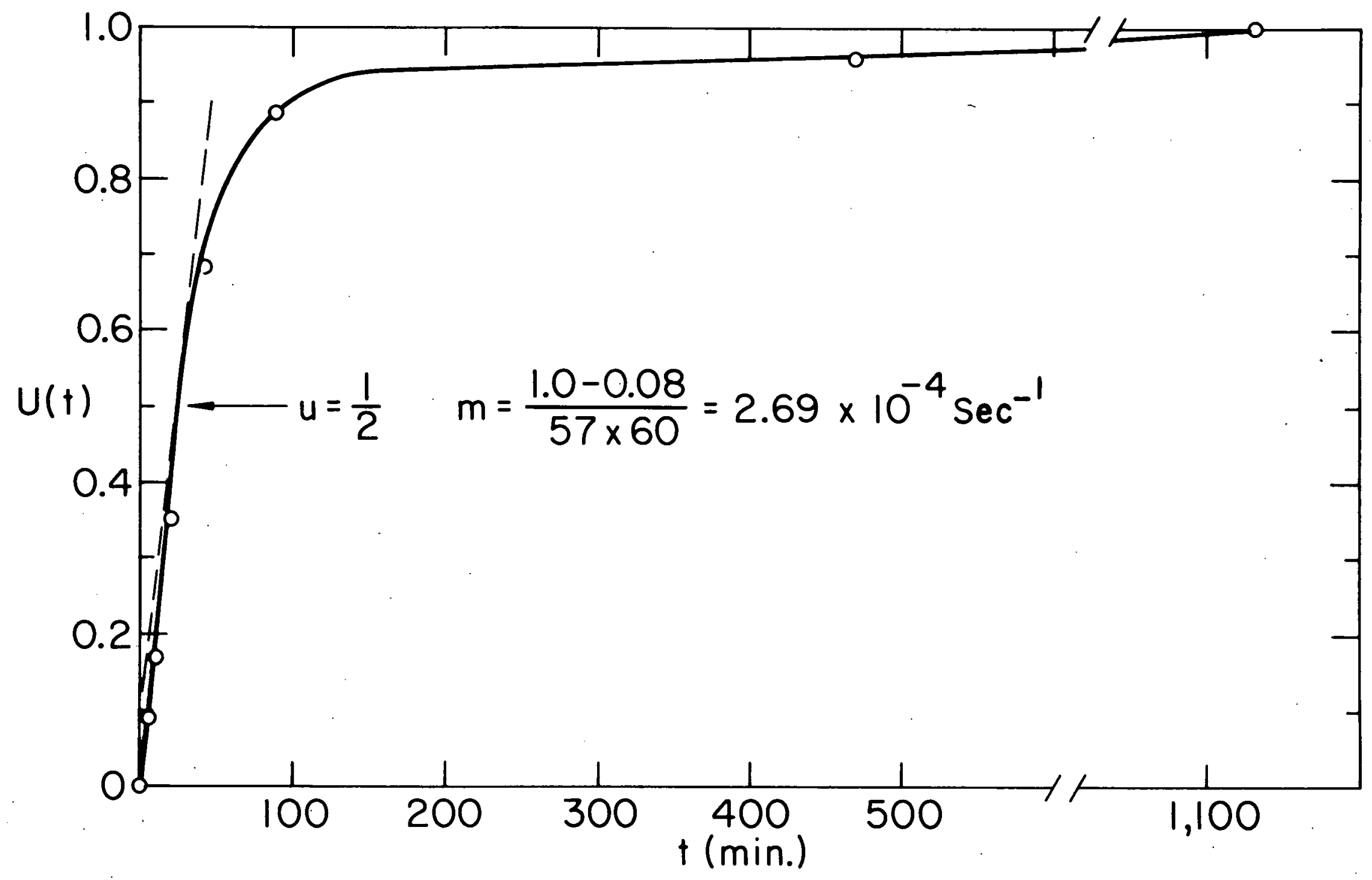


If we choose $u_{1}=\frac{1}{2}$, it is found from Fig. 9 that $\ln (\partial u / \partial t)_{u=u_{1}}=$ -9.309 , at $\mathrm{T}=280^{\circ} \mathrm{C}$; and $\mathrm{k}\left(\frac{1}{2}\right)$ can be determined by using an accepted value of the activation energy $Q$ for the diffusion of beryllium in copper, 37 $\mathrm{kcal} / \mathrm{mole}$.(36),(37)

$$
k\left(\frac{1}{2}\right)=-9.31+\frac{37 \times 10^{3}}{1.99 \times 553}=-9.31+33.62=24.31
$$

As a check of self-consistency. we can determine $Q$ by using this $k\left(\frac{1}{2}\right)$ and the slope of $u$ vs. $t$ curve at $T=350^{\circ} \mathrm{C}$, st11.1 with $u_{1}$ fixed at 0.5 ; thus, from Fig. 10,

$$
Q=\operatorname{Rx} 623 \times\left[24.31-\ln \left(2.69 \times 10^{-4}\right)\right]=40.3 \times 10^{3} \mathrm{cal} / \mathrm{mole}
$$

The difference between these two values of $Q$ is within 10 per cent, indicatIng that our approach is consistent with the bellef that the precipitation of beryllium in copper is mainly diffusion controlled.

If we assume that the alloy system has reached its equilibrium state we can use the model developed in Chapter II Section B to determine the extent to which the beryllium solubility as determined by the NMR technique Is In agreement' with earlier published phase diagrams.

Using Equation (46) and the values $c_{m}=0.13, C_{\gamma}=0.48$, valid below the eutectold temperature, measured intensities can be interpreted directly In terms of the $\alpha$ phase Be concentration $C_{\alpha^{*}}$ Thus

$$
\frac{I_{\infty}(T)}{I_{\text {sht }}}=\frac{\left(C_{\gamma}-C_{m}\right)}{\left(1-C_{m}\right)^{19}} \frac{\left(1-C_{\alpha}\right)^{19}}{\left(C_{\gamma}-C_{\alpha}\right)}=4.934 \frac{\left(1-C_{\alpha}\right)^{19}}{\left(0.48-C_{\alpha}\right)}
$$


The assumption implictt here, emphasized below Equation (46), is that the two-phase alloy consists of a simple mixture of depleted (final, equilibrium) $\alpha$ and $\gamma$. Using a $\mathrm{Cu}+13$ at.\% Be sample we determine the solvus line simply by solving for $C_{\alpha}$ in Equation (48). Experimental data are given in Table 8. The solvus line determined as described above is compared with the published one in Fig. 2 。

The beryllium concentration of the solvus line found using NMR deviates substantially from the published values; the lower the aging temperature 1s, the larger is the deviation (see Fig. 2). It appears that the temperature of aging affects in some extraneous way the concentration as determined by the MMR method. We assume that the published solvus line is the correct one. One potentiai source of interpretational error is that NMR intensity may be influenced by effects other than concentration alone. It is known, for example, that work hardening (lattice deformation) will decrease the intensity in some instances. We may be confronted here with an extreme case of such an effect causing a diminished central line intensity because of the strains present in the dispersion hardened materfal. To verify this hypothesis we require information about the precipitate size, shape and distribution.

An experiment designed primarily to check the basic assumptions leading to Equation. (48) has been conducted by R. S. Shalvoy。 (38) In that Instance a copper rich copper-silver binary alloy known to be free of very small scale precipitates of the type formed in copper-beryllium alloys was chosen for investigation. In outline the experiment followed the lines of the present one: a 4.8 at.\% Ag alloy was equilfbrated at 400,500 , and $600^{\circ} \mathrm{C}$. 
Table 8

Beryllium Concentration in Equilibrium $\alpha$-Phase

(A) Derived from NMR Intensity Measurements: Not Including Particle Size Effects

(B) From Published Phase Diagram (21)

\begin{tabular}{|c|c|c|c|c|}
\hline \multirow{2}{*}{ Aging Time } & \multirow[b]{2}{*}{$\begin{array}{l}\text { Aging } T \\
\left({ }^{\circ} \mathrm{C}\right)\end{array}$} & \multicolumn{2}{|c|}{$\begin{array}{c}\text { Beryllium Concentration in } \\
\text { Equilibrium } \alpha \text {-phase } \\
\text { (at.\% Be) }\end{array}$} & \multirow[b]{2}{*}{$\begin{array}{l}\text { Deviation } \\
(\mathrm{at}: \% \mathrm{Be})\end{array}$} \\
\hline & & $\begin{array}{c}\text { Present Work } \\
\text { (NMR) }\end{array}$ & Published ${ }^{(21)}$ & \\
\hline $16^{\mathrm{hr}} 29^{\mathrm{mln}}$ & 280 & 3.70 & 1.25 & 2.45 \\
\hline $20^{\mathrm{hr}}$ & 350 & 4.00 & 2.00 & 2.00 \\
\hline $12^{h r}$ & 420 & 4.40 & 3.40 . & 1.00 \\
\hline $6^{\mathrm{hr}} 35^{\min }$ & 500 & 7.85 & 6.60 & 1.25 \\
\hline $13^{h r} 10^{m i n}$ & 550 & 8.95 & 8.40 & 0.55 \\
\hline
\end{tabular}

No time dependence data were taken. The measured intensities in that case obeyed Equation (44), and thus Equation (48), exactly. 'It was concluded that Equation (44) "could be relied upon to correctly account for the resonance intensity in a two-phase system when it is known that the second (precipitate) phase is present only as large, incoherent precipitate particles:" 
A high field NMR measurement was also made on the same sample, 1.e., Cu+13 at.\% Be. The sample was mounted in a probe espectally designed for 6.6 MHz radio frequency observation. The probe and sample were then cooled down to liquid helium temperature $\left(4.2^{\circ} \mathrm{K}\right)$. With the temperature of the sample stablized at $4.2^{\circ} \mathrm{K}$, and after locating the $\mathrm{Cu}^{63}$ signals within the sweep range, the superconducting magnet was set into the persistent:mode. A single sweep of 100 gauss covers both $\mathrm{Cu}^{63}$ resonances, one from the 1 at.\% $\mathrm{Be}$ $\alpha$-phase, one from the 48 at.\% Be $\gamma$ precipitate phase (see Fig. 11). The $\mathrm{Cu}^{65}$ resonance was also observed on the low field side of $\mathrm{Cu}^{63}$ far away from the portion of the NMR spectrum in which we are interested.

The calibration of the scanning fleld was obtalned by recording the $\mathrm{Cu}^{63}$ resonance at constant static field $\mathrm{H}_{0}$ and at three different radio frequencles, namely $65.790,65.800$ and $65.810 \mathrm{MHz}$. From the callbration we can measure the Knight shift of the $\mathrm{Cu}^{63}$ resonance belonging to the two different phases. The relative shift between pure $\mathrm{Cu}$ and $\mathrm{Cu}+1$ at.\% $\mathrm{Be}$ is known to be negligibly small, thus the relative shift of the $\mathrm{Cu}^{63}$ resonance in CuBe ( $\gamma$-phase) with respect: to that of pure copper is

$$
\frac{\Delta v}{v}=\frac{70 \times 10^{3} \mathrm{~Hz}}{65.87 \times 10^{6} \mathrm{~Hz}}=0.11 \%
$$

which corresponds to a Knight shift $\mathrm{K}_{\mathrm{CuBe}}=0.13 \%$.

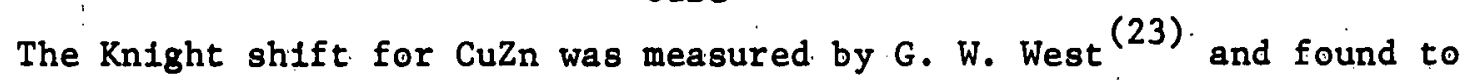
be $0.15 \%$. The CuZn alloy system is introduced here because both $\mathrm{Zn}$ and Be are in Group II of the perlodic table, having two s-electrons in the outermost. shel1; In addition CuZn and CuBe have the same crystal structure, 1.e., CsC1, with lattice parameters of 2.95 \& and 2.70 \& respectively. Equation (27) 
Figure 11

$\mathrm{Cu}^{63}$ NMR Spectrum of $\mathrm{Cu}+13$ at.\% Be, Two Phase System. Precipitation Completed at $2800 \mathrm{C}$. Data Taken at $66 \mathrm{MHz}$ and $4.2 \% \mathrm{~K}$. (Tracing of Original) 


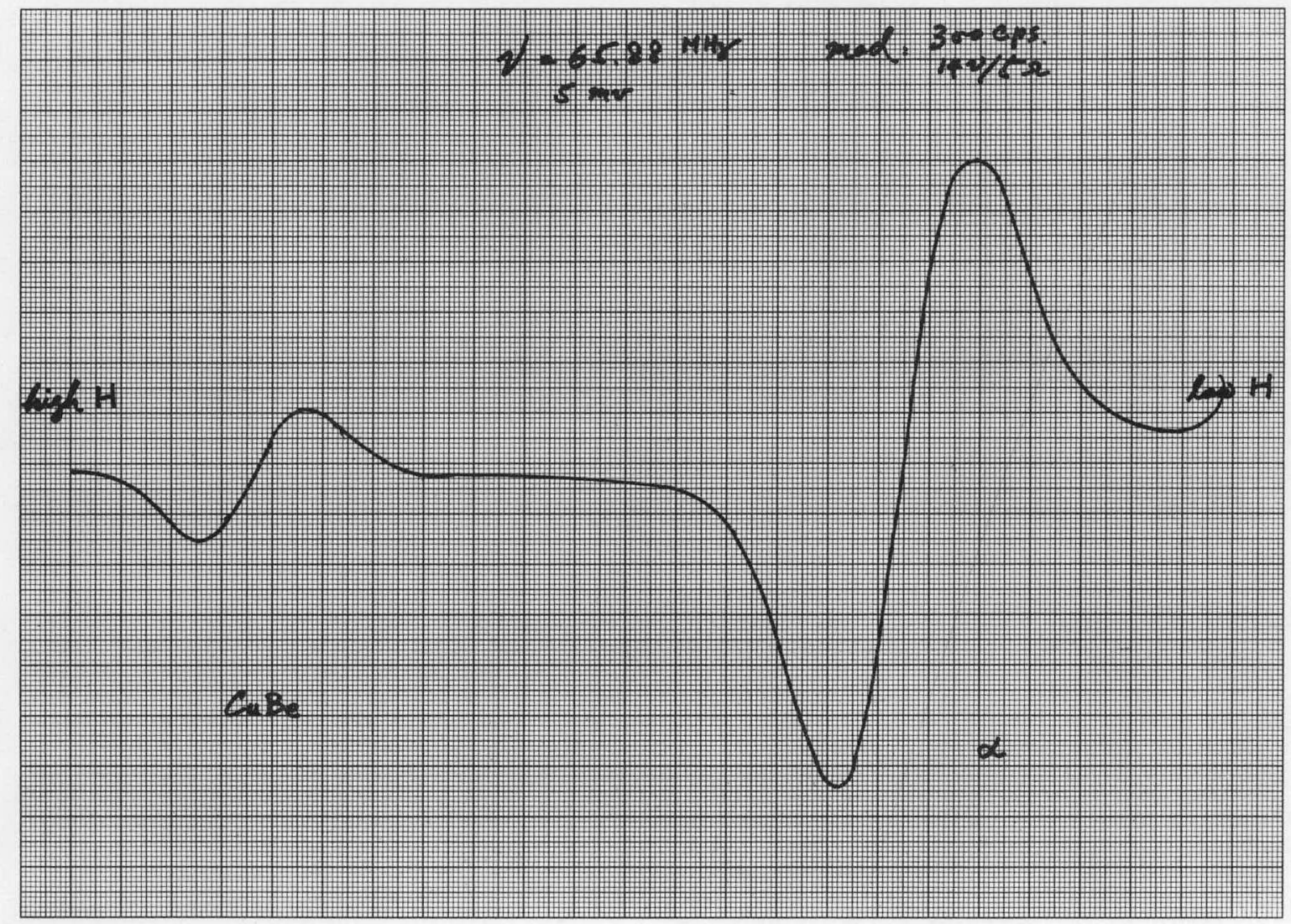


describes the relevant component of the Knight shift; it measures the magnetic hyperfine field at the nucleus produced by the conduction electrons which are polarized in a magnetic field. This mechanism suggests that the Knight shift of the above two alloy systems should be simflar, as indeed they are and that the small difference might be related to the difference in the unit cell volume for the two structures.

There is no simple theory that enables us to estimate the volume dependence of the Knight shifts in these compounds. It is reasonably well understood in some of the alkali metals, ${ }^{(39)}$ but for copper the best available information is the measured pressure dependence of the pure metal, which, when converted to volume dependence.through use of the compressibility, gives ${ }^{(39)}$

$$
K(v)=K_{C u}\left(V / v_{0}\right) 0.7 \pm 0.3
$$

If the same volume dependence were to hold for the $\mathrm{Cu}$ in the $\mathrm{CsCl}$ structure we. would expect the ratio of the Knight shifts in CuZn and CuBe to be equal to $\left(\mathrm{V}_{\mathrm{CuZn}} / \mathrm{V}_{\mathrm{CuBe}}\right)^{0.7}=1.31^{0.7}=1.21$. The measured value is $\mathrm{K}_{\mathrm{CuZn}} / \mathrm{K}_{\mathrm{CuBe}}=$. 1.15. The free electron model (which does not explain the pure Cu data) predicts a ratio of $\left(\mathrm{V}_{\mathrm{CuZn}} / \mathrm{V}_{\mathrm{CuBe}}\right)^{-1 / 3}=0.91$. It is notable that the Knight shifts in these two intermetallic compounds are a) nearly equal, and that $b$ ) the small difference can be ascribed to a volume effect consistent with that in pure $\mathrm{Cu}$. 
CHAPTER V

FIELD ION MICROSCOPY (FIM)

A. Polishing of the Specimen Tip

The general procedure followed in preparing the tip was as follows.

The 0.013 inch diameter wire is spot-welded onto a U-shaped tungsten loop. At this stage it has already undergone heat treatment to bring about the extent of precipitation we desire to observe in the field-ion microscope. It is then electropolished in ortho-phosphoric acid $\left(\mathrm{H}_{3} \mathrm{PO}_{4}\right)$ saturated with chromic acid $\left(\mathrm{CrO}_{3}\right)$, the polishing voltage being 2-10V DC and the polishing temperature around $80^{\circ} \mathrm{C}$. Immedlately after being polished the tip has to be thoroughly cleaned, first in water and then in absolute ethy1 alcohol. Any residual solvent could react with the tip materlal during bakeout of the vacuum system and increase the chance of failure. Figure 12 shows pictures of two sample tips polished as described above and observed in a scanning electron microscope with a magnification of $30,000 \mathrm{x}$; from these pictures the radil of these tips are estimated to be $500 \AA$ and $300 \AA$.

\section{B. Princlple of Imaging}

The microscope chamber is pumped down to a vacuum better than $3 \times 10^{-8}$ Torr, then the imaging gas (or, gas mixture) is leaked in up to a pressure of 2 to $3 \times 10^{-5}$ Torr. Some of the gas atoms are fonlzed near the tip surface and the fons are projected almost radially toward the grounded input face of a. channel plate. The incoming lons generate a number of electrons which, being accelerated by the potential difference between the input and output faces of the channel plate, go through a multiplication process which greatly increases the number of electrons. After emerging from the channel plate these electrons are accelerated by an electric field toward a fluorescent screen. 
Figure 12

Cu+13 at.\% Be Sample Tips Observed in a Scanning Electron Microscope $(30,000 \mathrm{X})$ 


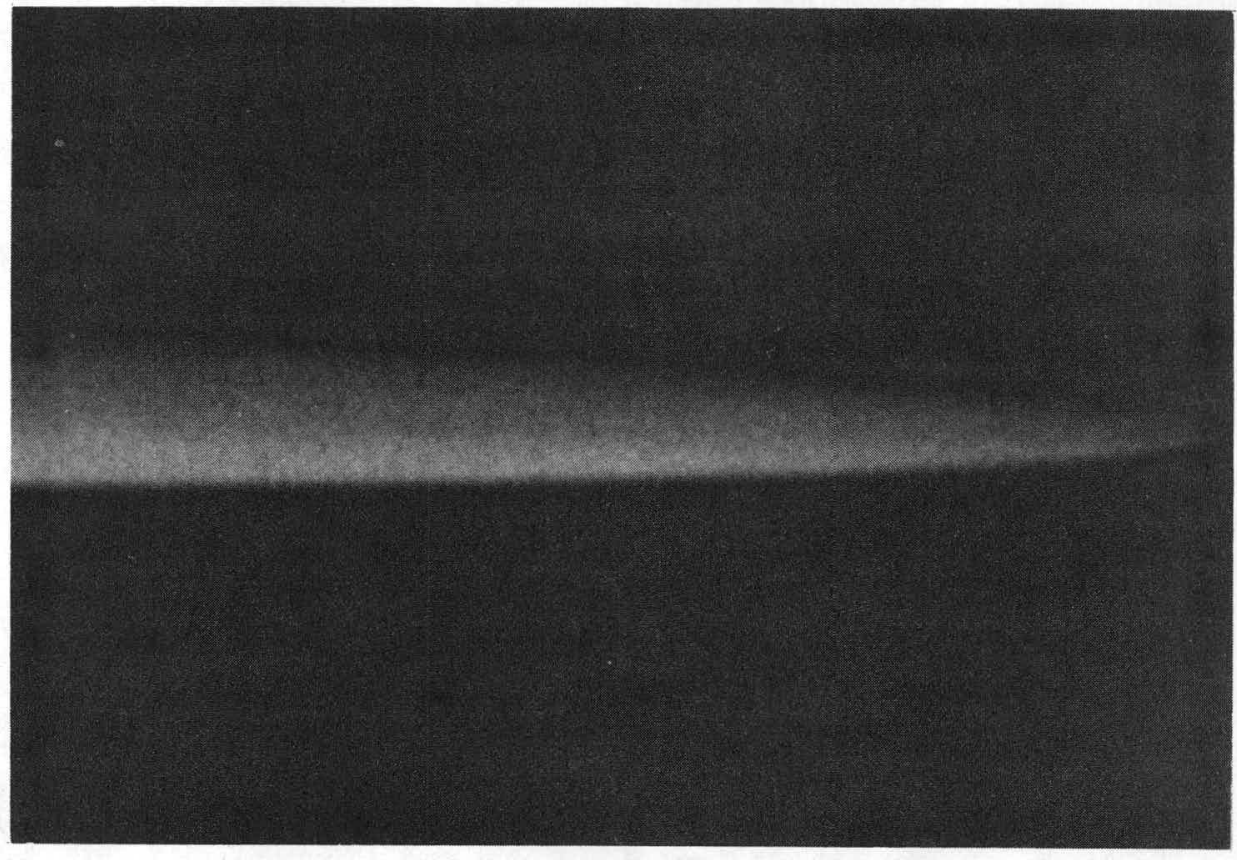


The image formed on the fluorescent screen is thus due to secondary electrons rather than imaging gas lons. Ions leave the points of highest field which correlate with the most protruding atoms on the tip surface to produce spots of highest intensity in the image. Every bright image spot corresponds to a prominent site on the tip surface.

It Is reasonable to approximate the field-ion image as a stereographic projection of the surface field modulations. Since the specimen tip is not an exact hemispherical cap, the field-ion image will generally not coincide exact:ly. with a standard crystallographic projection. The order of magnitude of the magnification is given by $M=R / B r_{t}$, where $R$ is the tip-toscreen distance, and $\beta$ represents an image compression factor which takes Into account the fact that the emitter is supported by a relatively extended structure at the same potential and is not a freely suspended sphere providing exactly radially symetric geometry. The value of $\beta$ is usually between 1.5 and $1.80(40) \cdot r_{t}$ is the radius of the specimen tip.

The resolution of the image depends principally on the size of the fmage gas atom and 1 ts lateral velocity. The lonization of the gas atoms occurs after they accommodate to the tip temperature through a number of hops over the tip surface. Therefore, the resolution is sensitively dependent on tip temperature. The best resolution is obtalned by working with the smallest possible tip radius, $r_{t}$, by reducing the thermal equivalent temperature of the image gas at the instant of Ionization, $T_{t}$, and by imaging with a gas with the highest ionization field $F_{0}$ and the smallest atomic radius $\rho_{0}\left(\delta_{0}\right.$, is approximately. equal to $\rho_{0}$ ) All these dependences are easily seen from the following formula given by Muller and Tsong,: (40) 


$$
\delta=\delta_{0}+\left[4\left(\frac{\beta^{2} r_{t} \hbar^{2}}{2 K e m F_{0}}\right)^{\frac{1}{2}}+16\left(\frac{\beta^{2} r_{t} k T_{t}}{k e F_{0}}\right)\right]^{\frac{1}{2}}
$$

where $\delta$ is the resolution defined as broadening of the ion beam divided by the magnification, $\hbar$ is Planck's constant divided by $2 \pi, k$ is a geometrical factor, $m$ is the atomic mass of image gas particle and $k$ is Boltzmann's constant. These conditions make helium the best choice at $4^{\circ} \mathrm{K}$; for sample materials with low ionization potentials, neon at $21^{\circ} \mathrm{K}, \mathrm{H}_{2}$ or $\mathrm{H}$ at $11^{\circ} \mathrm{K}$ are the best possibilities. The image gas atomic radil used in FIM are $1.1 \AA$ for $\mathrm{He}, 1.3 \AA$ for $\mathrm{Ne}$ and $1.9 \AA$ for $\mathrm{Ar}$. While the radil of $\mathrm{H}$ and $\mathrm{H}_{2}$ molecules were assumed to be $1.4 \mathrm{~A}$ 。( 40$)$

\section{Field Ionization}

The motion of the imaging gas particles is governed by kinetic theory when they are far away from the specimen tip; close to the tip, the rate of supply of the incoming gas atoms is greatly increased due to the force resultIng from the polarization of the gas atoms which in turn is induced by the applied field. The attracted atom will strike the specimen surface atom and rebound. If we assume during the striking most of its kinetic energy is lost to the lattice, then the amplitude of the subsequent rebounds is continuously decreasing. Consequently the time interval spent by a gas atom in the ionization zone near the tip surface is increased. The atom is close to the tip surface and is well accommodated to the tip temperature before being ionized by losing an electron during the ionization process. The critical distance $x_{c}$ for field-ionization is a distance at which the atom has an optimum Ionization probability. This distance, to a good approximation, has a simple form 


$$
x_{c}=(I-\phi) / e F
$$

where $I$ is the ionization energy of the gas atom and $\phi$ is the work function of the tip material. For a tungsten tip and having hellum as imaging gas with $\mathrm{F}=4.4 \mathrm{~V} / \AA, \mathrm{x}_{\mathrm{c}}$. is around $4.5 \AA$.

R. Gomer ${ }^{(42)}$ used the WKB (Wentzel-Kramer-Brillouln) approximation to estimate the probability of tunnelling through a potential barrier of the shape indicated in Figure 13, finding

$$
D=\exp \left[-0.68 \frac{\mathrm{I}^{3 / 2}}{F}\left(1-\frac{7.6 \mathrm{~F}^{1 / 2}}{I}\right)^{\frac{1}{2}}\right]
$$

where $I$ is in $e V$ and $F$ in $V / \AA$.

The lifetime of the gas atom before lonization occurs is

$$
\tau \cdot=\frac{1}{\mathrm{BV}}
$$

where $\nu$ is the frequency with which the electron inside the atom strikes the barrier. For hydrogen, $v=4.1 \times 10^{16} \mathrm{sec}^{-1}$, for helium, $v=2.4 \times 10^{16} \mathrm{sec}^{-1}$, and for argon, $\nu=1.5 \times 10^{16} \mathrm{sec}^{-1}$.

The lonization probability of a gas atom traveling. with velocity $v$ from point $x_{1}$, to $x_{2}$ near the surface is

$$
P(t)=1-\exp \left[-\int_{x_{1}}^{x_{2}} \frac{d x}{v(x) \tau(x)}\right]
$$

When the atom travels with a large acceleration produced by the dipole attraction due to the polarization of the atom in a high electrostatic field of the order of $10^{8} \mathrm{~V} / \mathrm{cm}$, the time interval, the atom needs pass through the ionization zone is so small it in turn makes the $P(t)$ exceedingly small. However, the fonization probability is increased due to 
Figure 13

(a) Potential-Energy Dlagram for the $1 \mathrm{~s}$ Electron of an $H$ Atom in a Field of $2 \mathrm{~V} / \mathrm{A}$. Broken Lines Show the Coulomb Potential in the Absence of an External Field.

(b) Same Atom at a Distance of $5.5 \AA$ from a Tungsten Surface: $\mu$, Fermi Energy; $\phi$, Work Function; $\mathrm{P}_{\mathrm{M}}$, Atom Potential; $\mathrm{P}_{W}$, Superposition of Applied and Pseudoimage Potential (42) 


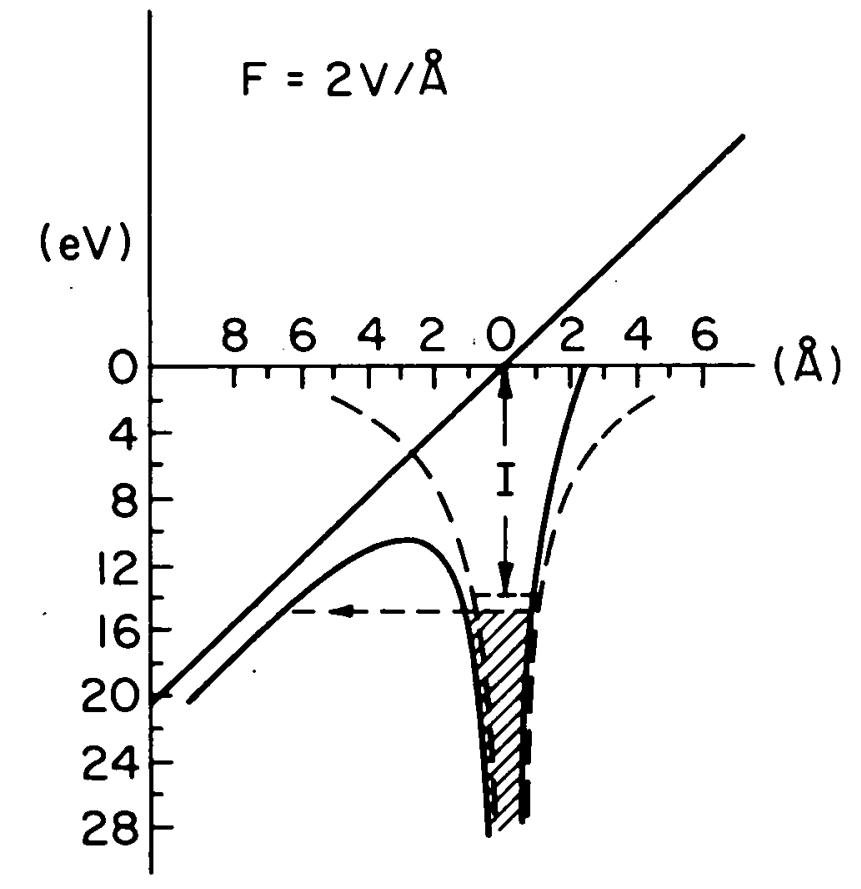

(a)

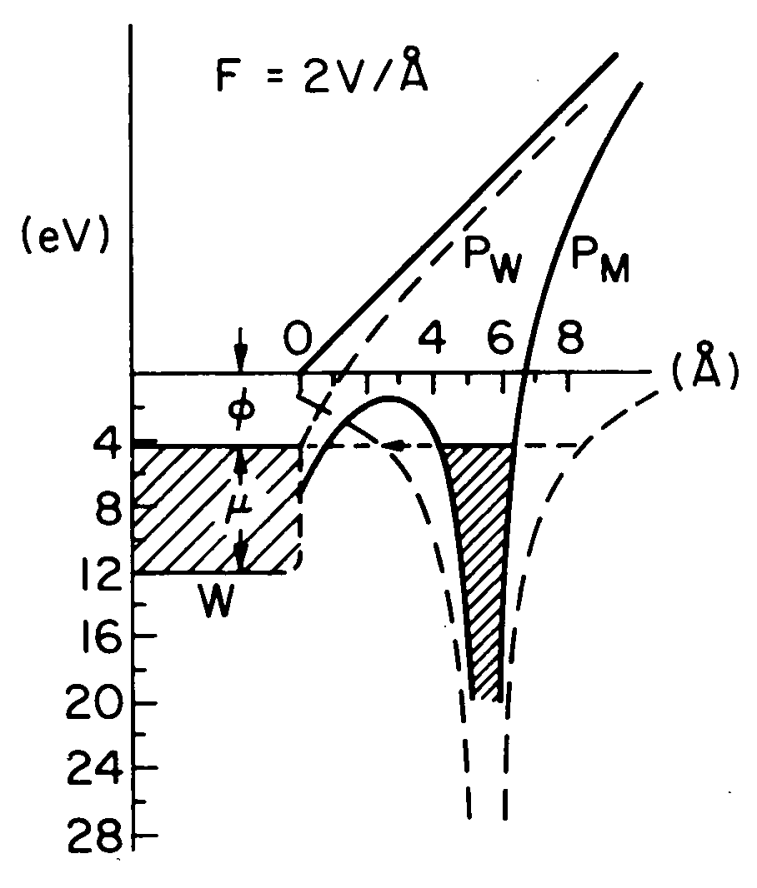

(b) 
the gas atoms spending more time in the high field region during the sequential hopping mentioned above.

The width of the fonization zone was determined by Tsong and Muller ${ }^{(43)}$ to be $0.136 \AA$ using a retarding potential energy analyser. Later Boudreaux and Cutler $(44),(45)$ applied time-dependent perturbation theory to both one and three dimensional models of the field ionization process; Their result is in good agreement with the above value. They also found that the probability of Ionization during a single pass through the ionization zone is of the order of $10^{-9}$.

To summarize, the field-ion current from the tip is governed by the product of the local ionization probability and the supply of gas atoms. At relatively low field the ion current is limited by the ionization probability. At very high field all particles approaching the tip become lonized before reaching it; i.e., the fonization probability is one, so that the ion current is governed by the supply of the gas atoms.

\section{Field Evaporation}

The outermost surface layer atoms together with any surface contamination can be further stripped off by the high applied electric field. The fleld evaporation can be thought of as operating through the following steps. The atoms sitting on a lattice step. will be preferentially evaporated off. A neutral atom leaves the tip surface, a process requiring the sublimation energy $\Lambda_{0}$ In general it is assumed for simplicity ${ }^{(46)}$ that this energy does not depend on the crystallographic orfentation of the tip surface. This atom is then fonlzed by absorbing 1ts lonization energy I. Finally the electron goes back into the metal that gains an energy equal to the work 
function $\phi$ of the crystal plane under consideration. Thus the total energy Q required to turn a surface atom into an ion is

$$
Q_{0}=\Lambda+I_{n}-n \phi
$$

where $n$ is the number of electronic charges of the ion. If we assume the Ionization is completed at a position suffictently far from the tip surface so we can neglect the repulsive force between ion cores; then the fon sees the potential

$$
V_{I}(x)=-\left(n e F x+\frac{n^{2} e^{2}}{4 x}\right)
$$

where $F$ is the electric fleld above the site of lonfzation and $x$ is the distance between the ion and the tip surface. The effective potential $V(x)$ 1s plotted in Fig. 14. The maximum value of $V_{I}(x)$ located at $x_{\text {max }}$ is found by differentiating Equation (56)

$$
V_{I}\left(x_{\max }\right)=-\left(n^{3} e^{3} F\right)^{\frac{1}{2}}
$$

This maximum is the so-called "Shottky hump," and the energy barrier which must be overcome by thermal activation is then

$$
Q=Q_{0}-\left(n^{3} e^{3} F\right)^{\frac{1}{2}}
$$

The rate constant of the fleld evaporation is

$$
k_{e}=v \exp (-Q / k T)
$$

where $V$ is the vibrational frequency of the atom bound at the tip surface. Combining Equations (55), (58) and (59) gives the evaporation field 


\section{Figure 14}

(a) Schematic Dlagram of the Form of the Potential Energy Curves when Fleld Evaporation Is Preceded by Ionization

(b) Schematic Diagram of the Form of the Potentlal Energy Curves when Ionization Occurs at the Moment of Field Evaporation (52) 


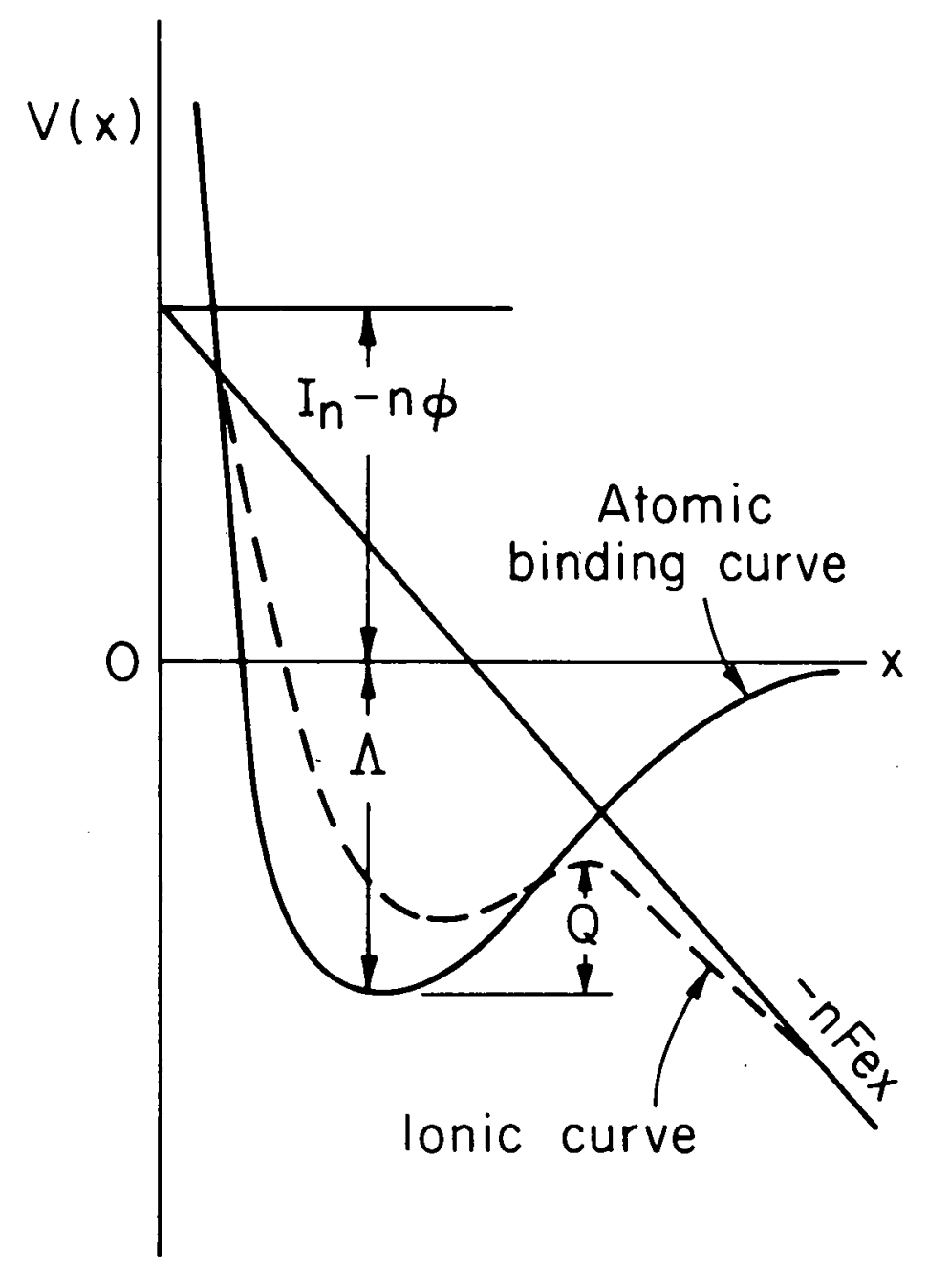

(a)

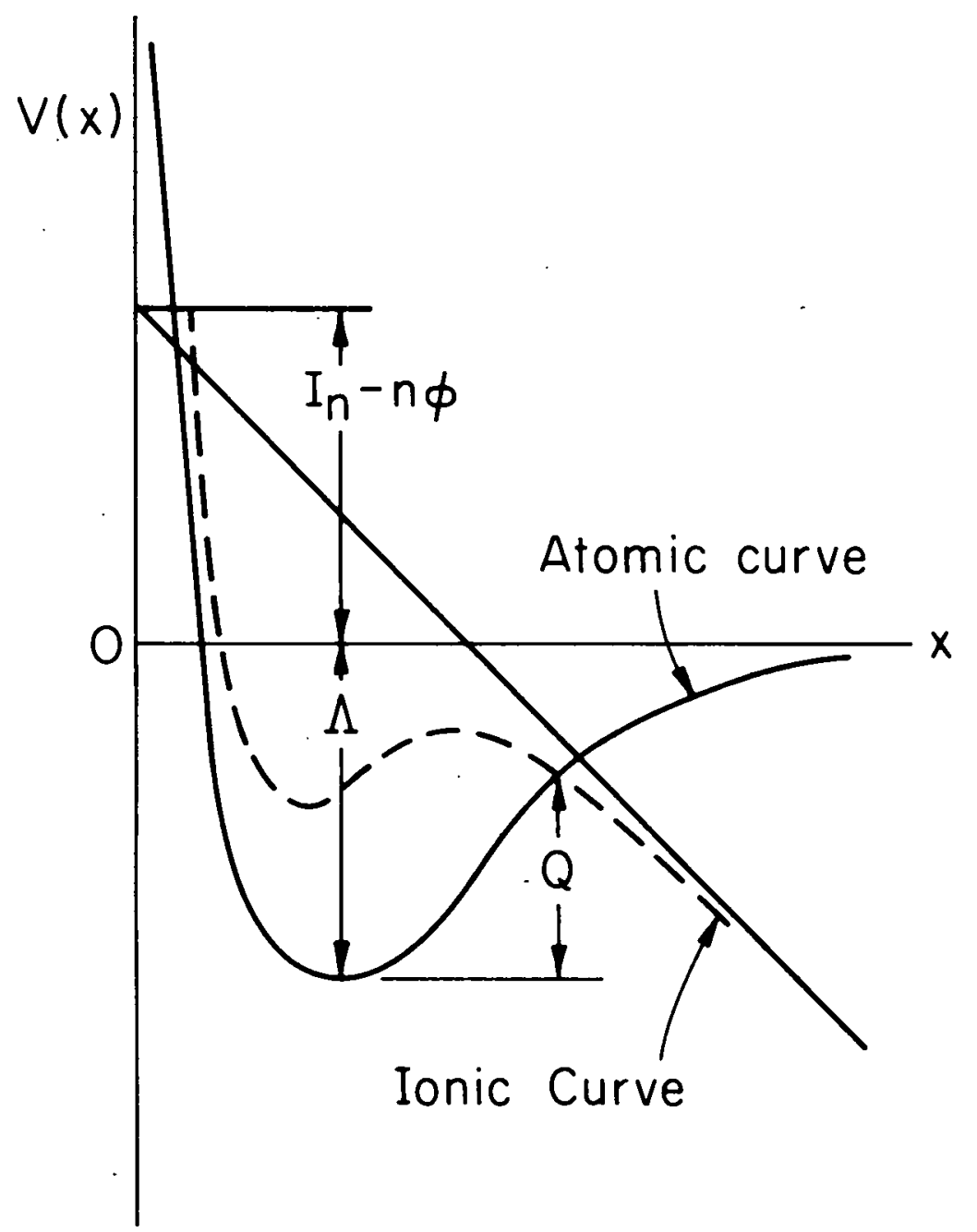

(b) 


$$
F_{e}=n^{-3} e^{-3}\left(\Lambda+I_{n}-n \phi-k T \ln \left(\nu / k_{e}\right)\right)^{2}
$$

This is the so-called image force method in which we have assumed the Ionfzed atom experiences the binding due to image force potential $V=-n^{2} e^{2} / 4 x$, together with that due to the applied field, as described in Equation (56). Gomer, (47) Gomer and Swanson $(48),(49)$ and Brandon $(50)$ have proposed a different mechanism to describe the field evaporation process wherein they considered the possibility that the ionic potential curve intersects the potential curve of the atom at a distance $x_{c}$ from the tip surface at which the field evaporation occurs. They concluded by saying that the field evaporation process involves three steps: (a) thermal activation to higher vibrational level, (b) electronic transition and (c) atomic or lonic tunnelling. (51) At high temperature, however, part (c) is negligible compared to the vibrational excitation. Thus the rate constant of the fleld evaporation is suggested to be: at high temperature

$$
\dot{k}_{e}=v \exp \left(-Q_{n} / k T\right)
$$

and at low temperature

$$
k_{e}=v \exp \left(-a Q_{n}^{3 / 2}\right)
$$

where

$$
Q_{n}=\Lambda+I_{n}-n \phi-\left(n^{3} e^{3} F\right)^{\frac{1}{2}}+n e F x_{e}
$$

and $x_{e}$ is the equilibrium distance of the ion from the metal surface in the presence of the applied fleld, and $a$ is the coefficient of the tunnelling probability. 
E. The Microscope

The field-ion microscope employed in this work is one designed by the author and constructed at this University with the exception of the sample chamber which is the same one Dr. H. C. Tong used in his thesis work here. This chamber contains two jackets, one for vacuum, one for liquid nitrogen. This microscope has been modified once during the observation period. In our early work the microscope was equipped with a Veeco pumping station (Model VS-9) consisting of a 5 cublc foot per minute mechanical pump, a 58 Iter per second diffusion pump and a liquid nitrogen cold trap. The best vacuum this microscope could achleve was in the high $10^{-8}$ Torr range with the cold finger filled with liquid helfum and the liquid nitrogen jacket of the sample chamber filled with liquid nitrogen. Observations were made under dynamic conditions; i.e., the image gas (or gas mixture) was continuously leaked into the sample chamber but the pumping speed was reduced by partially closing the valve so that the gas pressure inside the chamber was maintained at the selected value, usually about one to three microns. The gas leaking was done using a Granville Phillips variable leak valve and Granville Phillips type C valve, the gas pressure was measured by a Veeco RG-75K ionization gauge and Veeco RG-31X power supply. Since the same fonfzation gauge was used to read the pressure of different gases, it was necessary to multiply the current reading by a correction factor ${ }^{(53)}$ which is different for each gas. The microscope at this stage was not a bakeable one; however, the sample chamber was heated up by a heat gun for about thirty minutes.

After a few observations it was found that an imaging gas with a lower Ionization potential was required in order to make the image more complete and stable enough to allow sharp photographs to be made. Incompleteness in imaging 
was thought to be.caused by impurity gases present in the system. The microscope was therefore modified with particular attention to these two points.

The microscope after the modification will be described in detail in the following paragraphs since this is the fleld-ion microscope which produces useful pictures.

The arrangement of the entire microscope is sketched. In Figures $15^{\circ}$ and 16. The Veeco pumping station now is used as a roughing unit, After the vacuum has reached the 10w $10^{-5}$ Torr region the sample chamber is isolated from the Veeco pumping station by closing the Varian $1 \frac{1}{2}$ inch bakeable valve. A titanium sublimation pump and an efght liter per second Vacion pump controlled by a Varian ion pump control (Model 921-0011) are employed for further pumping.

\section{F. The Image Intensifier}

It is impossible to record the very weak neon image of berylliumcopper unless an image intensifier is employed: In this work a 2 inch channel plate (Channeltron Electron Multiplier Array, CEMA) from Bendix Corporation was used to intensify the neon image by the following mechanism.

Positive ions produced by fleld ionization are accelerated toward the Input face of the channel plate. Upon entering a channel the ion strikes the wall and produces secondary electrons. These electrons are accelerated by the potential difference between the input and output faces and strike the walls repeatedly, producing more and more electrons. This process continues unt11 the electrons emerge from the output face where they are accelerated toward the fluorescent screen by the potential difference between the output face and the screen. The gain in image intensity is about $10^{3}$. Figure 17 shows the 
Figure 15

Field-Ion Microscope. (Front View)
A. Tip Voltage Feed-Through
B. Titanium Sublimation Pump

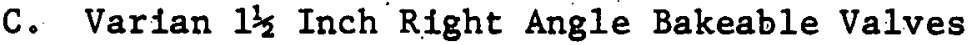
D. Channel Plate Voltage Feed-Throughs
E. Tektronix Inc., Type $\mathrm{C}-12$ ( $f 1.9$ ) Camera
F. Mirror
G. Veeco RG-75K Ionization Gauge 


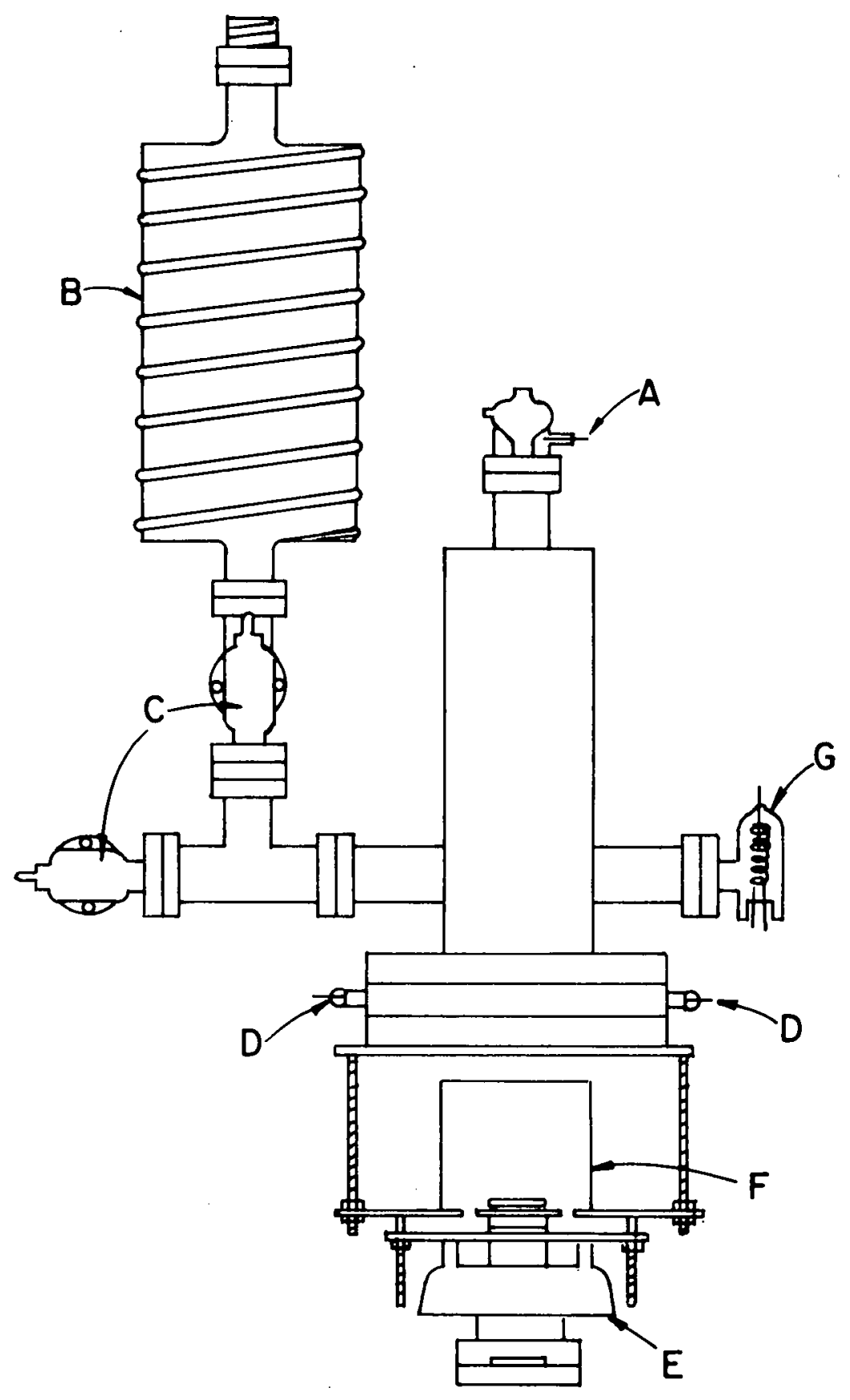


Figure 16

Field-Ion Microscope Including Image Gas Handling System. (Side Vlew)
A. Granville Phillips Type-C Valves
B. Granvilie Phillips Varlable Leak Valves
C. VacIon Pump, 8 11ter/sec.
D. Image Gas Bottles 


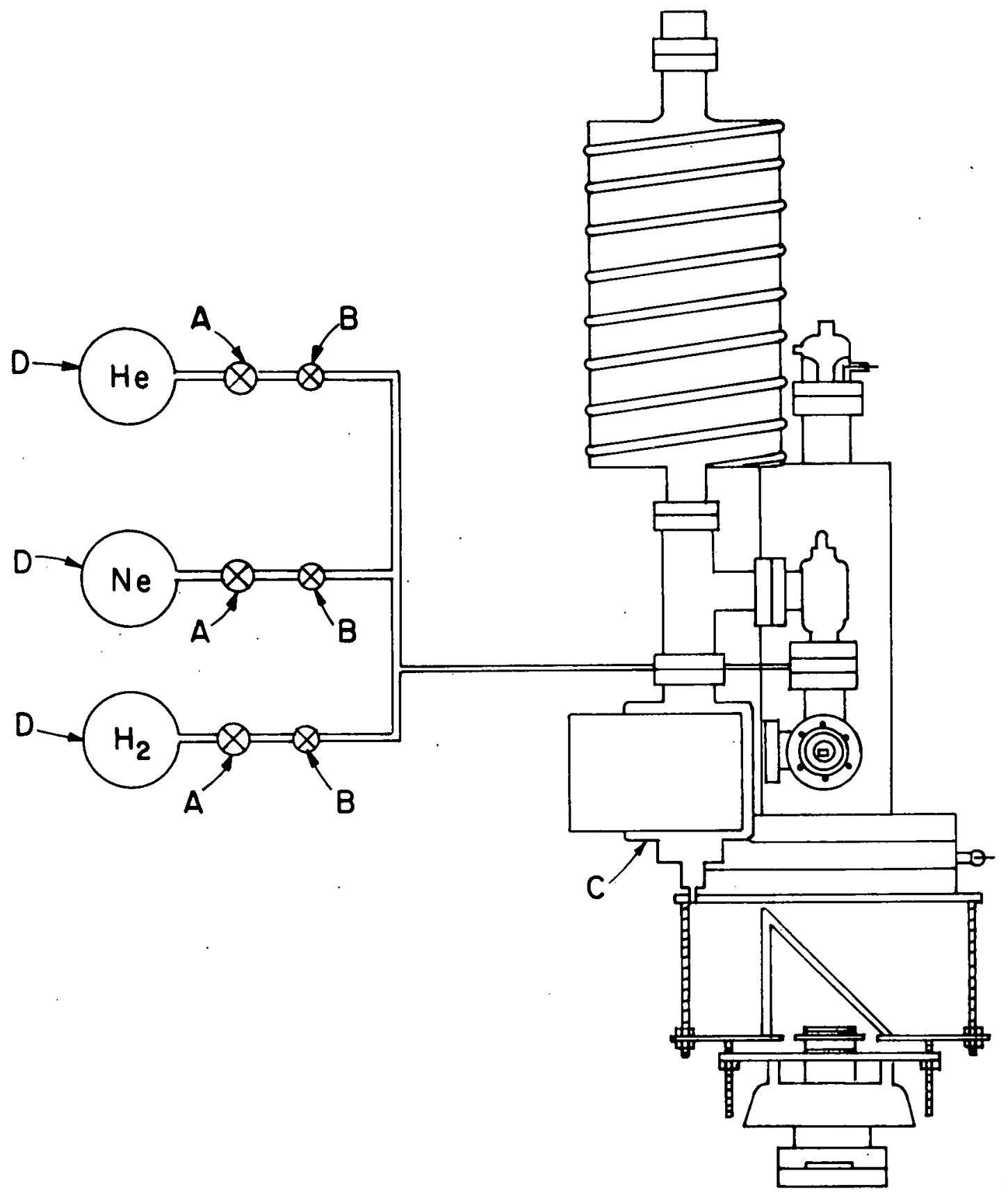


Figure 17

Relative Positions of Channel Plate and Fluorescent Screen with Respect to Sample Tip

A. Liquid Helium

B. Cold Finger.

C. Sample Tip Spot Welded on A U-Shaped Tungsten Loop

D. Electrode to Channel Plate Output Face$+1,000$ V CD with Respect to Ground

E. Pyrex Disk Used as Insulator and Screen

F. Electrode to Eluorescent Screen +2500 - V DC with Respect to Ground

G. Platinum Wire

H. Glass Coating Outside the Platinum Wire 


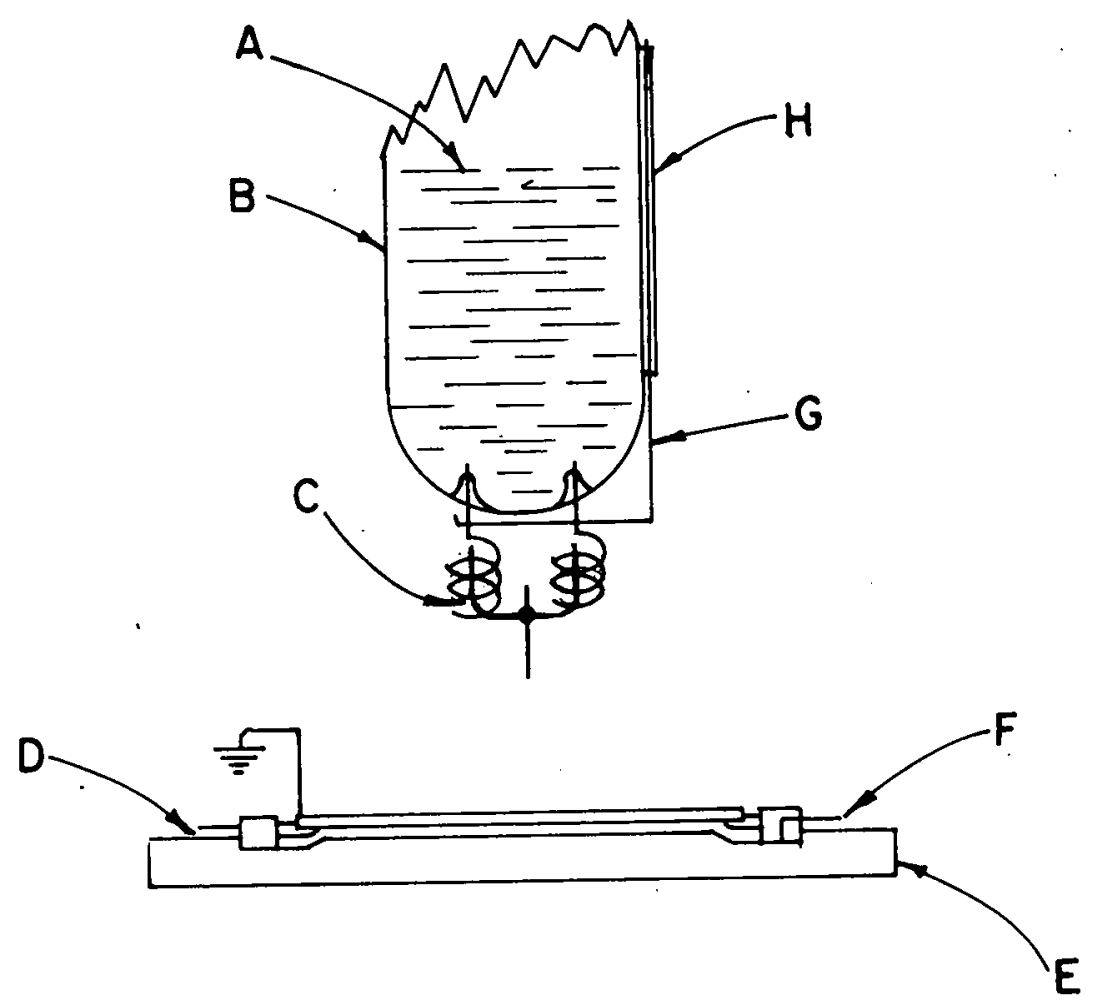


voltages applied to the channel plate and the fluorescent screen and their. connections. The channel plate and the fluorescent screen are fixed in position by clamping them between two stainless steel plates. Four legs are brazed on the top plate, each leg is fastened to the inner wall of an 8 inch flange by a slotted stainless steel screw. The clamp action holding the plate and screen in place is controlled by four screws and four springs all made of stainless steel. All the feedthroughs are made from kovar seals and tungsten wires coated with glass; the seals are heliarced onto stainless steel sleeves which are brazed onto the flange. The flange is then sandwiched between another two flanges of the same size, one is brazed onto the sample chamber body and the other serves as a mount for a six inch diameter $G$. E. viewing window glass which forms the bottom of the sample chamber. The input face of the channel plate is grounded; the voltage on the output face is provided by a constant current power supply (Electronic Measurements Company, Model (638). This voltage is varied from 800 to $1,200 \mathrm{~V} \mathrm{DC}$, and the current is limited to slightly more than the normal current of the channel plate in order to protect from arcing.

\section{G. The Fluorescent Screen}

The fluorescent screen is made from a 3 inch diameter and $3 / 16$ inch thick pyrex disk which is ground into the shape shown in Fig. 17. Proximity focusing of the secondary electron image is employed in this work, the distance between the fluorescent screen and the output face of the channel plate is 0.047 inch. The top surface of the pyrex disk is coated with tin-oxide. This surface is thoroughly cleaned with 10 per cent hydrochloric acid, then rinsed thoroughly and drled with ethyl alcohol. The disk is then heated in a furnace up to $460^{\circ} \mathrm{C}$ and a vapor of the mixture of stannic chloride and 
antimony tri-chloride is directed onto the cleaned surface. A tin oxide layer is formed which is transparent yet conducts sufficiently well for our purpose. The plate is then allowed to furnace cool. To bind the phosphor powder (G.E. P31) onto the tin-oxide coated surface, it is necessary to clean this surface thoroughly again with water, acetone, 10 per cent hydrochloric acid, water and pure ethyl alcohol in that sequence, then dry it in a stream of dry argon gas. The solution used to deposit the fluorescent powder on the screen 18 made of 120 cublc centimeters of fresh "KASIL" (potasium silicate) with one liter of pure water and 1 gram of G.E. P31 phosphor powder (particle size is 44 micron).

The cleaned pyrex disk is set at the bottom of a crystallizing dish before pouring the above phosphor solution into the dish; after pouring one walts until the powder particles settle down so the solution looks clean and transparent. A little hole drilled in the bottom of the dish is then uncorked and the clear liquid slowly drained out. Finally this coated disk is baked at $400^{\circ} \mathrm{C}$ in an air furnace for couple of hours.

The electric potential normally applied to this screen is $2,500 \mathrm{~V}$ DC above ground and is provided by an NJE high voltage power supply (Model S326). 
CHAPTER VI

FIM EXPERIMENTAL TECHNIQUE AND PROCEDURES

The field ion microscope observations have been made on pure tungsten, pure copper and copper with 13 atomic per cent of beryllium. After completing the construction of the microscope it was leak checked using a helium leak detector. Without baking the system, the highest vacuum achievable was in the high $10^{-7}$ Torr region. After baking for 24 hours at $150^{\circ} \mathrm{C}$ (the highest temperature at which this system could be baked) and immediately after turning off the baking oven, both the ionization gauge and the filament of the titanium sublimation pump were degassed for 10 minutes, at the same time the Vacion pump is turned on and left on until the image gas (or gas mixture) was admitted Into the sample chamber. Under these conditions the highest vacuum obtainable was around $3 \times 10^{-8}$ Torr.

During the sample changlng process the titanium sublimation pump and the VacIon pump were always isolated under a high vacuum by closing the $1 \frac{1}{2}$ inch bakeable valve connecting them to the sample chamber. This valve is opened again just before the baking process is infliated. When the sample chamber has to be opened to the atmosphere, dry nitrogen is always used to back fill the chamber to slightly above atmospheric pressure, thus avoiding unnecessary contamination by the air.

Our first observation was made on tungsten from which the following conditions were determined for this microscope: (1) The most sultable distance between sample tip and the channel plate is about $2.0 \mathrm{~cm}$, (2) The voltage on the output face of the channel plate is 800 to $1,200 \mathrm{~V} \mathrm{DC}$, (3) The He 1mage gas pressure is in the range of 3 to $5 \times 10^{-5}$ Torr, (4) The voltage on the fluorescent screen is ixed at $2,500 \mathrm{~V} \mathrm{DC}$. If, under all 
these conditions, the tip is cooled down to about $82^{\circ} \mathrm{K}$, the helium-ion image of tungsten shown in Fig. 18 is observed.

The most troublesome part of the fleld-ion microscope study of copper with 13 at.\% beryllium or pure copper is sample preparation, including tip selection, electropolishing and field evaporation. A few fleld-ion. microscope observations on copper and copper alloys have been made by other workers recently。 $(16)-(18)$ They have encountered similar difficulties. Boyes et al. (17) found that multistage electropolishing and preselection by electron microscopy reduced the incidence of premature mechanical fallure during field-ion microscopy from an inftial 90 per cent to negligible proportions in the case of their copper with 0.1 atomic per cent silicon. They also found that the larger size tip, with a radius of the order of 1,000A, will have a smoother surface, thus reducing the fallure possibllity further during the field-ion microscopy. Brenner (32) suggested hydrogen-promoted field-evaporation at a temperature of $100^{\circ} \mathrm{K}$ and continuing the evaporation until the final temperature was around $30^{\circ} \mathrm{K}$; after the gas mixture of helium +3 per cent hydrogen had been pumped out, additional field evaporation was carried out in the neon atmosphere just before imaging his pure copper (neon-ion image). The author has followed Dr. Brenner's suggestion, but none of his trials was successful. It is desirable to choose the smallest possible tip radius in order to have better resolution and higher magnification. Therefore the freshly polished samples were always observed under an optical microscope (600x), and only those with smooth shanks and their tips fust barely resolved under the microscope were used in this experiment. The probability of ultimate success in imaging a tip is tremendously low; it is around 20 per cent. 
A Hellum Ion Image of Tungsten at Liquid Nitrogen Temperature and $8 \mathrm{kV}$ Tip Voltage, in $4.5 \times 10^{-5}$ Torr Hellum Gas. 


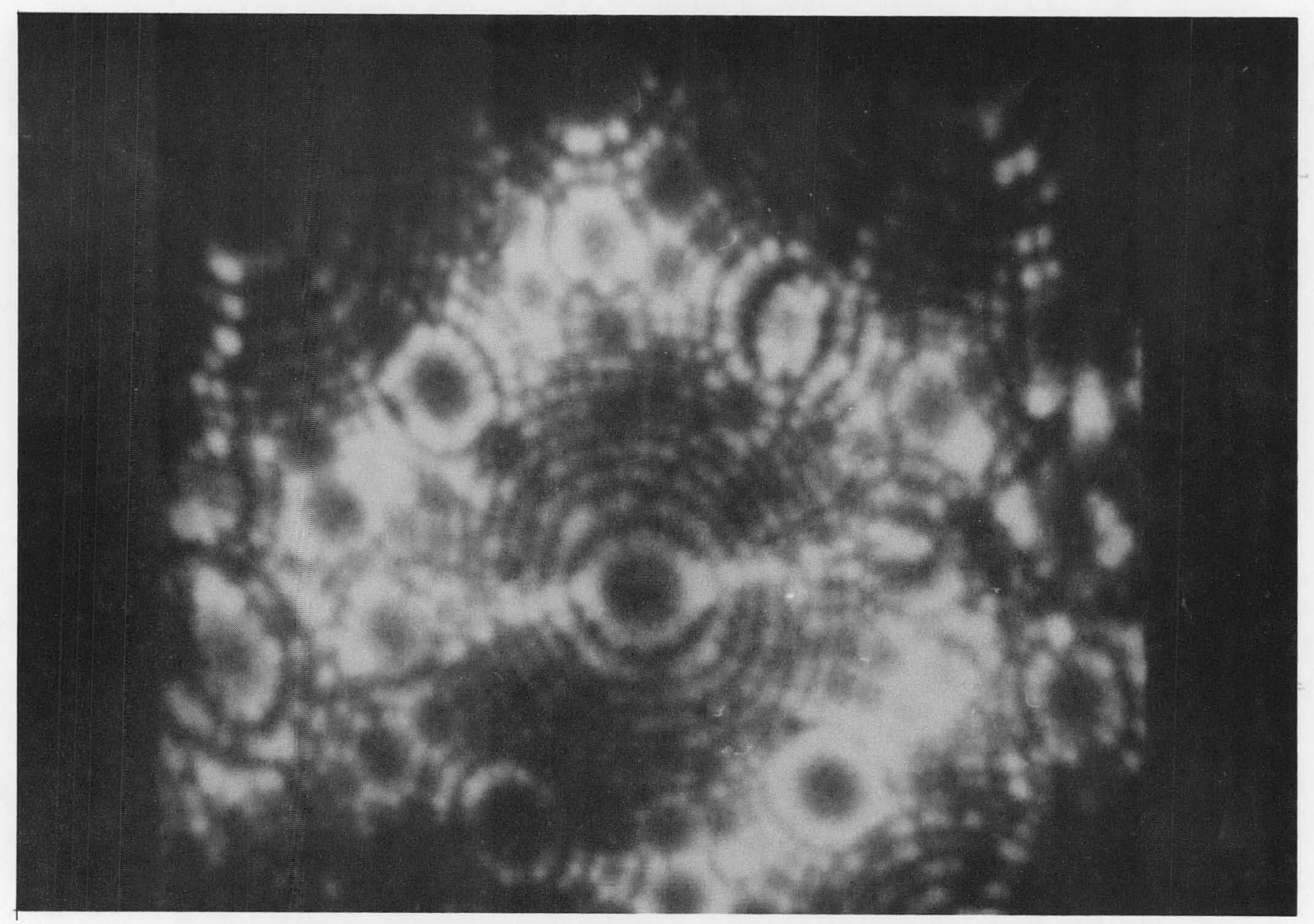

-

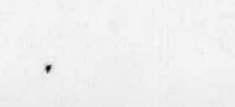


After the vacuum reaches $3 \times 10^{-8}$ Torr, the tip is field evaporated at liquid hellum temperature and under $1 \times 10^{-5}$. Torr of helium image gas pressure. Under these conditions one is able to observe visually and control the evaporation rate. (It is the author's experience that while the tip was going through the hydrogen promoted field-evaporation, $3 \times 10^{-5}$ Torr helium plus 3 per cent hydrogen, there was very vague image showing on the screen, thus it. was very hard to know exactly what was the evaporation rate of the tip material. Often the tip fractured prematurely, even before swltchlng to pure neon Image gas.). Usually about 50 or more layers of atoms are removed in the regions where the evaporation rate is the highest, then the imaging process is started. Elther the pure neon-1on Image or 80 per cent helium mixed with 20 per cent neon-ion image is recorded.

During the fleld-ion microscopy, the tip is cooled by liquid hellum or cold helium gas from a liquid helium dewar. The tip temperature is controlled simply by adjusting the flow rate of the dry helium gas into the dewar through an Andonian 11quid helium transfer tube (Model IV 4-0500). The tip temperature is measured by a Speer carbon resistor $\left(470 \Omega\right.$ at $0^{\circ} \mathrm{C}$ temperature) which was calibrated against a platinum resistance temperature sensor (Rosemount Engineering Company, Model 137AAK). The calibration curve is shown in Fig. 19. The tip voltage is provided by a $30 \mathrm{kV} \mathrm{DC,} 1 \mathrm{~mA} \mathrm{high}$ voltage power supply (Spellman Model RHR 30PN30)。 
Figure 19

Temperature Calibration of a Speer Resistor $\left(470 \Omega\right.$ at $\left.0{ }^{\circ} \mathrm{C}\right)$ 


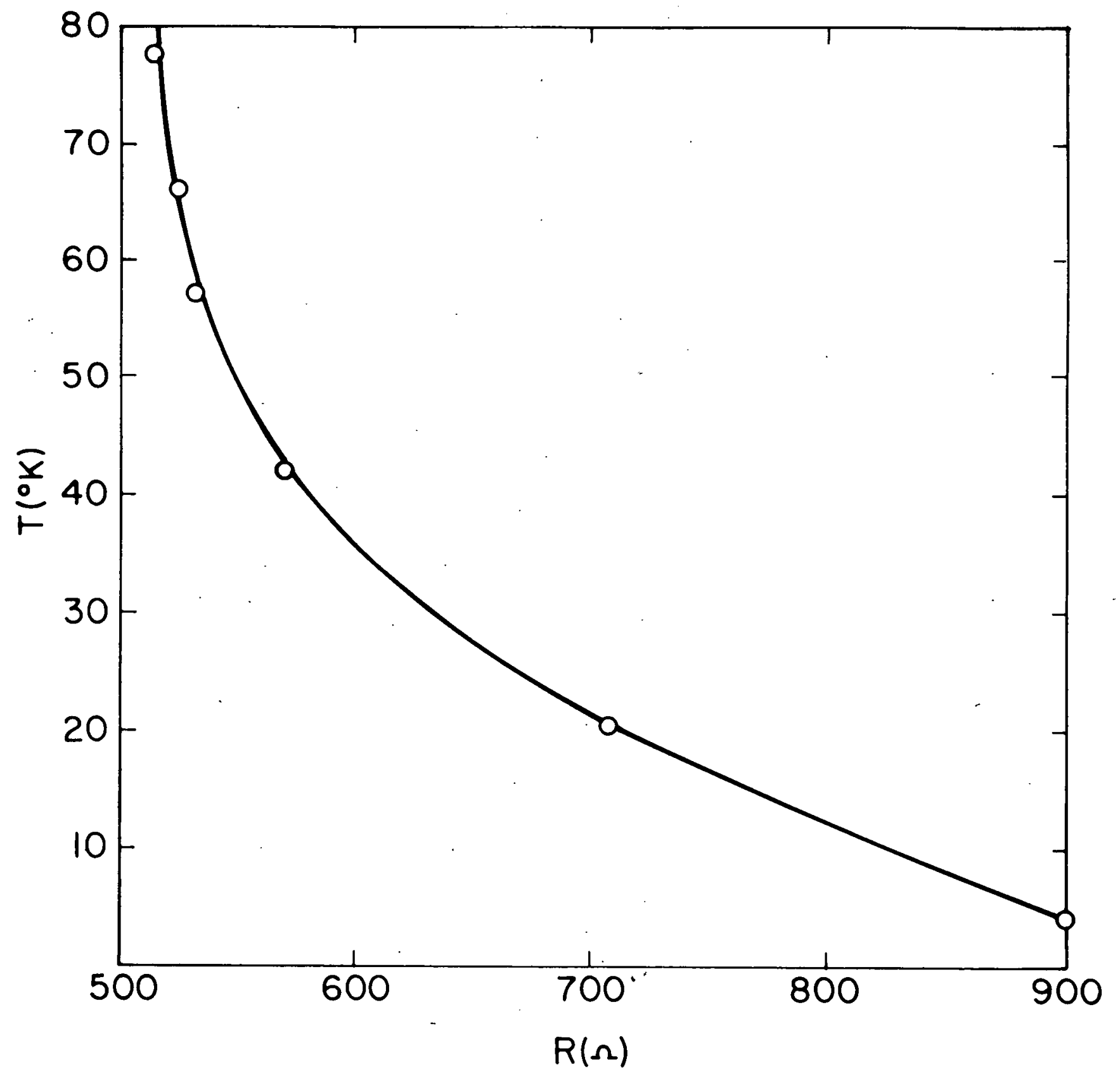


CHAPTER VII

FIM EXPERIMENTAL RESULT AND DISCUSSION

In our early work, the helium ion image of beryllium-copper at a temperature near 1iquid helium temperature clearly shows the symmetry of its wire axis. One of the best recorded pictures of beryllium-copper is shown in Fig. 20, the threefold symmetry of the (111) oriented wire axis is clearly shown. This observation was made under dynamic conditions as described in Chapter V Section E.

It was found that even in the best resolved picture there was not much to be seen besides few poles of low Miller indices.

When the vacuum of $3 \times 10^{-8}$ Torr became available, observations on pure copper and $\mathrm{Cu}+13$ at.\% Be alloy at various precipitation stages, namely $0 \%$, $25 \%, 50 \%$ and fully precipitated stages, were attempted. A pure copper tip Imaged at $22^{\circ} \mathrm{K}$ in $3.8 \times 10^{-4}$ Torr Ne gas with tip voltage at $18 \mathrm{kV}$ is shown in Fig. 21. The alloy at early stages of precipitation is very unstable under high tip voltages. The $50 \%$ precipitated state is the earliest stage which has been successfully imaged. The alloy tips with 50 per cent precipitation completed fractured prematurely upon increasing the tip voltage. One was thus forced to record the images before the whole tip was well developed by field evaporation. Figure 22 is a picture of such a tip just before fracture: It is imaged in $6 \times 10^{-5}$ Torr He gas at about $8^{\circ} \mathrm{K}$ and with a tip voltage of $8.5 \mathrm{kV}$. Another tip at the same metallurgical state is imaged in $2.5 \times 10^{-5}$ Torr He gas mixed with $1.5 \times 10^{-5}$ Torr Ne gas, and at $22^{\circ} \mathrm{K}$ as shown in Fig. 23 , the tip voltage is $5.7 \cdot \mathrm{kV}$. 
Figure 20

A Helfum Ion Image of Fully Precipitated $\left(280^{\circ} \mathrm{C}\right)$ $\mathrm{Cu}+13$ at.\% Be at Liquid Helium Temperature and $18.8 \mathrm{kV}$ Tip Voltage, in $2.1 \times 10^{-3}$ Torr of Helium Gas 


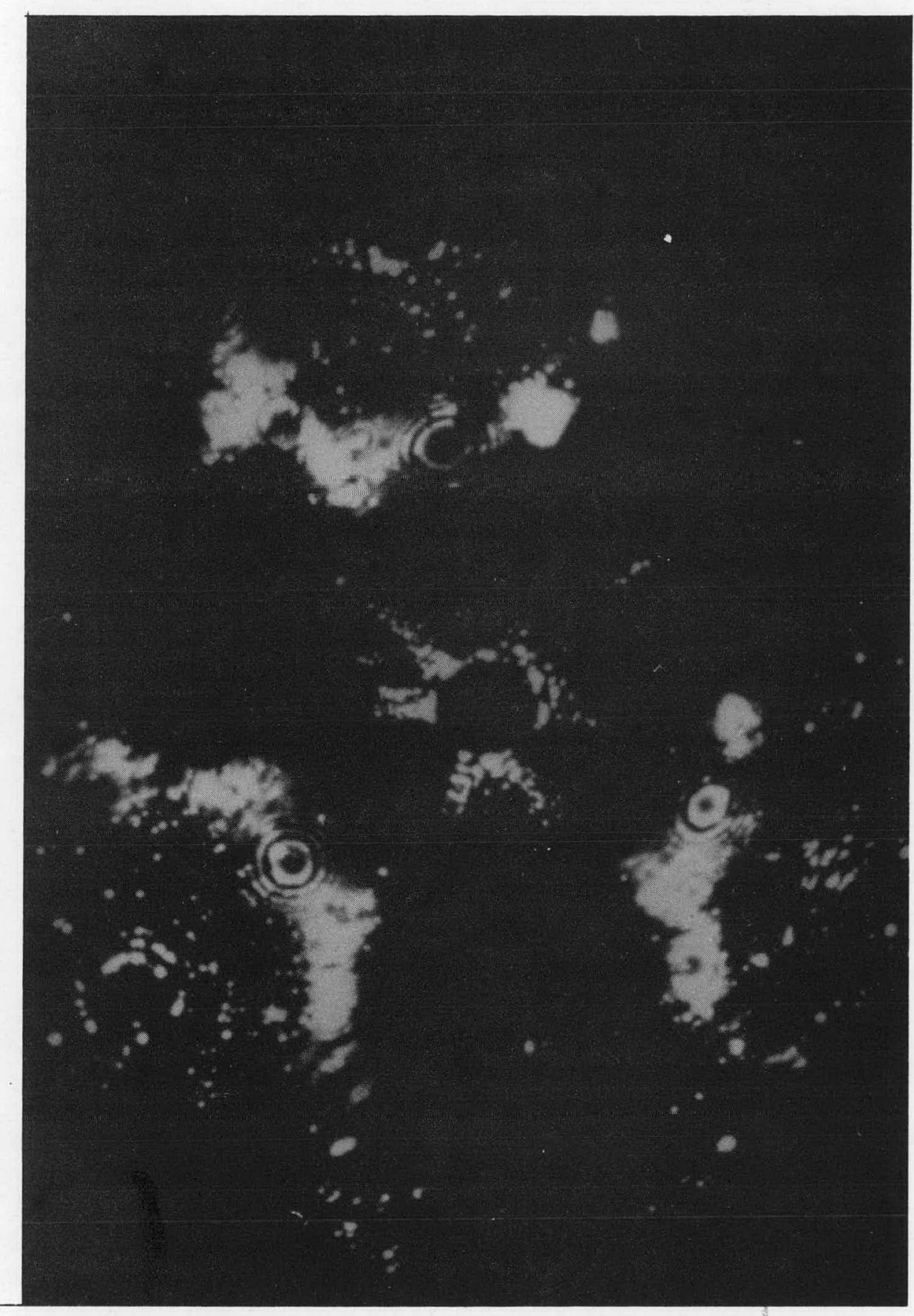




\section{Figure 21}

Pure Copper Tip Imaged in $3.8 \times 10^{-4}$ Torr Neon Gas and at $220 \mathrm{~K}$, the Tip Voltage Is $17.6 \mathrm{kV}$ 


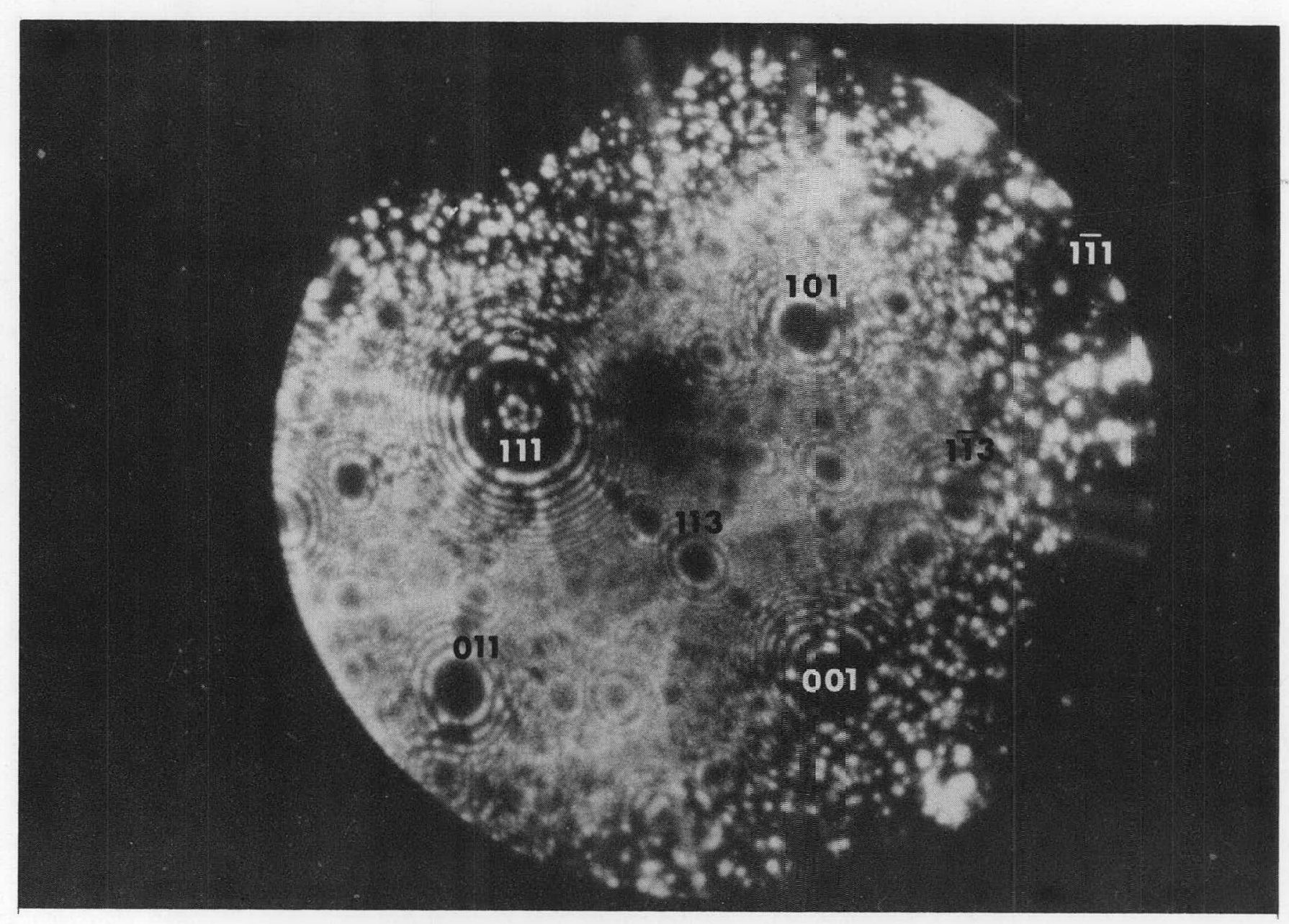


Figure 22

A Cu+13 at.\% Be Tip with 50\% Precipitation Completed. Imaged in $6 \times 10^{-5}$ Torr Helium Gas at Liquid Helium Temperature, the Tip Voltage Is $8.5 \mathrm{kV}$ 


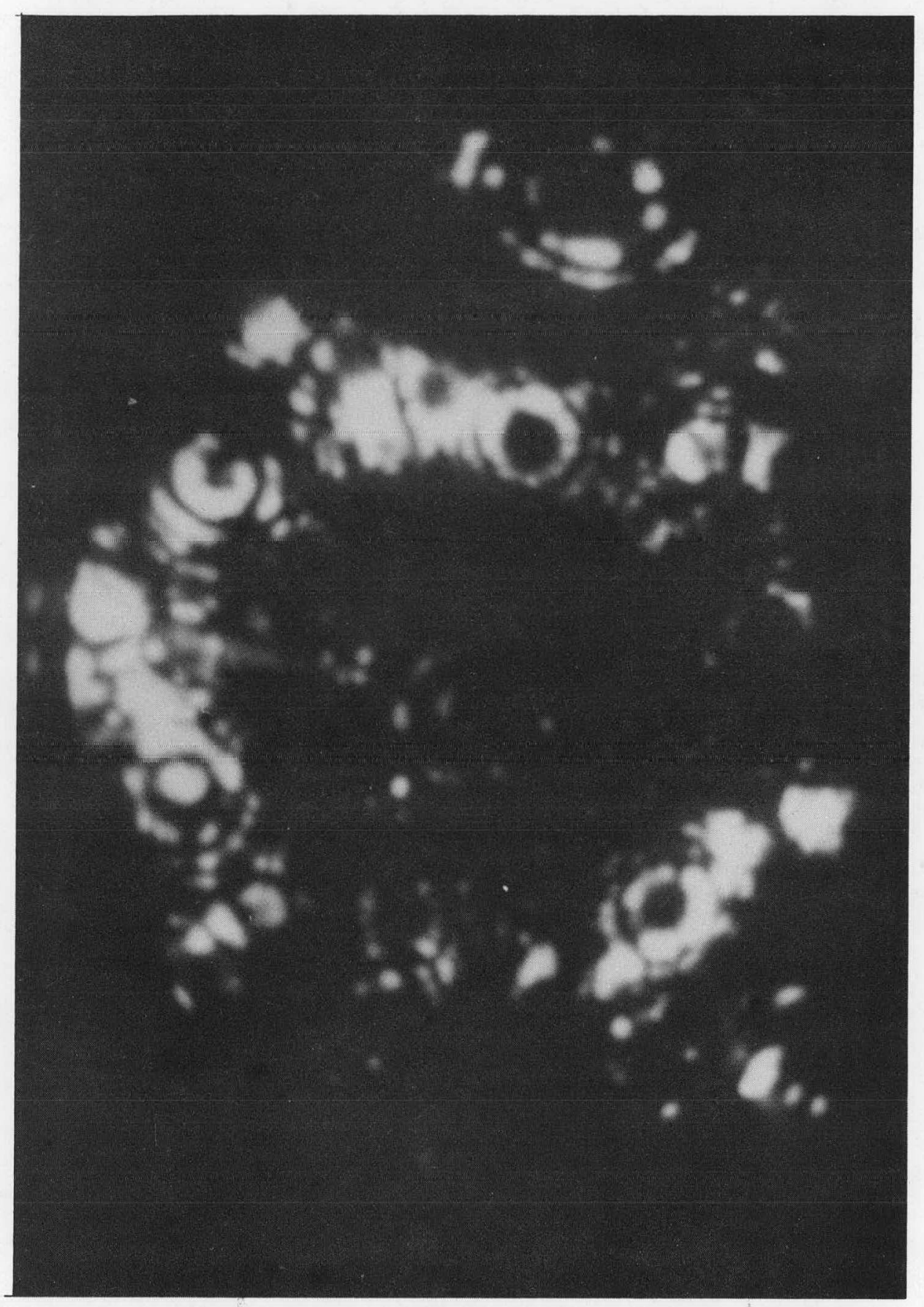

$\bullet$ 
Figure 23

A $\mathrm{Cu}+13$ at.\% Be Tip with $50 \%$ Precipitation Completed.

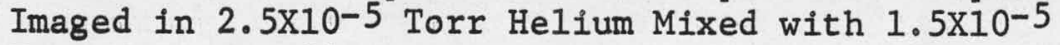

Torr Neon, at $220 \mathrm{~K}$, the Tip Voltage Is $5.7 \mathrm{kV}$ 


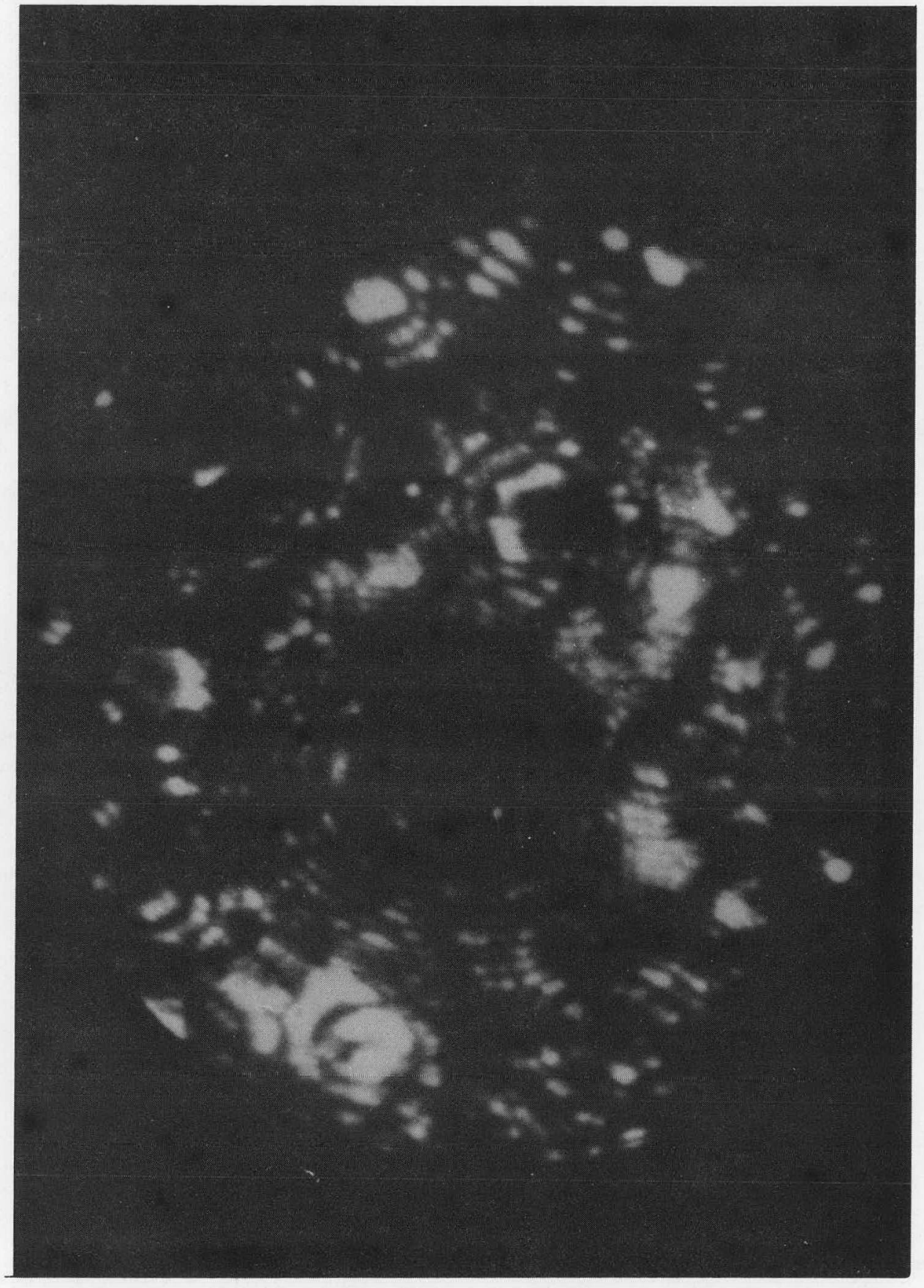

$\bullet$ 
Figures 24 through 28 are the images of tips in the fully precipitated state. These tips, after field evaporation at $1 \times 10^{-5}$ Torr He gas and at $8^{\circ} \mathrm{K}$, show relatively well developed tip surfaces. It is possible for us to locate the suspicious sites which are isolated from nearby areas by a sharp dark boundary and tentatively associate these with precipitate particles. A small shallow void, for example, as well as the precipitate, could cause the same effect in the field ion images, and at the present time we are unable to differentiate one from the other. However, as will be seen later, this average particle size of the precipitate correlates with NMR results very well. Furthermore, field ion image irregularities such as those indicated in Figures 24 through 28 were almost never observed in pure copper (Fig. 21).

Sometimes we can see the precipitate growing and disappearing gradually. For example, Fig. 29 shows sequentially the change in the precipitate C of Fig. 28 resulting from successive field evaporations. The local radius of curvature $r$ at the tip surface where we find the precipitate can be estimated as follows. The Miller indices are found for each pole on the field ion image pattern (see Fig. 30). It is clear that the precipitate particle in Fig. 29 is located nearby poles (101) and (3ī3); there are seven (101) net planes between these two poles each with step height $\mathbf{s}$ then

$$
r=\frac{7 S}{1-\cos \gamma}
$$

where $\gamma=13^{\circ} 16^{\prime}$ is the angular distance between the above two poles and $s$ in this case is

$$
s=\frac{a}{2\left(h^{2}+k^{2}+1^{2}\right)^{\frac{1}{2}}}=\frac{a}{2 \sqrt{2}}
$$


Figure 24

A. A Completely Precipitated $\mathrm{Cu}+13$ at.\% Be Tip, After Field Evaporation in $1 \times 10^{-5}$ Torr Helium Mixed with $1 \times 10^{-5}$ Torr Neon at $22 \% \mathrm{~K}$. Imaged in the Same Conditions. Its Tip Voltage Is $14 \mathrm{kV}$

B. Selected Area Enlarged. Arrows Point at a Precipitate Particle. 

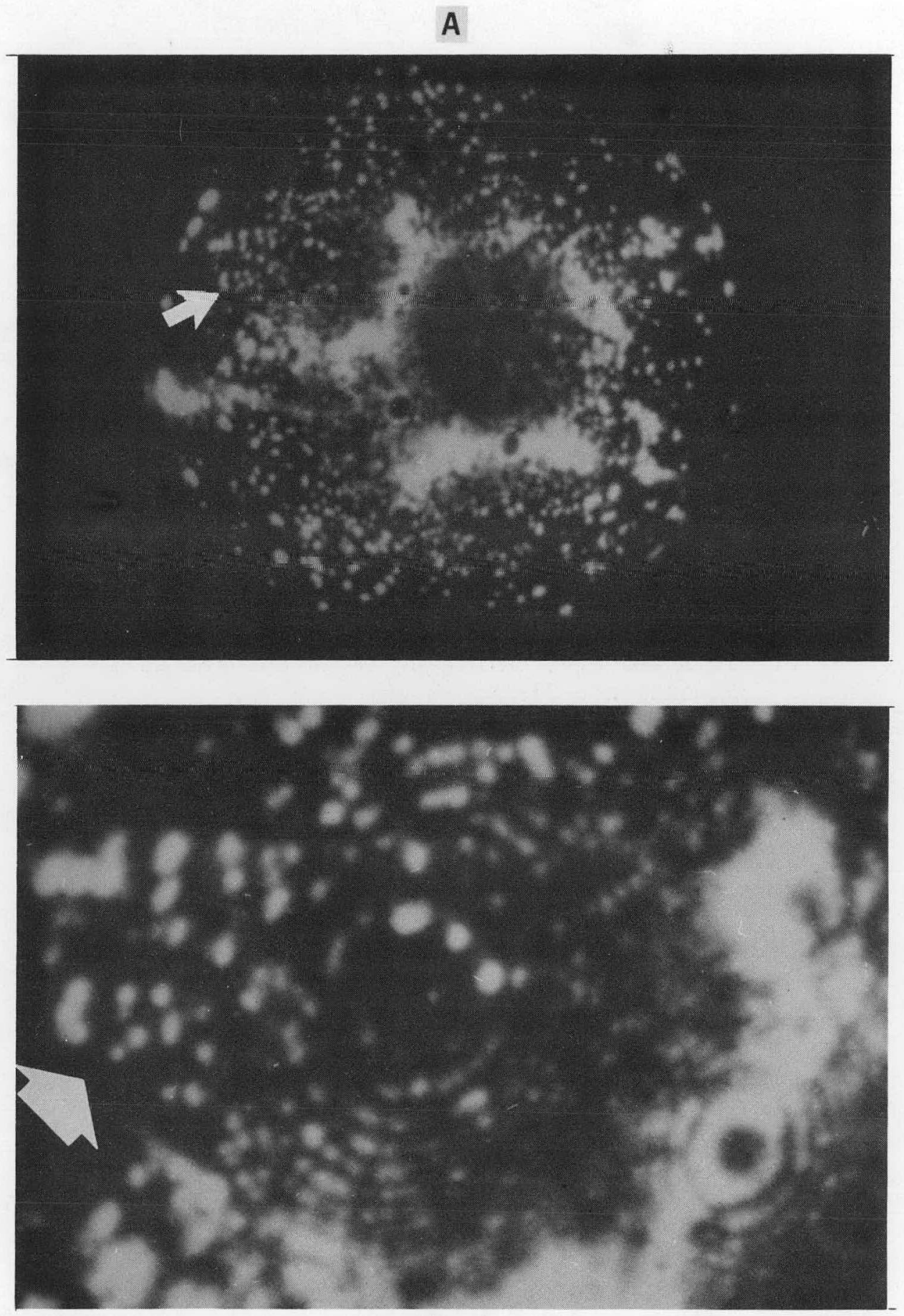

B 
Figure 25

A. A Completely Precipitated $\mathrm{Cu}+13$ at.\% Be Tip After Field Evaporation in $1 \times 10^{-5}$ Torr Helium Gas at Liquid Helium Temperature. Imaged in 1. $5 \times 10^{-5}$ Torr Helium Mixed with $1.25 \times 10^{-5}$ Torr Neon Gas and at $22^{\circ} \mathrm{K}$, the Tip Voltage Is $11.5 \mathrm{kV}$

B. Selected Area Enlarged. Arrows Point at a Precipitate Particle. 

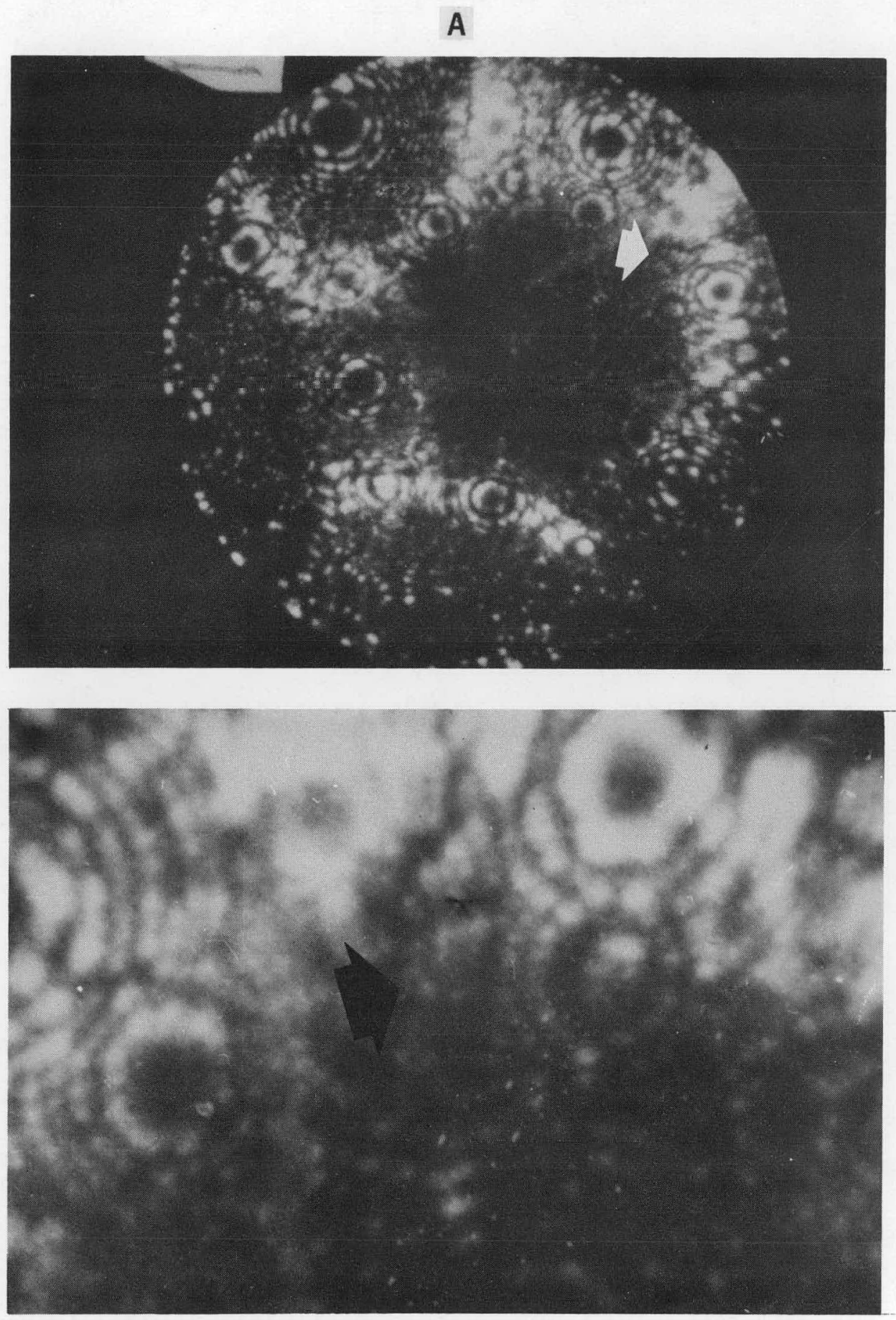

B 
Figure 26

A. A Completely Precipitated Cu+13 at.\% Be Tip After Field Evaporation in $1 \times 10^{-5}$ Torr Helium Gas at Liquid Helium Temperature. Imaged in $3.8 \times 10^{-4}$ Torr Neon Gas at $220 \mathrm{~K}$, the Tip Voltage is $23.8 \mathrm{kV}$

B. Selected Area Enlarged. Arrows Point at Precipitate Particle. 

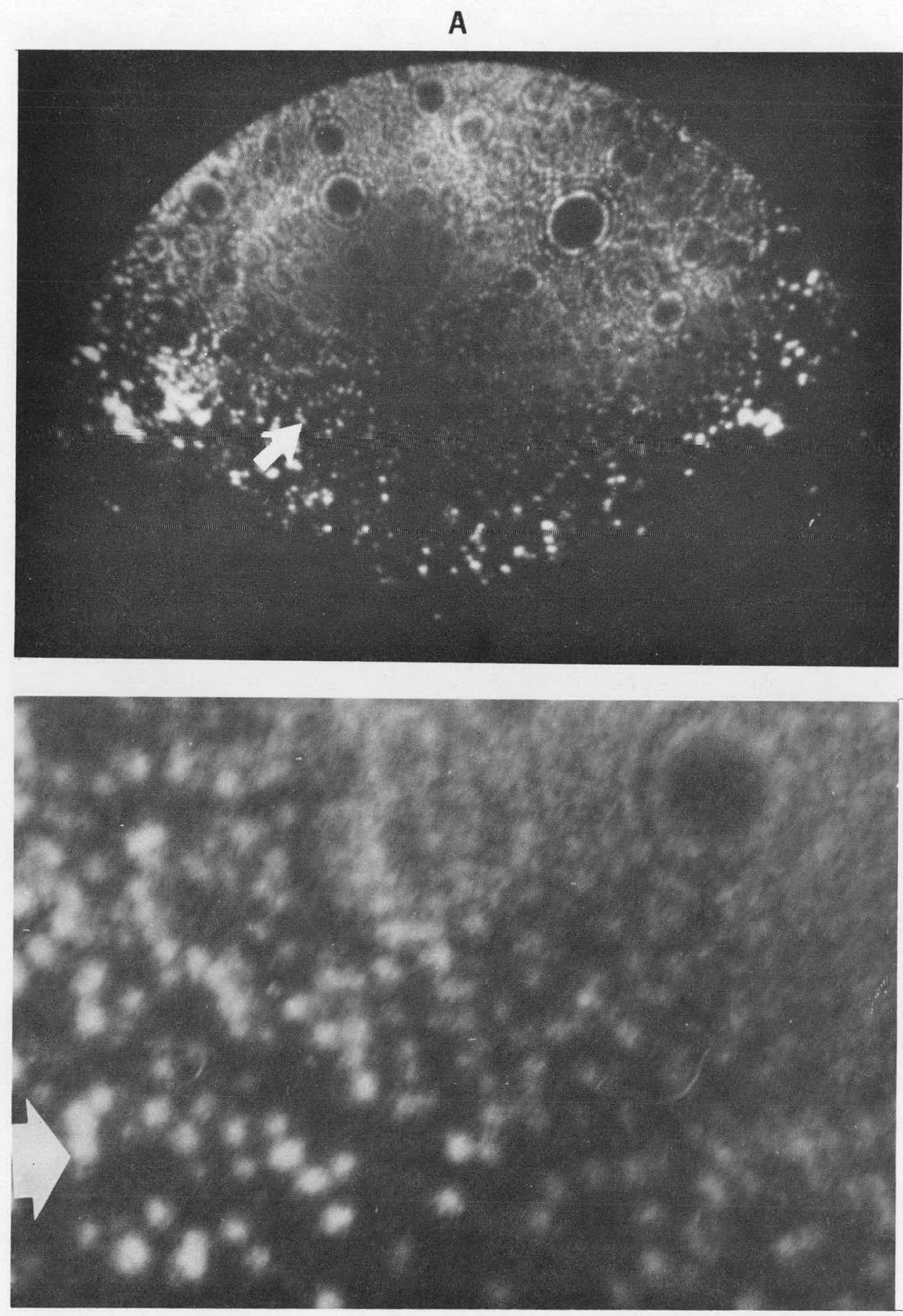
Figure 27

A. Same Tip as in Fig. 26 and Under Same Conditions, but Tip Voltage Is $27 \mathrm{kV}$

B. Selected Area Enlarged. Arrows Point at Precipitate Particle. 
A
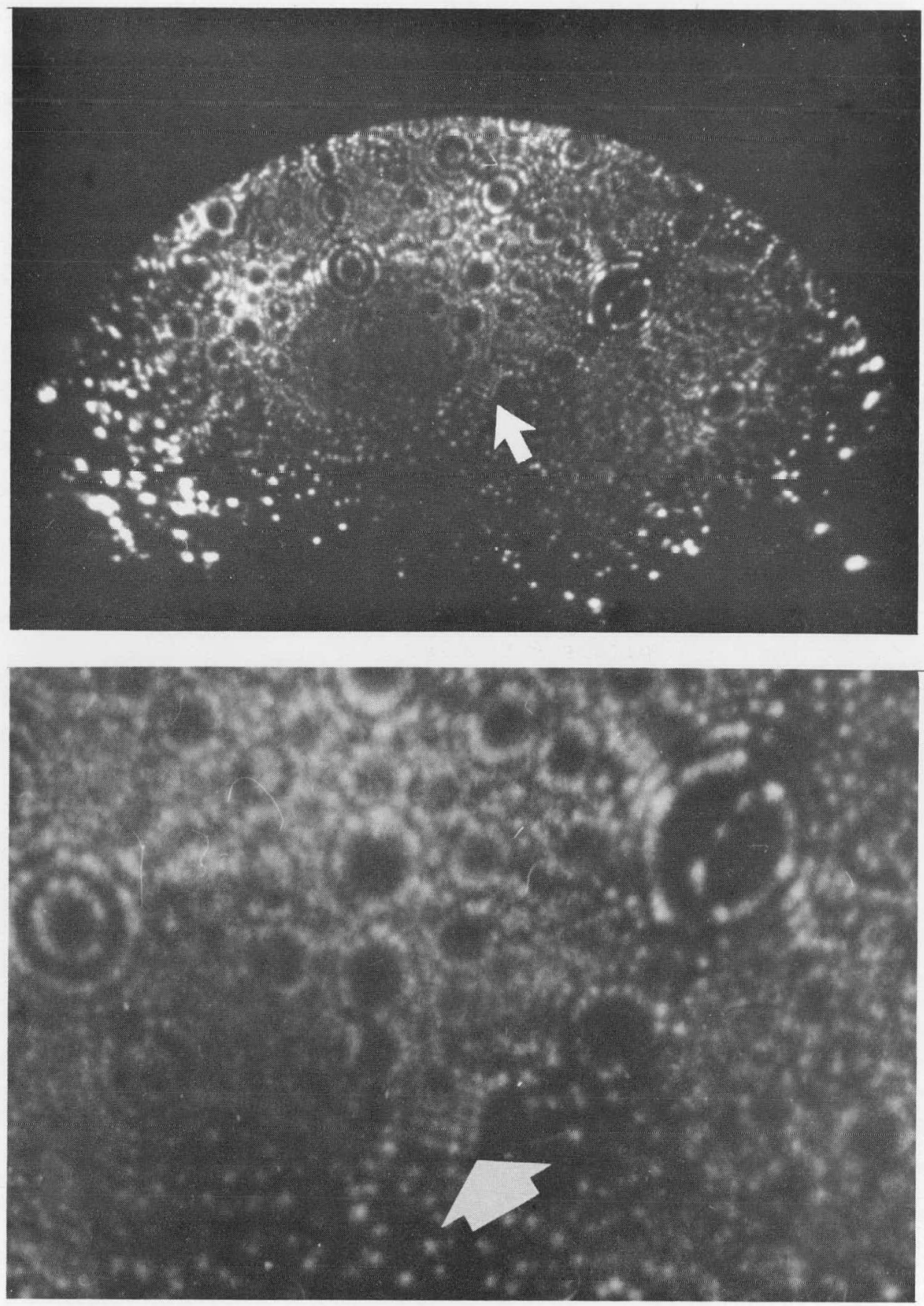

B 
A. Same Tip as in Fig. 26 and Under Same Conditions, but Tip Voltage Is $28 \mathrm{kV}$

B. Selected Area Enlarged. Arrows Point at Precipitate Particles. 


\section{A}

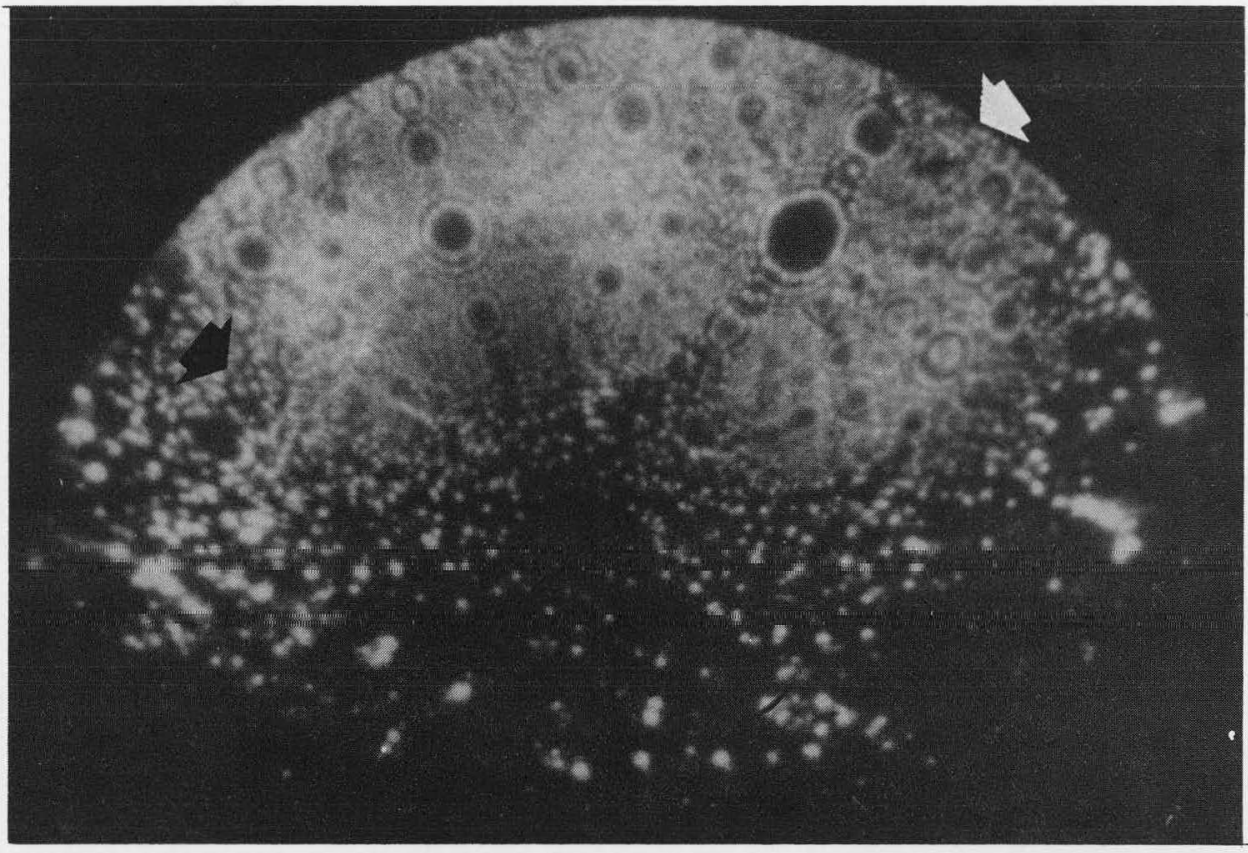

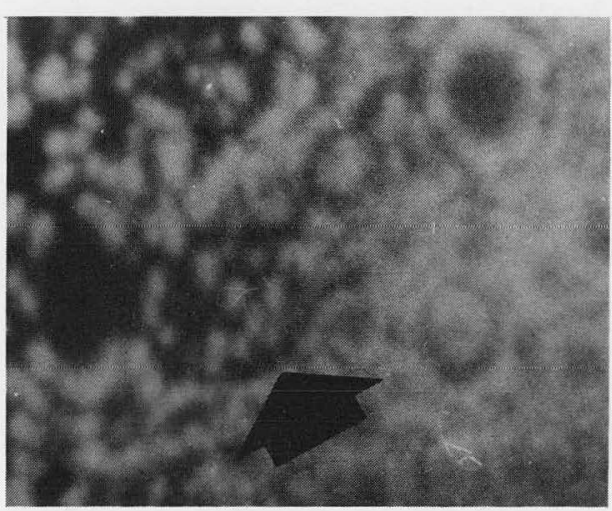

B

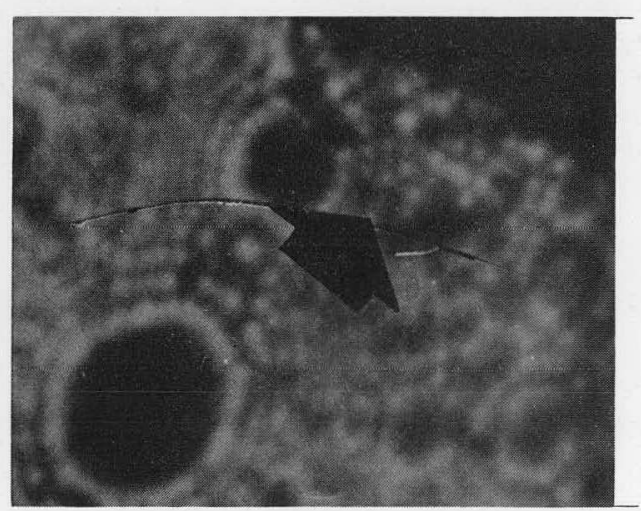

C 
Figure 29

Sequential Change of the Precipitate (C) of Fig. 28 Resulting from Successive Field Evaporations. 

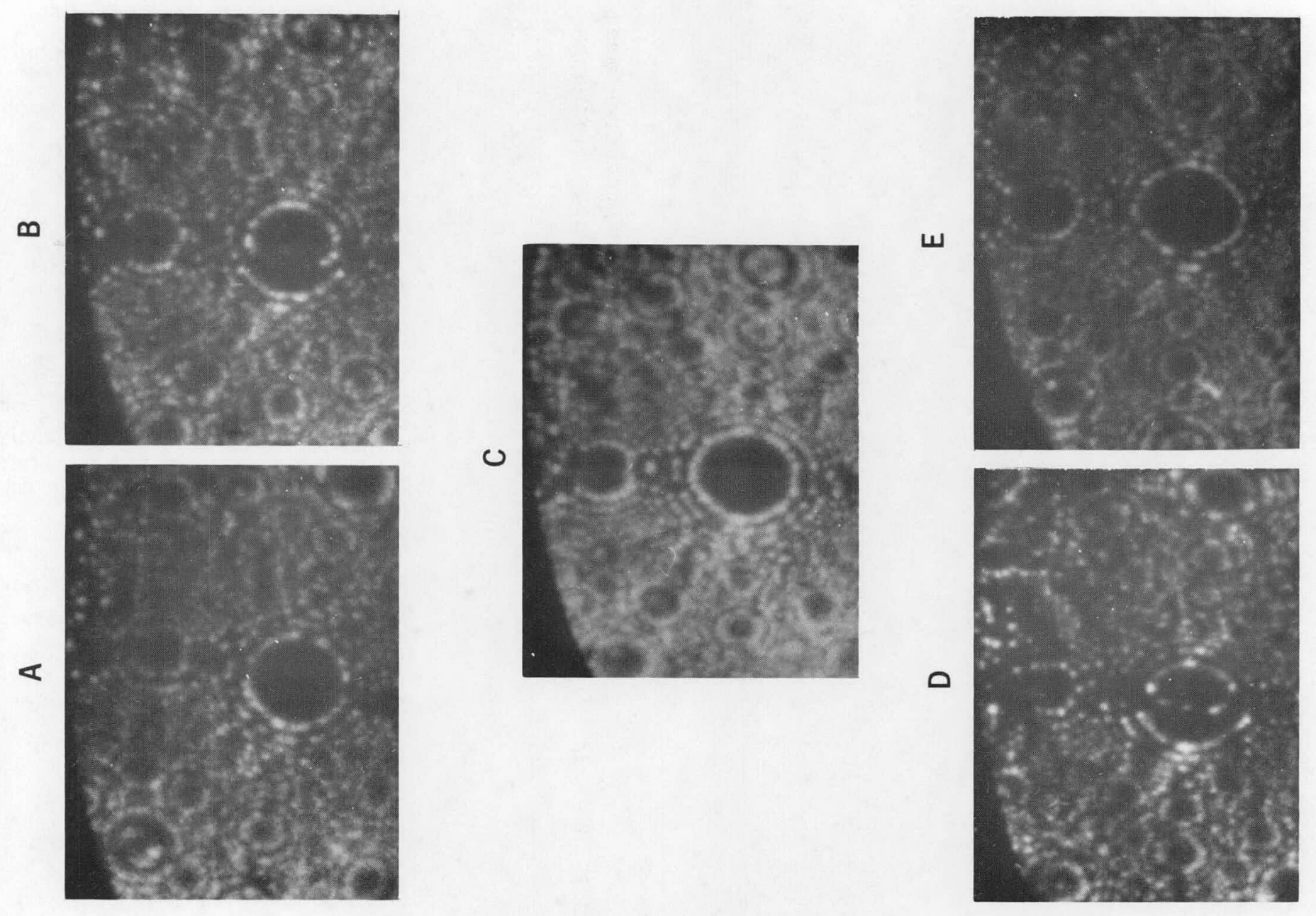
Figure 30

Indexed Crystal Planes in the Same Sample Tip as in Fig. 26 


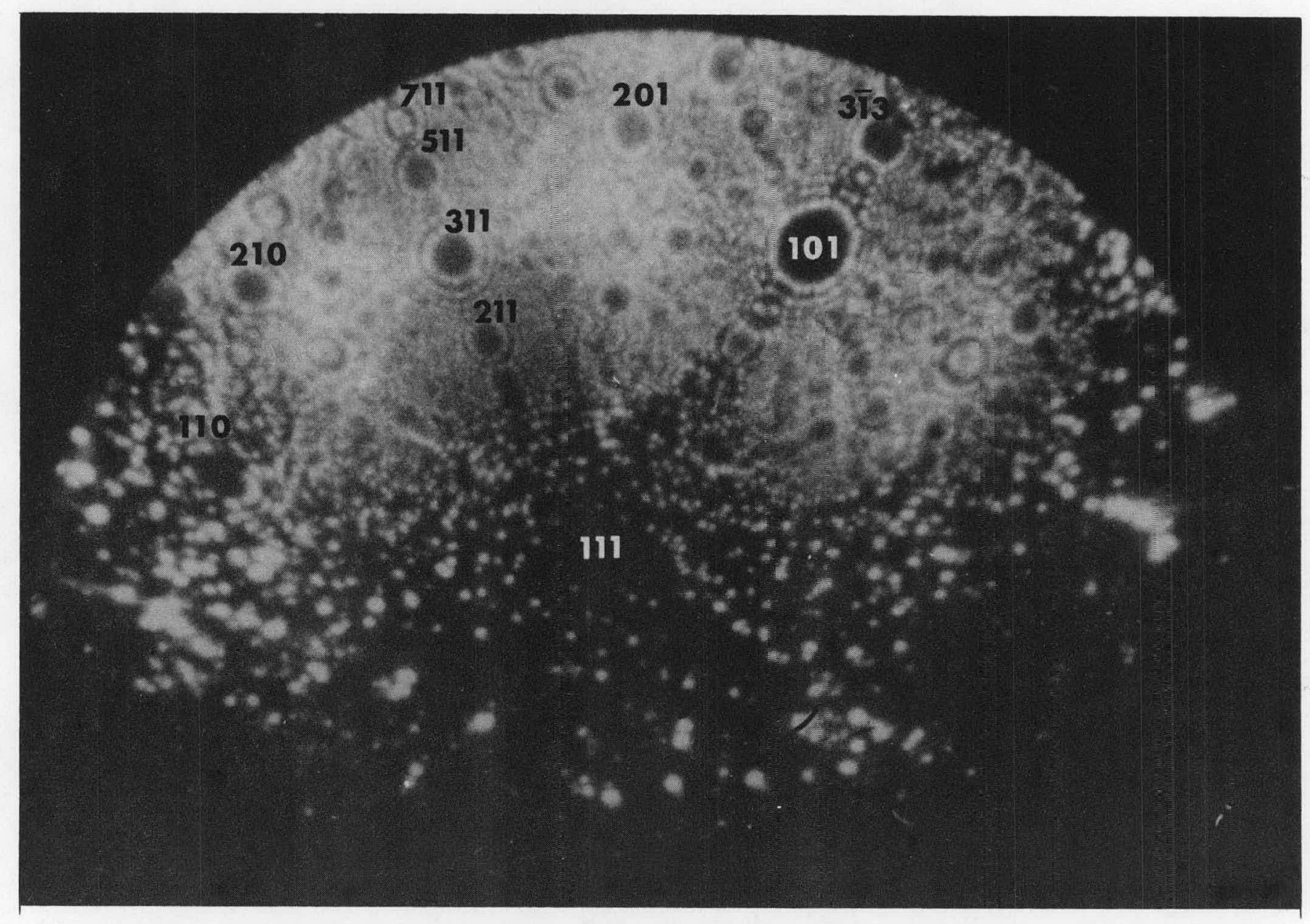


Since the (fcc) lattice parameter of the remaining matrix (copper and 1.3 at.\% $\mathrm{Be}$ ) is $3.610 \mathrm{~A}$, we find $\mathrm{r}$ to be $335 \mathrm{~A}$. The distance between sample tip and the channel plate input face is $R=2.0 \mathrm{~cm}$; we then get the local magnification to be

$$
M=\frac{2.0 \times 10^{8}}{1.5 \times 335}=4 \times 10^{5}
$$

Knowing the image to object ratio for the camera is $1: 1$ and the magnification we can measure the precipitate size from the original photographs and find the actual size.

From the area and depth measurements the average particle size is found to be $2.4 \times 10^{4}(\AA)^{3}$. If, for simplicity, we assume that the precipitate is cubic in shape, then 1ts side is $28.9 \AA$ in length. Copper atoms up to the second nearest neighbor of the precipitate will not contribute to the NMR intensity.. The second nearest neighbor 1 s at a distance $3.61 \mathrm{~A}$ in the remaining $\alpha$-phase ( $\mathrm{fcc}, \mathrm{Cu}+1.25$ at.\% $\mathrm{Be}$ ); therefore the shell of thickness approximately 3.61\& 1mmediately next to the precipitate should be excluded when calculating the NMR intensity. The shell. volume is found to be $1.03 \times 10^{4}(\AA)^{3}$. Converting it into atomic ratio we have

$$
\frac{\text { No. atoms in shell }}{\text { No. atoms in particle }}=\frac{4 \times\left[\left(1.03 \times 10^{4}\right) / 3.61^{3}\right]}{2 \times\left[\left(2.4 \times 10^{4}\right) / 2.70^{3}\right]}=0.4
$$

Again from the phase diagram, the atomic fraction of the alloy in the remaining $\alpha$-phase

$$
\frac{48-13}{48-1.25}=\frac{35}{46.75}
$$


and the atomic fraction of the alloy in $\gamma$-phase

$$
\frac{13-1.25}{48-1.25}=\frac{11.75}{46.75}
$$

The atomic fraction of the equilibrium $\alpha$-phase which does not contribute to the measured NMR intensity is

$$
\frac{0.4\left(\frac{11.75}{46.75}\right)}{\left(\frac{35}{46.75}\right)}=0.134=13.4 \%
$$

Thus $I_{0}$, which is directly proportional to the number of copper atoms contributing to the NMR intensity, in Equation (44) has to be reduced by 13.4 per cent, before $\mathrm{C}_{\alpha}$ can be determined. Accordingly the $\mathrm{C}_{\alpha}$ at $280^{\circ} \mathrm{C}$ Is found to be 2.97 at.\% Be. We can cleariy see that when the interface volume is considered, its effect on the beryllium solubility in copper is quite important. The effect alone moves the solubility from 3.7 at.\% to 2.97 at.\% $\mathrm{Be}$, and 1 ts accepted value is 1.25 at.\% $\mathrm{Be}$ at a temperature $\mathrm{T}=280^{\circ} \mathrm{C}$.

When a second phase particle rich in solute is very small and is immersed in an $\alpha$ solid solution of low solute concentration, there may be a marked concentration deviation from the equilibrium bulk solute solubility in

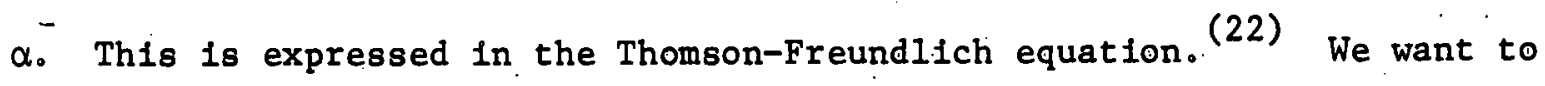
determine the plausibility of suggesting that the remaining discrepancy between our value of $\mathrm{C}_{\alpha}$ and the accepted value is a particle size effect. The Thomson-Freundlich equation takes the form. 


$$
\frac{\left[\mathrm{C}_{\mathrm{Be}\left(\mathrm{sat}_{0}\right)}^{\alpha}\right]_{r}}{\left[\mathrm{C}_{\mathrm{Be}\left(\mathrm{sat}_{.}\right)}^{\alpha}\right]_{\infty}}=\exp \left(2 \sigma \mathrm{V}^{\gamma} / \mathrm{rRT}\right)
$$

where the C's are beryllium concentrations of: $\alpha$ in equilibrium with $\gamma$-phase partfcles with radius of curvature $r$ and $\infty$ respectively. $v^{\gamma}$ is the molar volume of $\gamma$-phase, $\sigma$ is the surface energy between the precipitate particle and $\alpha-$ solid solution.

We know $\left(\mathrm{C}_{\mathrm{Be}}^{\alpha}\left(\mathrm{sat}_{0}\right)\right)_{\mathrm{r}}$ is 2.97 at.\% Be as determined above, the accepted $\left(C_{B e\left(s a t_{0}\right)}^{\alpha}\right)_{\infty}$ is 1.25 at.\% $B e$, and for internal consistency we use $r=17.4 \AA$. (This corresponds to the volume used previously in estimating the excluded volume) At $\mathrm{T}=280^{\circ} \mathrm{C}$ we find $\alpha=577 \mathrm{ergs} / \mathrm{cm}^{2}$ from Equation (65). This value falls reasonably well within the range of known surface energies, ${ }^{(22)}$ and we conclude that it is posstble to rationalize the difference between our estimated concentration and the accepted value on the basis of particle size effects. 
CHAPTER VIII

CONCLUSIONS

The nuclear magnetic resonance technique has been demonstrated in this work to be a useful tool to explore the precipitation process of a binary alloy system. The line shape of the copper nuclear signal does not change with the length of aging time nor with the aging temperature; within the range of solute concentration examined we have to consider only the second-order quadrupole effects. A complete separation of the two copper nuclear signals, one from the precipitate and one from the remaining matrix, must be accomplished or the course of the precipitation process w111 be very difficult or even impossible to follow. The very strong dependence of the nuclear signal on the solute concentration enables one to follow the progress of the precipitation process, and if the particle size is known, the matrix composition can be found. It is also possible in favorable cases to follow the increase in the amount of precipitate directly by means of the resonance absorption of one of Its components.

The copper-beryllium binary alloy is an example which satisfies all of the above conditions; the NMR measurement is fully utilized to probe its precipitation process. The wipe-out-number, $n$, for this alloy system is found to be $18,1 . e .$, up to second nefghbors are affected. Simllarly we have considered up to the second nearest neighbors of the precipitate particle will not contribute to the measured copper nuclear signal in interpreting our data. The fleld fon microscopy of copper-beryllium is possible with the assistance of an image intensifier, neon is then used as imaging gas. At best imaging voltage, the field evaporation of the tip material still exists. 
Long-time stability of images is almost impossible to achieve. The probability of tip fracture is high even when great care is exercised during its preparation. A possible improvement would utilize the transmission electron microscope to select the most suitable sample tips. Most of ten failure occurs during field evaporation, or after fleld evaporation, but during the process of admitting the additional image gas. The precipitate particle is found to be very small, and without an atom probe FIM it cannot be unambiguously differentiated from other surface features. The estimated average precipitate size is used to interpret the NMR results if we take into account the layer of disturbed matrix around the precipitate and the effect of precipitate particle size on the equilibrium matrix concentration.

When the corrected solubility and the equilibrium (bulk) matrix solubility are used together with the Thomson-Freundlich equation the estimated interface energy between the $\gamma$ and $\alpha$ has a value with reasonable order of magnitude.

In this experiment we neglect the Knight shift between $\mathrm{Cu}+1.25$ at.\% Be and pure copper; and the relative Knight shift of CuBe (CsCl structure) is obtalned from a single trace containing both copper nuclear signals (CuBe and $\mathrm{Cu}+1.25$ at.\% Be). The Knight shift of CuBe is found to be $0.13 \%$. For CuZn, which has the same structure and is electronically similar, the corresponding quantity is $0.15 \%$. 


\section{LIST OF REFERENCES}

1. Harker, D. and Murphy, Mo J., Trans, AIME 161, 75 (1945).

2. Tanner, L。 E。, Phil。 Mag。 14, 111 (1966)。

3. Garvilova, A。 R。, Typakin, Y。 D。 and Usikov, M. P。, Soviet Phys. 12, 970 (1966):

4. Mishima, Y. and Shiromizu, R。, Trans. AIME 242, 751 (1968).

5. Yamamoto, S., Matsu1, M. and Murakami, Y., Trans. Jap. Inst. of Met. 12, 159 (1971)。

6. Shimfzu, K。, Murakam1, Y。, Mitani, H. and Otsuka, K., Trans. Jap. Inst. of Met. 12, 206 (1971)。

7. Kreye, H。, Z。 Metal1k。62, 556 (1971)。

8. Phillips, V。A. and Tanner, L. E., Acta Met. 21, 441 (1973).

9. Guinier, A。 and Jacquet, P., Nature 155, 69.5 (1945)。

10. Guy, A. F。, Barrett, C。 S. and Mehl, R。F。, Trans。 AIME 175, 216 (1948).

11. Gelsler, A. H., Mallery, J. H. and Steigert, F.. E., J. of Metals 4 , 307 (1952):

12. Tyapdin, Y. Do, Soviet Phys. - Cryst. 10, 418.(1966)。

13. Murakami, Y., Yoshida, $H_{0}$ and Yamamoto, So, Trans, Jap. Inst. of Met. 9, 11 (1968)。

14. Danesh, K。 B., M。 S. Thesis, Univ。 of Illinois (1969)。

15. Perra, M. W., M.S. Thesis, Univ. of California (1972).

16. Brenner, S. S., 19th Field Emission Symposium Abstracts, 58, Univ. of - Illinois at Urbana-Champaign, Illinois (1972).

17. Boyes, E. B. and Southon, M. Jo, Vacuum 22, 447 (1972).

18. Goodman, S. R., Brenner, S. So and Low, Jr. J.R., Met. Trans. 4 , 2363 (1973)。

19. Brenner, S. So, Private Communication.

20. Bloembergen, N. and Rowland, T. J., Acta Met: 1, 731 (1953). 
21. Hansen, M., Constitution of Binary Alloys, McGraw-Hill Book Company, Inc. New York, 282 (1958).

22. Swalin, R. A., Thermodynamics of Solids, John Wiley \& Sons, Inc. New York (1962).

23. West, G. W., Phil. Mag. 5, 899 (1960).

24. Thomas, H. A., Driscoll, R. L. and Hipple, J. A., Phys. Rev. $\underline{75}$, 902 (1950).

25. Thomas, H. A., Driscoll, R. L. and Hipple, J. A., Phys. Rev. 78, 787 (1950).

26. Thomas, H. A., Driscoll, R. L. and Hipple, J. A., J. Res. Nt1. Bur. Std/: (U.:S.) 44,569 (1950).

27. Kittel, C., Introduction to Solid State Physics, John Wiley \& Sons, Inc. New York (1956).

28. Block, F., Phys. Rev. 70, 460 (1946).

29. Knight, W. D., Phys. Rev. 76, 1259 (1949).

30. Bloembergen, N., Phys. Soc. Bristol Conf. (1955).

31. Rowland, T. J., Nuclear Magnet1c Resonance in Metals, Pergamon Press (1961).

32. Tompa, K., J. Phys. \& Chem. Solids (G.B.) 33, 163 (1972).

33. H1llert, M., Acta Met. I, 653 (1959).

34. Imura, T., Welssmann, S. and Slade, J. J., Acta Cryst. 15, 786 (1962).

35. Lo, D., Ph.D. Thesis, Univ of Illinots (1972).

36. Rhines, F. N. and Meh1, R. F., Trans. AIME 128, 185 (1938).

37. Smlthells, C. J., Metals Reference Book; Vol. 2, 591 (1962).

38. Shalvoy, R. S.; M.S. Thesis, Univ. of Illinois (1973).

39. Benedek, B. and Kushida, J. Phys. Chem. Solids, $\underline{5}, 241$ (1958).

40. Muller, E. W. and Tsong, T. T., Field Ion Microscopy, Principle and Applications, American Elsevier Publishing Company, Inc. (1969).

41. Muller, E. W., Adv. Electronfcs and Electron Phys. 13, 83 (1960). 
42. Gomer; R., Field Emission and Field Ionization, Harvard Univ. Press, Cambridge, Mass. (1961).

43. Tsong, To To and Muller, E。 Wo, Jo Chem. Phys. 41, 3279 (1964).

44. Boudeaux, D。 S. and Cutler, P.H., Surface Sc1. $\underline{5}, 230$ (1966).

45. Boudeaux, D. S. and Cutler, P. H., Phys. Rev. 149, 170 (1966).

46. Southon, M. J. and Brandon, D. G., Phil. Mag. $\underline{8}, 579$ (1963).

47. Gomer, R., J. Chem。Phys。 31, 341 (1959).

48. Gomer, R. and Swanson, L. W., J. Chem. Phys. 38, 1613 (1963).

49. Swanson, L. Wo and Gomer, R., J. Chem. Phys. 39, 2813 (1963).

50. Brandon, D.. G., Brit。 J. Appl。 Phys。 14, 474 (1963).

51. Tsong, T.: T., Surface Sc1. 10, 102 (1968).

52. Brandon, D. G., Fleld Ion M1croscopy, Eds. Hren and Ranganathan, Plenum Publishing Company, New York (1968).

53. Anderson, H. U., Rev。 of Sc1. Iṇtr., 34, 703 (1963). 